\title{
WEAR AND MECHANICAL PROPERTIES OF RAILROAD BEARING BRONZES AT DIFFERENT TEMPERATURES
}

\author{
By H. J. French, S. J. Rosenberg, W. LeC. Harbaugh, and H. C. Cross
}

\section{ABSTRACT}

A study was made of the wearing and mechanical properties of two groups of copper-tin-lead alloys in both chill-cast and sand-cast conditions. The bronzes were tested under rolling and sliding friction without lubrication at atmospheric and elevated temperatures up to $350^{\circ} \mathrm{F}$. $\left(175^{\circ} \mathrm{C}\right.$.), under both sliding and rolling and sliding friction with lubrication at atmospheric temperatures, and under tension, impact, and pounding at temperatures from 70 to $600^{\circ} \mathrm{F}$. $\left(20\right.$ to $315^{\circ}$ C.). A detatiled description is given of all apparatus used in the tests.

No one of the selected laboratory tests yielded information which by itself was adequate for general comparisons.

Variations in chemical composition of the bronzes produced major changes in properties, but within certain ranges variations in chemical composition were much less important than variations in the method of casting.

Generally, chill-cast bronzes were less resistant to wear and impact than sandcast bronzes but were more resistant to pounding and tension.

Increase in lead, particularly in the range 0.25 to 10 per cent, improved wearing properties but lowered resistance to pounding, impact, and tension. Increase in tin improved all properties. Increase in temperature of test generally decreased resistance to tension, impact, pounding, and wear, the changes being most marked from 350 to $600^{\circ} \mathrm{F}$. (175 to $315^{\circ} \mathrm{C}$.).

\section{CONTENTS}

I. Introduction

II. The problem of testing bearing metals

III. Previous investigations

IV. Alloys tested and their preparation.

V. Equipment and test methods employed

1. The Amsler wear testing machine

(a) Calculation of unit contact pressures........ 361

2. Sand abrasion tests.

3. Single-blow impact tests

4. Tension tests

5. Repeated-blow pounding tests

VI. Experimental results

1. Wear under sliding and rolling friction in the presence of oil.

2. Wear tests at ordinary temperatures in the absence of oil -

(a) Film formation

(b) Bronzes varying in lead and in tin

(c) Data showing that the wear test results can be duplicated

3. Wear tests at elevated tempreatures in the absence of oil _-

(a) Bronzes varying in lead....

(b) Bronzes varying in tin

(c) Frictional properties $v$. wear

(d) Wear of the steels_... 
VI. Experimental results - Continued.

3. Wear tests at elevated temperatures in the absence of oilContinued.

4. Sand abrasion tests

5. Single-blow impact tests.

6. Tensile tests

7. Repeated-blow pounding tests

VII. General discussion

1. Questions relating to methods of test

2. Chill casting $v$. sand casting

3. Effects of lead and tin in bearing bronzes

4. Specifications

\section{INTRODUCTION}

The need for a study of bearing bronzes was recognized about 1920 by certain of the executives of the Bostwick-Lyon Bronze Co., Waynesboro, Pa., who felt that such wide variations encountered in the specifications of different carriers for bearing metals were against the interests of the carriers as well as those of the metal manufacturers.

During the latter part of 1925 , subsequent to the merger of the interests of the Bostwick-Lyon Bronze Co. with those of the Chicago Bearing Metal Co., Chicago, Ill., work was begun under the research associate plan ${ }^{1}$ at the Bureau of Standards. During the summer of 1927 , while the tests were still in progress, the interests of the Chicago Bearing Metal Co., were merged with those of the Magnus Co., Chicago, Ill., which continued to support the work until September, 1927. The final phases of the program, including most of the mechanical tests, were completed subsequent to this time by the staff of the Bureau of Standards.

The tests were started largely through the active efforts of E. R. Darby, formerly chief metallurgist, and W. M. Corse, formerly consulting metallurgíst, Chicago Bearing Metal Co., who acted in an advisory capacity throughout the investigation. Cooperation with the Magnus Co. was largely through R. J. Shoemaker, engineer of tests.

Between 1920 and 1925 the technical staff of the Chicago Bearing Metal Co. developed certain definite views concerning the manufacture and practical application of bearing bronzes. A search of the literature for support or disproval of these views revealed mostly theories and personal opinions, with few dependable facts. Records of service tests of bearings were conflicting. Likewise, specifications found to be satisfactory by one group seemed to fail in the hands of another.

1 Described in B. S. Circular No. 296. 
Progress toward standardization of specifications for bearing metals was made by some of the technical societies, but due to lack of definite reproducible data, or for other reasons, many individuals in these organizations refused to adopt recommendations. While a natural tendency toward standardization could be detected during this period,

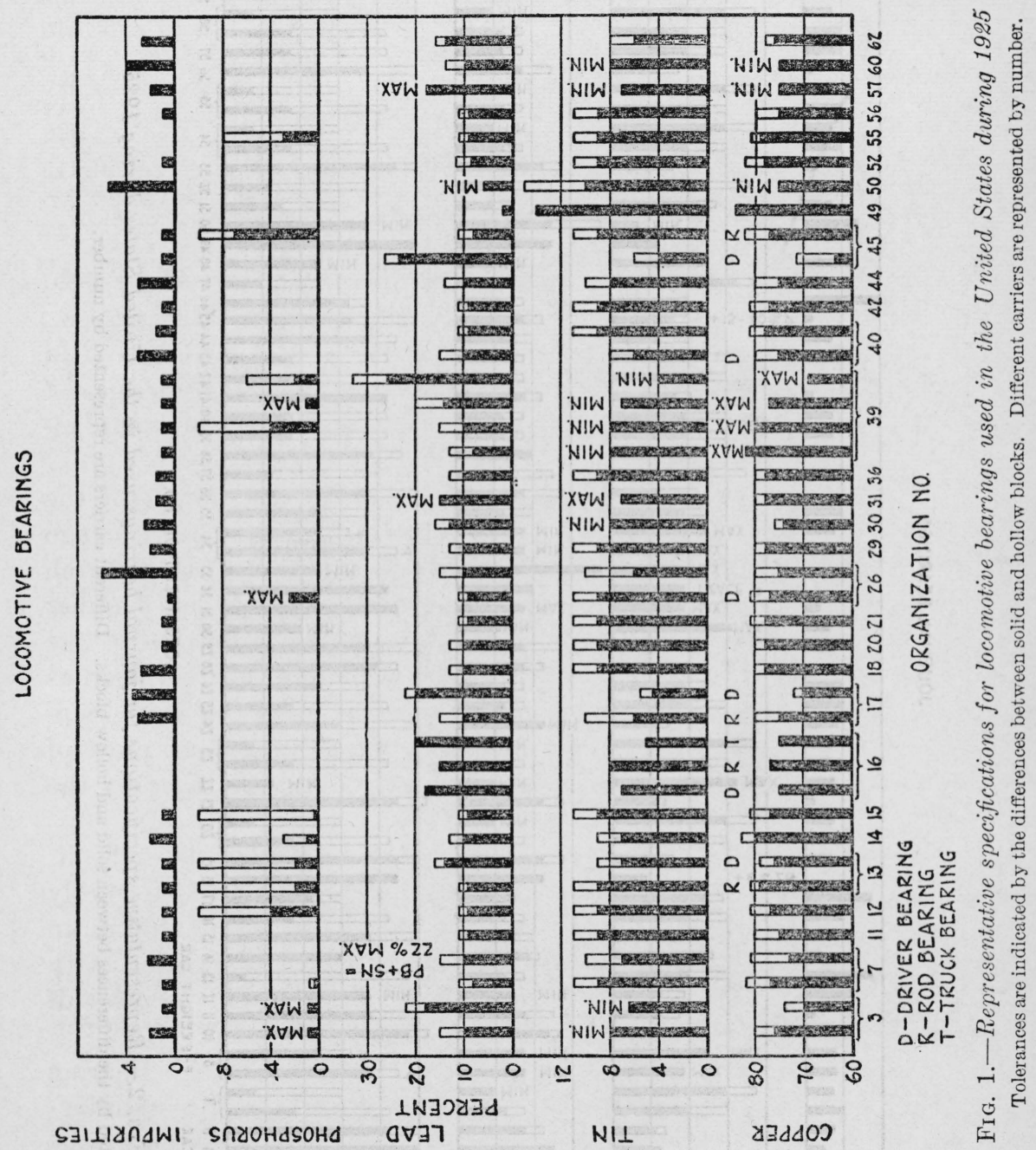

there was still a wide variation in specifications for similar types of bearings at the end of the year 1925, as will be evident from Figures 1,2 , and 3 .

In January, 1925, an important trunk-line railroad experienced considerable trouble with "back-end main-rod brasses" which were breaking in service and causing costly delays along its lines. Consideration was given to replacement of sand-cast alloys by alloys cast 


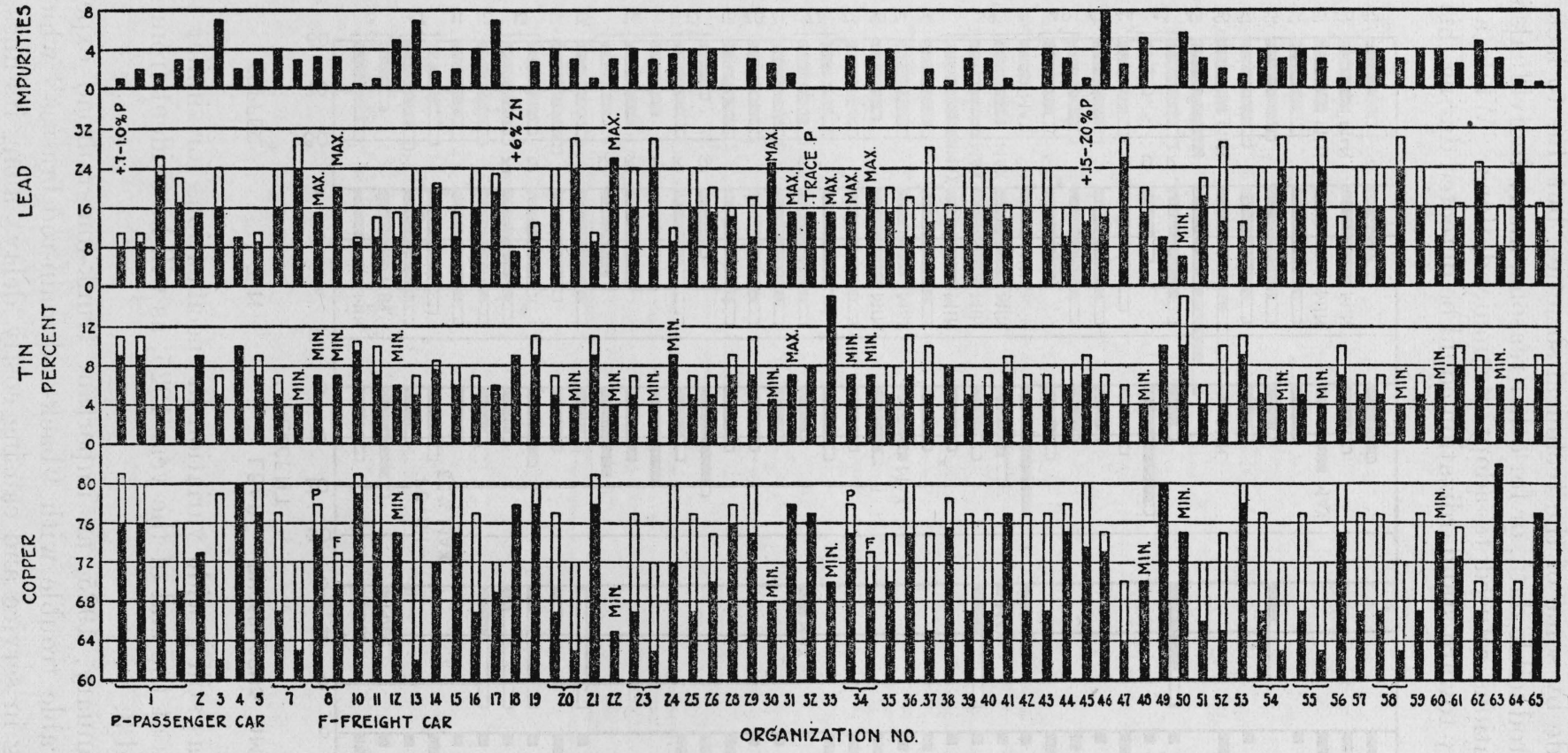

FIG. 2.-Representaitive specifications for journal bearings used in the United States during 1925 Tolerances are indicated by the differences between solid and hollow blocks. Different carriers are represented by number. 
in metal molds in an attempt to overcome these difficulties, but an investigation developed conflicting views and little information on which to base predictions that this and other proposed changes would be beneficial.

The lack of such information was probably the most important single factor which influenced the Chicago Bearing Metal Co. to

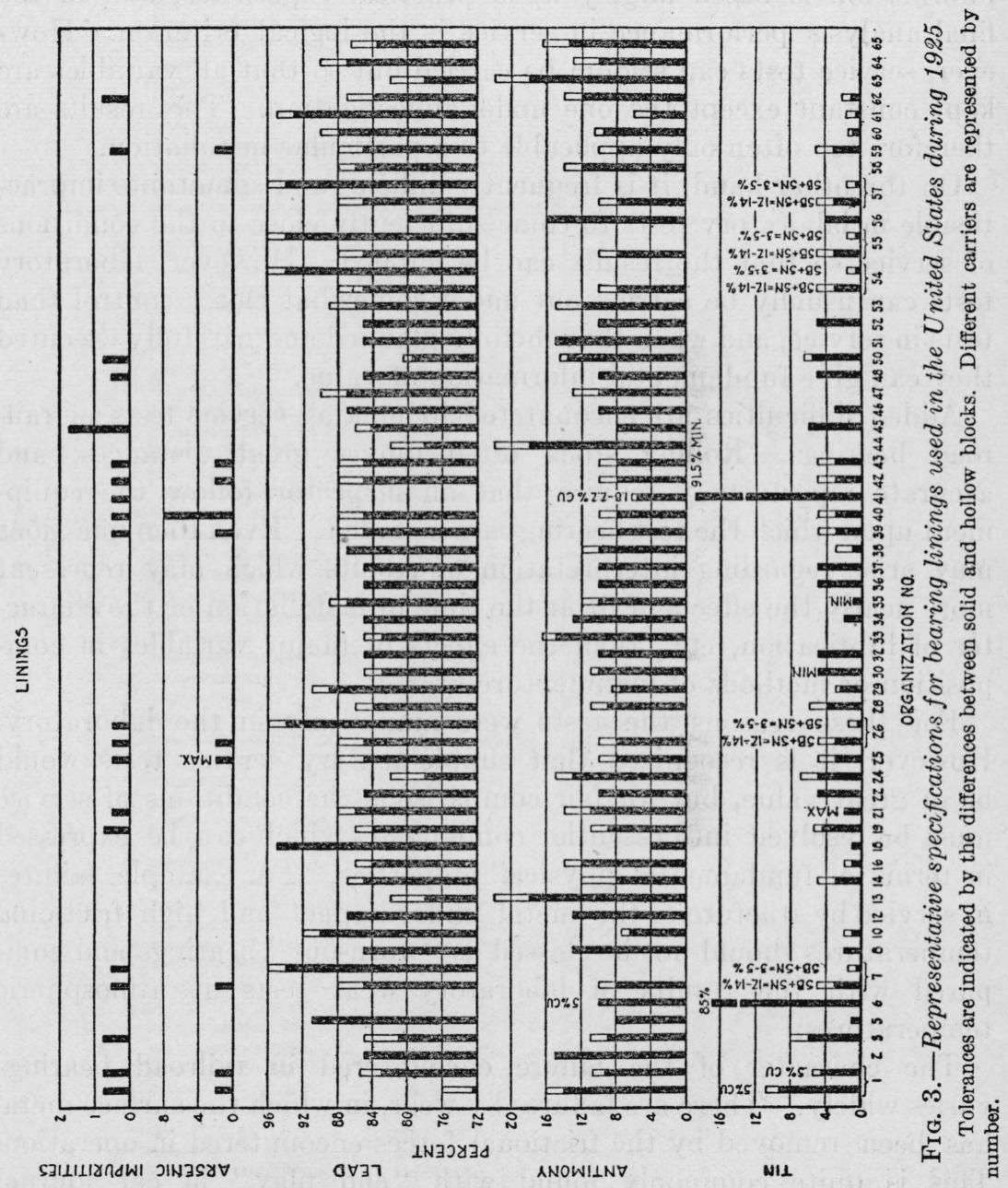

undertake the investigation here reported. The primary object of the tests was to determine important physical properties of a group of copper-tin-lead alloys within, and in some cases beyond, the limits of chemical composition and constitution ordinarily applied industrially in railroad bearings and to supply information that might ultimately permit a logical revision of specifications. 


\section{THE PROBLEM OF TESTING BEARING METALS}

The first problem encountered in the study of bearing metals is the choice of test methods. At present there are no generally accepted methods of test nor any well-defined procedure which may be followed in attempting comparisons of different bearing metals. Reliable information is based largely upon practical experience, and in the final analysis performance in service is the logical criterion. However, service tests can seldom be carried out so that all variables are kept constant except the one under investigation. The results are therefore too often only applicable to a particular installation.

On the other hand, it is frequently difficult and sometimes impracticable in laboratory tests to come sufficiently close to the conditions of service so that the results can be applied. However, laboratory tests can usually be carried out under somewhat closer control than tests in service, and when thoughtfully planned and carefully executed they can give fundamental information of value.

Added difficulties are encountered in making service tests of railroad bearings. Rolling stock often moves great distances, and accurate reports may require that an inspector follow the equipment upon which the test bearings are installed. Even then questions may arise regarding interpretation of results which may represent more nearly the effects of fit at the time of installation or the character of lubrication, etc., than the effects of major variables in composition or methods of manufacture.

For these reasons the tests were made only in the laboratory. However, it is recognized that supplementary service tests would be of great value, but for fair comparisons the conditions of service must be resolved into essential components which can be expressed in terms of fundamental physical properties. For example, failures in service by fracture of the metal under impact and high frictional temperatures should not be classed as "worn-out" bearings and compared with the results of laboratory wear tests at atmospheric temperatures.

The character of the failure encountered in railroad bearings varies widely. There are failures by wear, in which the surface metal has been removed by the frictional forces encountered in operation. This is quite commonly found with "end play" in car journal bearings. Another type of failure is that due to deformation or "pounding out." A third type of failure commonly observed is fracture of the bearing.

Service failures of such types indicate that consideration should be given in laboratory tests of railroad bearing metals to (1) the resistance to wear and (2) resistance to both static and dynamic stresses. Since railroad bearings are frequently called upon to operate for 
short periods at elevated temperatures and some types ordinarily "run hot" (at temperatures as high as $500^{\circ} \mathrm{F}$. ( $260^{\circ} \mathrm{C}$.) or more), the different properties should be considered at elevated temperatures as well as atmospheric.

There are other items which should be considered. One is starting torque, but it was not practicable to study this feature with the equipment used. However, consideration was given to the average torque in the wear tests, and the results throw some light upon the frictional properties of the different alloys.

Properties which contribute to ease of manufacture are also of importance. Good casting properties and ease of machining are desirable, and variations in such characteristics may materially affect the choice of metals. These features are considered in a general way in the final discussion of results.

The tests made which will be described in detail are (1) wear tests, (2) notched-bar single-blow impact tests, (3) tension tests, and (4) repeated-blow pounding tests.

\section{PREVIOUS INVESTIGATIONS}

Technical literature contains little data which have a direct bearing upon the subject of this investigation. This applies to both the methods of test for bearing bronzes and their high temperature properties.

The majority of published investigations of wear relate to ferrous metals, and the methods of study and equipment used have varied widely. Very few wear testing machines have been applied to nonferrous metals, and little information has been developed upon which to base the selection of a method of test for bearing bronzes.

About 35 years ago, C. B. Dudley ${ }^{2}$ outlined three factors which he considered to have an important influence upon the wear of metals.

These were:

1. That metal which will suffer the most distortion without rupture will wear best (least).

2. The first variable being obtained in satisfactory amount, an increase in tensile strength will add to the wearing power (resistance) of the metal.

3. * * * of two metals which have the same tensile strength and the same elongation, the one which is finer in granular structure will wear the slower.

This brings in the idea that wear resistance is dependent on both hardness and toughness, and this has been confirmed in more recent work.

Portevin and Nusbaumer, ${ }^{3}$ using a Derihon "abrasion mill," tested a number of copper-tin alloys with and without additions of

${ }^{2}$ C. B. Dudley, Bearing metal alloys, J. Franklin Inst., 133, pp. 81 and 161; 1892.

${ }^{3}$ Portevin, A., Nusbaumer, E., “Note on the wear of bronzes," Intl. Assn. of Test. Matls., 6th Congress, $\mathrm{III}_{4} ; 1912$. 
phosphorus and zinc. They reported that "when the bronzes are submitted to constant friction, account should be taken of the phenomena of cold work, which tends to diminish the wear until the limit of the depth to which the cold work has penetrated is reached." They also concluded that the introduction of phosphorus decreased the wear in high-tin bronzes and increased the wear in low-tin bronzes and that the wear (weight loss) of their copper-tin alloys was "proportional to the tin percentage or, more exactly, to the percentage of delta (constituent)."

Jannin ${ }^{4}$ made wear tests under lubrication and arrived at the conclusion that the principal cause of wear of bearing metals was insufficient polish of the bearing and that the principal cause of wear of the shaft was lack of cleanliness of the lubricant. He also found that leaded bronzes were at first less resistant, and later more resistant, to wear than bronzes practically free from lead. His phosphorus bronzes showed a relatively high resistance to wear.

G. H. Clamer ${ }^{5}$ reported some of the general conclusions drawn from tests made for a thesis by Messrs. Knapp and Miskella at Cornell University about the year 1903. Clamer's summary of this work follows:

1. Operating temperature of a bearing is of importance and should, therefore, be properly considered when selection of alloys for car journal bearings is to be made. A bearing which operates normally at a low temperature is less liable to reach the danger point resulting in so-called hot box when the ideal conditions of lubrication are disturbed.

2. Friction and wear are two factors which depend upon the lubrication of the bearings. *** The property of a bearing to absorb oil is of considerable importance.

3. Wear on both journal and bearings is regulated to a large extent by the film of lubrication existing between the two rubbing surfaces.

4. * * * bearing tests which record the action of one metal as against another, as far as friction and wear are concerned, are more or less unsatisfactory, due to the element of lubrication, which of itself at the best must be more or less imperfect. If by some method the influence of this element could be removed, a better idea of the wearing qualities of the metals tested comparatively would be secured.

As a result of further study of copper-tin-lead alloys and also copper-tin-lead-zinc alloys, Clamer supported these conclusions and made a number of recommendations concerning car journal bearings. These were that " 65 per cent of copper is the lowest percentage of copper which should be used ***; there should be a proper balancing of the four metals used-that is, copper, tin, lead, and zinc"-but that it did not seem desirable in car journal bearings to have over approximately 5 per cent of tin.

\footnotetext{
4 Jannin, M. L., "Nouvelle methode d'essai des metaux a l'usure, Machine d'essai a l'usure," Rev. de Met. Mem., 19, p. 109; 1922.

$s$ Clamer, G. H., "Effect of changes in composition of alloys used by American railroads for car journal bearings," Tr. Am. Inst. Metals, 2, p. 241; 1915.
} 
Clamer's wear tests showed that an increase in zinc tended to increase the rate of wear in bronzes and that it was desirable to increase lead and decrease the tin in the range of compositions studied. As stated by Clamer, "a better wearing (more resistant) metal results from an alloy of 70 per cent copper, 5 per cent tin, 20 per cent lead, and 5 per cent zinc than with an alloy of 80 per cent copper, 10 per cent tin, and 10 per cent lead."

Joachim and Case ${ }^{6}$ studied the wear of a variety of commercial bearing materials, including copper-tin-lead alloys. The different materials were tested in the presence of gasoline, and it was found that when a machine-steel shaft was used a hard bearing material wore less below the seizing load than a soft bearing material. This order was reversed when the bearing material was operated in contact with a hardened tool-steel shaft. In general, the hard bearing materials produced more wear on the shaft than the soft bearing materials.

Kuhnel and coworkers ${ }^{7}$ recently studied the copper corner of the copper-tin-zinc system. An alloy containing about 86.5 per cent copper, 8 per cent tin, 3.5 per cent zinc, 2 per cent lead, and small amounts of nickel and iron was less resistant to wear than a lower tin alloy, containing 83 per cent copper, 6 per cent tin, 9 per cent zinc, 2 per cent lead, and small amounts of nickel and iron.

The mechanical properties of copper-tin alloys at ordinary temperatures have received considerable attention. Increase in tin from 0 to about 19 per cent raises the tensile strength from around 25,000 lbs./in. ${ }^{2}$ to about $40,000 \mathrm{lbs} / \mathrm{in}^{2}{ }^{2}$ At the same time hardness increases, ${ }^{8}$ and under equilibrium conditions the structure changes from (1) a single phase comprising the alpha solid solution of tin in copper to (2) a duplex or two-phase condition. In (1) all crystals have similar properties, but in (2) particles of the hard alpha-delta eutectoid are embedded in the relatively soft alpha matrix.

According to the results reported by Matsuda,${ }^{9}$ increase in tin raises the resistance of bronzes to repeated impact in the Stanton machine until appreciable proportions of the alpha-delta eutectoid appear in the structure, when the number of blows required for fracture of the test specimens decreases materially and continues to decrease with further increase in the tin.

According to Hoyt,${ }^{10}$ the copper-tin alloys containing a considerable amount of the eutectoid possess the desirable properties of

o Joachim, W. F., Case, H. W., "Tests of several bearing metals lubricated by gasoline," Technological Notes, No. 241, Natl. Adv. Com. for Aeronautics; 1926.

7 Kuhnel, R., "On the constitution and properties of red brass," Zeit. f. Met., 18, pp. 306-11; 1926; J. Inst. Met., No. 1, p. 465; 1927.

${ }^{8}$ Matsuda, T., Shiba, J., "On the hardness of brass, aluminum bronze," and bronze, Sci. Rpts. Tohoku Imp. Univ., 13, No. 4, p. 413; 1925.

- Matsuda, T., "Repeated impact tests on brass, aluminum bronze, and bronze," Sci. Rpts. Tohoku Imp. Univ., 13, No. 4, p. 419; 1925.

${ }^{10}$ Hoyt, S. L., Metallography-Metals and Common Alloys, 2, McGraw-Hill Co., New York, p. 116 et seq., 1922 . 
mechanical strength and low coefficients of friction but lack sufficient plasticity and are too liable to overheat locally to make good bearing alloys. Additions of lead in proportions from 5 to 30 per cent improve plasticity but lower the strength.

Much less attention has been given to the properties of copper-tin alloys and the leaded bronzes at elevated temperatures. A summary prepared by Upthegrove and White in $1924{ }^{11}$ will serve to illustrate the general effects of temperature on the mechanical properties of these alloys:

The influence of temperature upon the properties of copper-tin bronzes, according to Bregowsky and Spring, ${ }^{12}$ becomes most marked between $400^{\circ}$ and $600^{\circ} \mathrm{F}$. $\left(205^{\circ}\right.$ and $315^{\circ}$ C.), all of the properties except the elastic limit decreasing very rapidly within that range of temperature. At temperatures below $300^{\circ}$ to $350^{\circ}$ F. $\left(150^{\circ}\right.$ to $175^{\circ}$ C. $)$ no appreciable difference in tensile strength is found for the bronzes carrying 12 per cent of tin. At all higher temperatures the 12 per cent bronze is superior in strength to the bronze of a lower tin content. The influence of the additional tin is also shown in the effect on elongation and reduction of area at temperatures above $750^{\circ} \mathrm{F} .\left(400^{\circ} \mathrm{C}\right.$.). Variations in properties at elevated temperatures seemingly are dependent upon the presence of the delta constituent, the final decrease in elongation and tensile strength coming at the temperatures corresponding to the absorption of this constituent.

Low-tin bronze, according to Huntington, ${ }^{13}$ shows a gradual decrease in strength with increasing temperature. Elongation and reduction of area decrease rapidly at $500^{\circ} \mathrm{F}$. $\left(260^{\circ} \mathrm{C}\right.$. $)$, reaching a minimum at $700^{\circ} \mathrm{F}$. $\left(370^{\circ} \mathrm{C}.\right)$. The results obtained by Huntington are very similar to the results obtained in 1893 by Rudeloff ${ }^{14,15}$ with copper carrying 1.86 per cent tin. This copper-tin alloy shows a tensile strength superior to that of copper at all temperatures up to $900^{\circ} \mathrm{F}$. $\left(480^{\circ}\right.$ C. $)$.

Matsuda ${ }^{16}$ studied dynamic hardness of bronzes at different temperatures. The dynamic hardness number represents the energy required to depress a unit volume of metal when a weight having a spherical penetrator similar to a Brinell ball is dropped on the specimen. Alpha bronzes showed a regular and gradual decrease in dynamic hardness with increase in temperature, while bronzes containing a considerable proportion of the eutectoid showed a sharp decrease within the transformation temperature range. However, at atmospheric or elevated temperatures up to the transformations increase in tin from 0 to about 15 per cent resulted in an increase in the dynamic hardness.

11 Upthegrove, C., White, A. E., "A symposium on the effect of temperature upon the properties of metals," Proc. Am. Soc. Test. Matls., 24, p. 9; 1924; Proc. Am. Soc. Mech. Engrs., 46, p. 349; 1924.

12 Bregowsky, I. M., Spring, L. W., "The effect of high temperature on the physical properties of some alloys," Proc. Int. Assoc. Test. Matls., 6th Congress, 2, VII ; 1912.

${ }^{13}$ Huntington, A. K., "The effect of temperatures higher than atmospheric on tensile tests of copper and its alloys and a comparison with wrought iron and steel," J. Inst. Met., 8, p. 126; 1912.

${ }^{14}$ Rudeloff, M., "Untersuchungen uber den Einfluss der Wärme auf die Festigkeitseigenschaften von Metallen," Mitteilungen aus den kgl. Versuchsanstalten zu Berlin, 11, p. 292; 1893.

15 Rudeloff, M., "The influence of increased temperature on the mechanical qualities of metals," Proc. Int. Assoc. Test. Matls., 5th Congress, $1, \mathrm{VI}_{1} ; 1909$.

16 Matsuda, T., "On the dynamic hardness of bronze, aluminum bronze, and brass at high temperature," Sci. Rpts. Tohoku Imp. Univ., 13, No. 4, p. 401; 1925. 
An idea may be obtained of the effect of lead on the high temperature mechanical properties of bronzes from comments of Upthegrove and White ${ }^{17}$ relating to copper-tin-zinc-lead alloys of the "steam bronze" type:

Alloys of the leaded type invariably show loss in tensile strength and decrease in ductility when the melting point of the lead is approached, as indicated by the decrease in strength and ductility slightly below $600^{\circ} \mathrm{F}$. $\left(315^{\circ} \mathrm{C}\right.$.).

\section{ALLOYS TESTED AND THEIR PREPARATION}

Two groups of copper-tin-lead alloys were studied. Their chemical compositions are given in Table 1. In the first group the copper-tin ratio was approximately 92.5 to 7.5 and the proportion of lead was varied from 0.25 to about 25 per cent. In the second group the copperlead ratio was approximately 84 to 16 , and the proportion of tin was varied from a trace to about 10 per cent.

TABLE 1.-Chemical compositions of the bearing metals tested (per cent)

[NotE.-S, denotes sand-cast alloys; C, chill-cast alloys; < less than; n. d., not detected]

\begin{tabular}{|c|c|c|c|c|c|c|c|c|c|}
\hline Lot No. & $\mathrm{Cu}$ & Sn & $\mathrm{Pb}$ & $\mathrm{Sb}$ & $\mathrm{Ni}$ & $\mathrm{Fe}$ & $\mathrm{Zn}$ & Total & Used for tests indicated \\
\hline $\begin{array}{l}9 \mathrm{~S} \\
9 \mathrm{C}- \\
1 \mathrm{X} \\
1 \mathrm{X}\end{array}$ & $\begin{array}{l}93.2 \\
93.1 \\
88.2 \\
88.2\end{array}$ & $\begin{array}{l}6.4 \\
6.5 \\
8.3 \\
8.3\end{array}$ & $\begin{array}{l}0.25 \\
.25 \\
3.4 \\
3.4\end{array}$ & $\begin{array}{r}0.06 \\
.06 \\
.03 \\
.03\end{array}$ & $\begin{array}{l}<0.005 \\
<.005 \\
<.005 \\
<.005\end{array}$ & $\begin{array}{l}<0.03 \\
<.03 \\
<.03 \\
<.03\end{array}$ & $\begin{array}{l}\text { n. d. } \\
\text { n. d. } \\
\text { n. d. } \\
\text { n. d. }\end{array}$ & $\begin{array}{l}99.94 \\
99.94 \\
99.96 \\
99.96\end{array}$ & $\left\{\begin{array}{l}\text { Wear and mechanical prop- } \\
\text { erties. } \\
\text { Wear. }\end{array}\right.$ \\
\hline $11 \mathrm{C}$ & $\begin{array}{l}87.6 \\
87.5 \\
83.8 \\
83.7\end{array}$ & $\begin{array}{l}7.4 \\
7.4 \\
6.3 \\
6.3\end{array}$ & $\begin{array}{l}4.7 \\
4.8 \\
9.6 \\
9.7\end{array}$ & $\begin{array}{l}.14 \\
.13 \\
.17 \\
.17\end{array}$ & $\begin{array}{l}.05 \\
.05 \\
.07 \\
.07\end{array}$ & $\begin{array}{l}<.03 \\
<.03 \\
<.03 \\
<.03\end{array}$ & $\begin{array}{l}\text { n. d. } \\
\text { n. d. } \\
\text { n. d. } \\
\text { n. d. }\end{array}$ & $\begin{array}{l}99.91 \\
99.90 \\
99.96 \\
99.96\end{array}$ & $\left\{\begin{array}{l}\text { Wear and mechanical prop- } \\
\text { erties. } \\
\text { Wear. }\end{array}\right.$ \\
\hline $\begin{array}{l}12 \mathrm{~S} \\
12 \mathrm{C} \\
13 \mathrm{~S}\end{array}$ & $\begin{array}{l}78.8 \\
78.8 \\
73.3 \\
73.3\end{array}$ & $\begin{array}{l}\text { 6. } 3 \\
6.2 \\
5.3 \\
5.3\end{array}$ & $\begin{array}{l}14.6 \\
14.7 \\
20.9 \\
20.9\end{array}$ & $\begin{array}{l}.15 \\
.16 \\
.27 \\
.29\end{array}$ & $\begin{array}{l}.06 \\
.06 \\
.11 \\
.12\end{array}$ & $\begin{array}{l}<.03 \\
<.03 \\
<.03 \\
<.03\end{array}$ & $\begin{array}{l}\text { n. d. } \\
\text { n. d. } \\
\text { n. d. } \\
\text { n. d. }\end{array}$ & $\begin{array}{l}99.93 \\
99.94 \\
99.90 \\
99.93\end{array}$ & $\left\{\begin{array}{l}\text { Wear and mechanical prop- } \\
\text { erties. } \\
\text { Wear. }\end{array}\right.$ \\
\hline $22 \mathrm{C}_{-}$ & $\begin{array}{l}70.4 \\
70.2 \\
70.3 \\
70.3\end{array}$ & $\begin{array}{l}5.45 \\
5.3 \\
5.1 \\
4.9\end{array}$ & $\begin{array}{l}23.9 \\
24.3 \\
24.5 \\
24.7\end{array}$ & $\begin{array}{l}.13 \\
.12 \\
.03 \\
.03\end{array}$ & $\begin{array}{r}.04 \\
.04 \\
<.005 \\
<.005\end{array}$ & $\begin{array}{r}<.03 \\
<.03 \\
<.03 \\
<.03\end{array}$ & $\begin{array}{l}\text { n. d. } \\
\text { n. d. } \\
\text { n. d. } \\
\text { n. d. }\end{array}$ & $\begin{array}{l}99.94 \\
99.98 \\
99.96 \\
99.96\end{array}$ & Mechanical properties. \\
\hline $\begin{array}{l}23 \mathrm{~S} \\
23 \mathrm{C}\end{array}$ & $\begin{array}{l}84.4 \\
84.9 \\
86.1 \\
84.6\end{array}$ & $\begin{array}{l}.73 \\
.68 \\
.02 \\
.30\end{array}$ & $\begin{array}{l}14.7 \\
14.3 \\
13.8 \\
14.9\end{array}$ & $\begin{array}{l}.02 \\
.02 \\
.01 \\
.07\end{array}$ & $\begin{array}{c}.08 \\
.08 \\
<.005 \\
\text { n. d. }\end{array}$ & $\begin{array}{l}<.03 \\
<.03 \\
<.03 \\
<.03\end{array}$ & $\begin{array}{l}\text { n. d. } \\
\text { n. d. } \\
\text { n. d. } \\
\text { n. d. }\end{array}$ & $\begin{array}{r}99.95 \\
100.00 \\
99.96 \\
99.89\end{array}$ & Mechanical properties. \\
\hline $\begin{array}{l}21 S \\
21 \mathrm{C}\end{array}$ & $\begin{array}{l}83.7 \\
84.2 \\
80.1 \\
80.2\end{array}$ & $\begin{array}{l}\text { 2. } 4 \\
\text { 2. } 35 \\
\text { 5. } 7 \\
\text { 5. } 65\end{array}$ & $\begin{array}{l}13.8 \\
13.4 \\
13.8 \\
13.8\end{array}$ & $\begin{array}{l}.02 \\
.02 \\
.24 \\
.23\end{array}$ & $\begin{array}{l}\text { n. d. } \\
\text { n. d. } \\
0.08 \\
.08\end{array}$ & $\begin{array}{r}<.03 \\
<.03 \\
<.03 \\
<.03\end{array}$ & $\begin{array}{l}\text { n. d. } \\
\text { n. d. } \\
\text { n. d. } \\
\text { n. d. }\end{array}$ & $\begin{array}{l}99.94 \\
99.99 \\
99.94 \\
99.98\end{array}$ & $\left\{\begin{array}{l}\text { Wear and mechanical prop- } \\
\text { erties. } \\
\text { Wear. }\end{array}\right.$ \\
\hline $17 \mathrm{~S}$ & $\begin{array}{l}83.5 \\
80.8 \\
78.9 \\
78.9\end{array}$ & $\begin{array}{l}5.2 \\
4.3 \\
7.9 \\
7.8\end{array}$ & $\begin{array}{l}11.2 \\
14.7 \\
12.9 \\
13.0\end{array}$ & $\begin{array}{l}.03 \\
.13 \\
.17 \\
.17\end{array}$ & $\begin{array}{l}\text { n. d. } \\
\text { n. d. } \\
0.04 \\
.04\end{array}$ & $\begin{array}{l}<.03 \\
<.03 \\
<.03 \\
<.03\end{array}$ & $\begin{array}{l}\text { n. d. } \\
\text { n. d. } \\
\text { n. d. } \\
\text { n.d. }\end{array}$ & $\begin{array}{l}99.95 \\
99.95 \\
99.93 \\
99.93\end{array}$ & $\left\{\begin{array}{l}\text { Mechanical properties. } \\
\text { Wear. }\end{array}\right.$ \\
\hline $\begin{array}{l}18 \mathrm{~S} \\
18 \mathrm{C} \\
25 \mathrm{~S} \\
25 \mathrm{C}\end{array}$ & $\begin{array}{l}77.6 \\
77.6 \\
75.5 \\
75.4\end{array}$ & $\begin{array}{r}10.1 \\
10.0 \\
9.8 \\
9.8\end{array}$ & $\begin{array}{l}12.0 \\
12.1 \\
14.5 \\
14.5\end{array}$ & $\begin{array}{l}.18 \\
.18 \\
.03 \\
.03\end{array}$ & $\begin{aligned} & .03 \\
&<03 \\
&<.005 \\
&<.005\end{aligned}$ & $\begin{array}{l}<.03 \\
<.03 \\
<.03 \\
<.03\end{array}$ & $\begin{array}{r}\text { n. d. } \\
\text { n. d. } \\
0.13 \\
.15\end{array}$ & $\begin{array}{l}99.93 \\
99.93 \\
99.99 \\
99.91\end{array}$ & $\left\{\begin{array}{c}\text { Do. } \\
\text { Mechanical properties. }\end{array}\right.$ \\
\hline
\end{tabular}

The alloys were cast into "sticks" about 12 inches long and $21 / 2$ inches in diameter. Originally, commercial mixtures of journal bearings, scrap engine castings, railroad turnings, ingot metal, and 
some copper, tin, or lead were melted in a Fisher furnace and the resulting metal poured by the molder who had made the molds.

Both the chill-cast and the sand-cast "sticks" were cast "on end" and were gated at the bottom. Details of the chill mold are shown in Figure 4, where dotted areas represent green sand and cross-hatched areas represent cores. Similar equipment was used for the sand castings, the split chill mold being replaced by a sand mold. The pouring temperature was kept around $2,050^{\circ} \mathrm{F}$. $\left(1,120^{\circ} \mathrm{C}\right.$.) for the sand castings and around $1,900^{\circ} \mathrm{F}$. $\left(1,035^{\circ} \mathrm{C}\right.$.) for bronzes cast in the metal molds, which were preheated to $350^{\circ} \mathrm{F}$. ( $\left(175^{\circ} \mathrm{C}\right.$.).

When machined into test specimens, the "sticks" prepared in the manner described were found to be filled with tiny gas pockets and

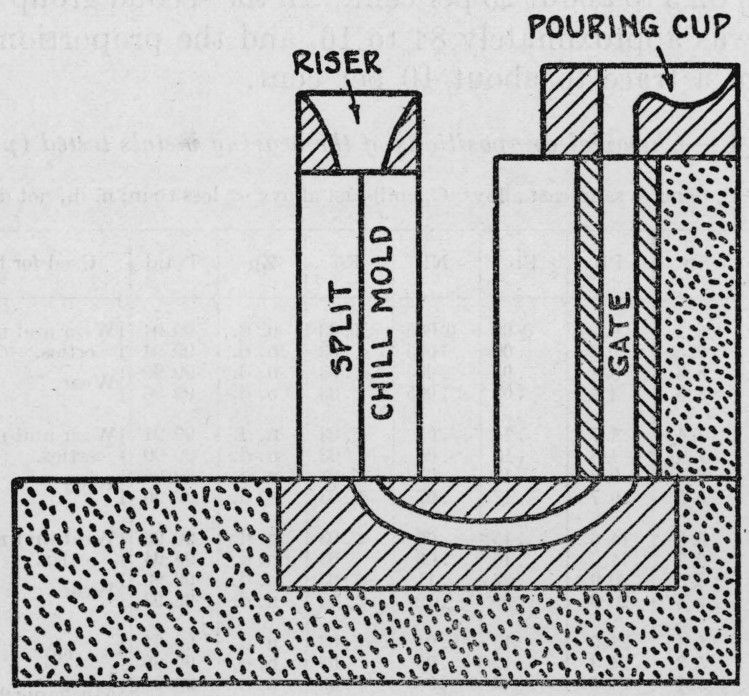

FIG. 4.-Chill-mold used

The thickness or mold wall was 1 inch.

were therefore discarded. Different methods of melting and degasification were next tried, including additions of magnesium, calcium carbide, manganese dioxide or barium sulphate, but the resultant castings were not entirely free from similar imperfections.

The method next tried, and one which gave castings practically free from gas pockets and porosity, was as follows: Ingots of two compositions were prepared from ingot copper, pig tin, and pig lead. One group contained about 92.5 per cent copper and 7.5 per cent tin, and a second group contained about 84 per cent copper and 16 per cent lead. Ingots of the first group, with pig lead to make a desired composition, or ingots from the second group, with the required pig tin, were melted in crucible furnaces without covering. The temperature was brought to about $2,100^{\circ} \mathrm{F}$. $\left(1,150^{\circ} \mathrm{C}\right.$.) and the fuel supply 
shut off, the melt then being allowed to freeze with only occasional stirring. When the surface of the melt could no longer be penetrated by the stirring rod, it was covered with glass and again melted. The metal was then poured at a temperature around $2,050^{\circ} \mathrm{F}$. $\left(1,120^{\circ} \mathrm{C}\right.$. $)$.

While this method of melting, freezing, and then remelting under glass gave satisfactory results, it was considered too slow for the production of any appreciable amount of test material. Most of the alloys were melted under glass in a Fisher crucible furnace under regular shop conditions. The ingots prepared in the manner already described were used as the basis of the melt. The sand-cast "sticks" were poured "on end" through the top, the mold being rammed up entirely in the drag half of the flask and not being covered at all. The chill castings were made in a similar manner in the metal molds, with the exception that a cup was placed on top of the mold.

It is seen from the foregoing that several methods were used in the production of the test castings at the manufacturer's plant. The manufacturer did not keep a record of the alloys produced by each method, and therefore such information could not be included in this report. However, close inspection was made of the castings to guarantee freedom from minute gas holes which might not be detected in commercial inspection. This was considered of greater importance than a record of whether individual castings were poured through horn gates or top poured.

Variations in structure and properties are to be expected from the outside to the center of the castings so that all specimens for chemical analysis, ${ }^{18}$ metallographic examination, and the mechanical tests were taken from areas representative of the metal at the surfaces of the wear-test specimens, as is shown in detail in Figure 5. Thus, comparable conditions were studied.

The microstructures of the different alloys are shown in Figures 6 to 11 , inclusive. Figures 6 and 7 represent the unetched specimens, and show principally the size, amount, and distribution of the lead particles. The number of these increases with the proportion of lead, and they are generally smaller in size in alloys cast in metal molds than in the corresponding alloys cast in sand molds.

Figures 8 to 11, inclusive, show the structures of etched specimens. The alloys consist of a matrix of alpha grains plus varying amounts of the alpha-delta eutectoid, depending upon the proportion of tin present and the method of casting. The insoluble lead particles are likewise distributed throughout the matrix.

According to the customary copper-tin equilibrium diagrams, about 12 per cent tin is required for the first appearance of the eutectoid. 
This is equivalent to a tin-copper ratio of approximately $0.14,{ }^{19}$ Under the casting conditions encountered in the preparation of the test ingots, which do not represent equilibrium conditions, the eutectoid was found in alloys containing around 7.5 to 8 per cent tin, which is equivalent to a tin-copper ratio in the matrix of about $0.09+$. A greater proportion of this eutectoid was generally found in the alloys cast in metal molds than in the corresponding alloys cast in sand
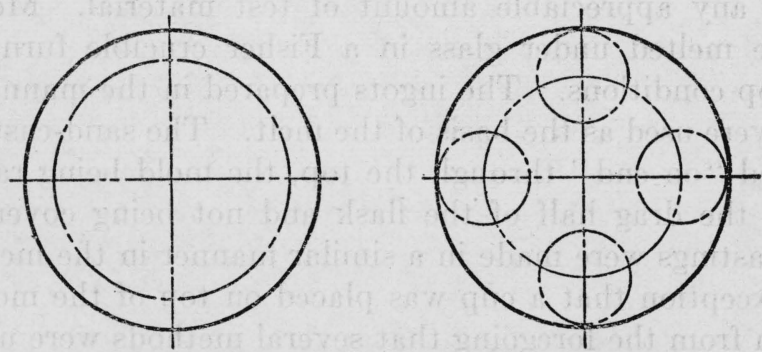

LOCATION OF WEAR TEST SPECIMENS
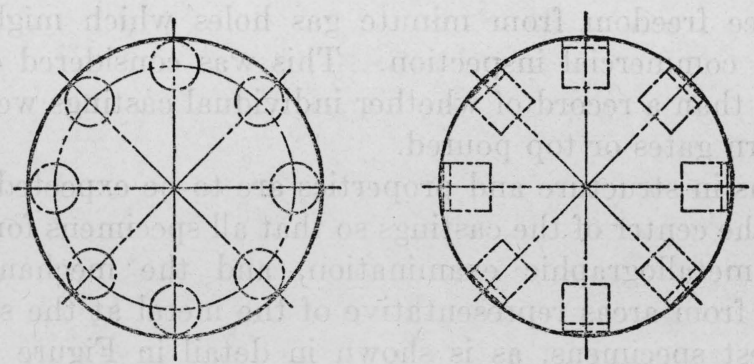

LOCATION OF POUNDING TEST SPECIMENS

LOCATION OF

IMPACT TEST SPECIMENS.

Fig. 5.-Locations of the test specimens with respect to the test castings

molds, as will be evident from examination of Figures 8 and 9 . However, the eutectoid areas present in the sand castings were usually the larger. There was likewise an increase in the amount of the eutectoid as the tin was raised from around 7.5 to 10 per cent.

Thus, the alloys containing less than around 7.5 per cent tin consisted of alpha grains with particles of lead distributed throughout the matrix and no readily visible areas of the eutectoid; alloys con-

19 This ratio is still in dispute. Stockdale's recent studies reported in the $1925 \mathrm{~J}$. Inst. of Metals, 34, p. 111, show the range of alpha-solid solubility to be 16 per cent tin with long-time annealing. However, this does not alter the fact that the eutectoid is found under commercial casting conditions with much lower tin concentration than that required under equilibrium conditions. 




FIG. 6.-Photomicrographs of unetched specimens of the bronzes varying in lead. $\times 100$ 


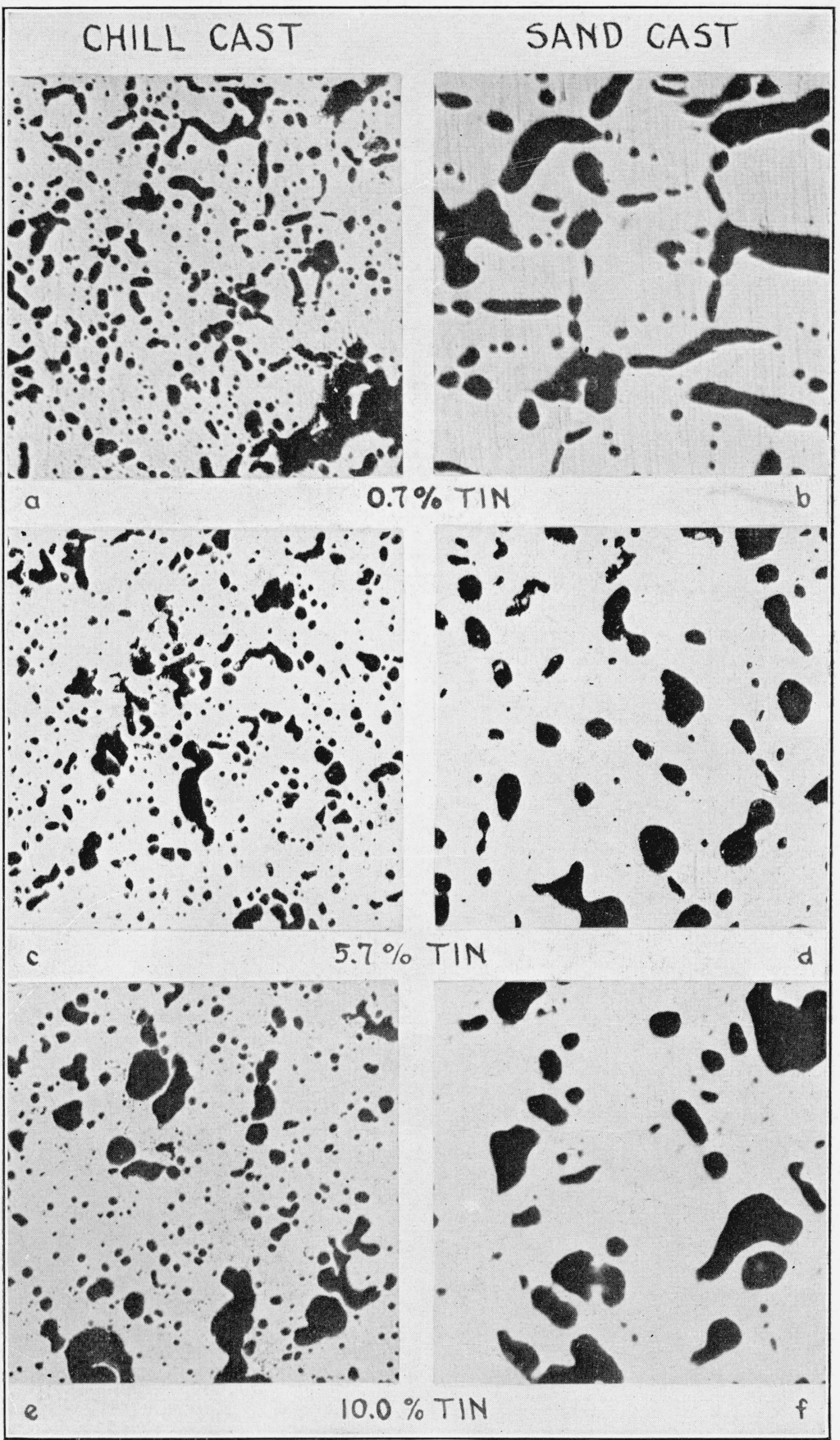

FIG. 7.-Photomicrographs of unetched specimens of the bronzes varying in tin. $\times 100$ 




FIG. 8.- Structure of some of the bronzes varying in lead

Etched with solution of 3 parts $\mathrm{NH}_{4} \mathrm{OH}$ plus 1 part $\mathrm{H}_{2} \mathrm{O}_{2}$. Then etched with acidic ferric chloride solution. $\times 100$ 




Fig. 9.-Structure of some of the bronzes varying in lead

Etched with solution of 3 parts $\mathrm{NH}_{4} \mathrm{OH}$ plus 1 part $\mathrm{H}_{2} \mathrm{O}_{2}$. Then etched with acidic ferric chloride solution. $\times 100$ 


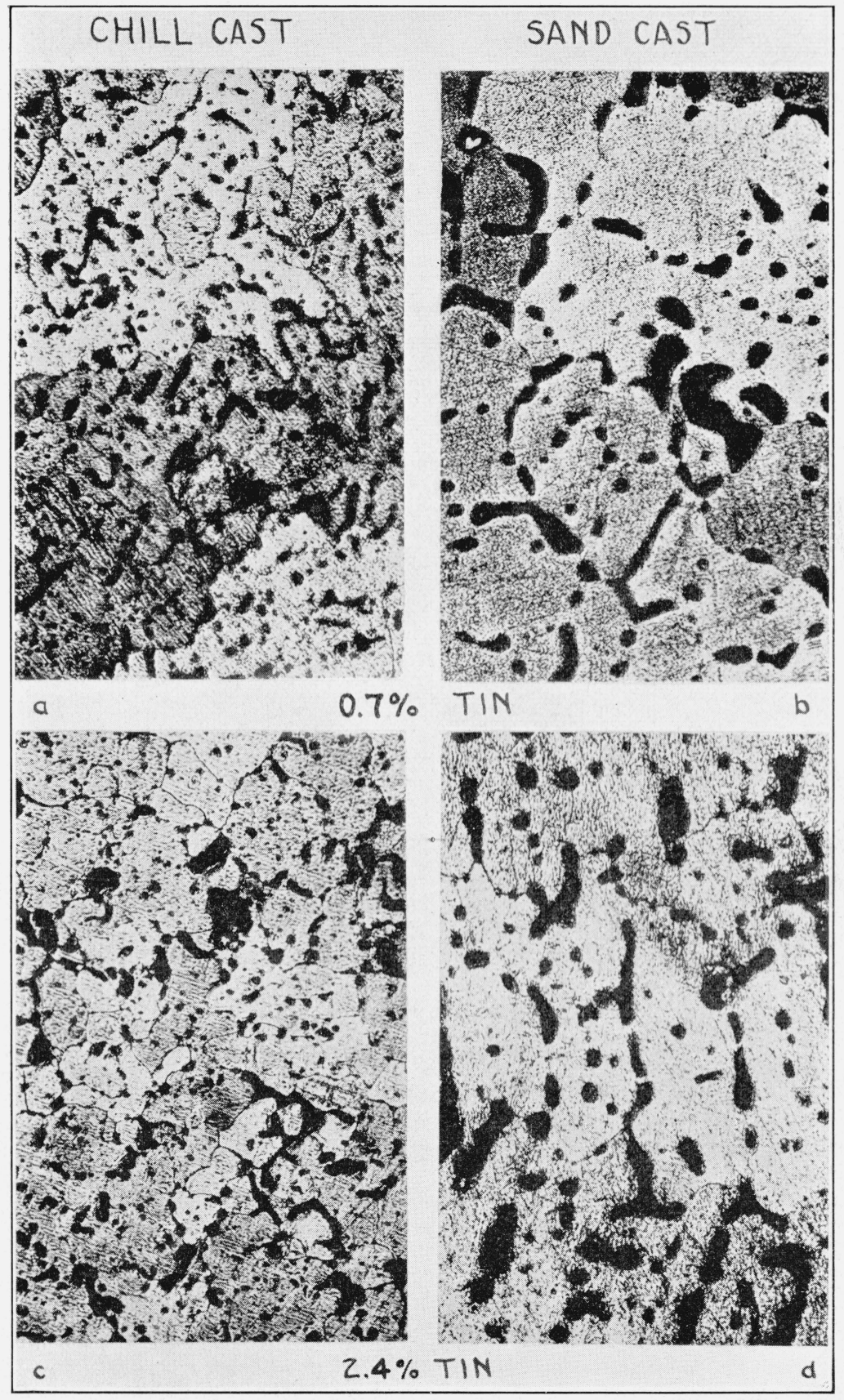

FIG. 10.- Structure of some of the bronzes varying in tin

Etched with solution of 3 parts $\mathrm{NH}_{4} \mathrm{OH}$ plus 1 part $\mathrm{H}_{2} \mathrm{O}_{2}$. Then etched with acidic ferric chloride solution. $\times 100$ 


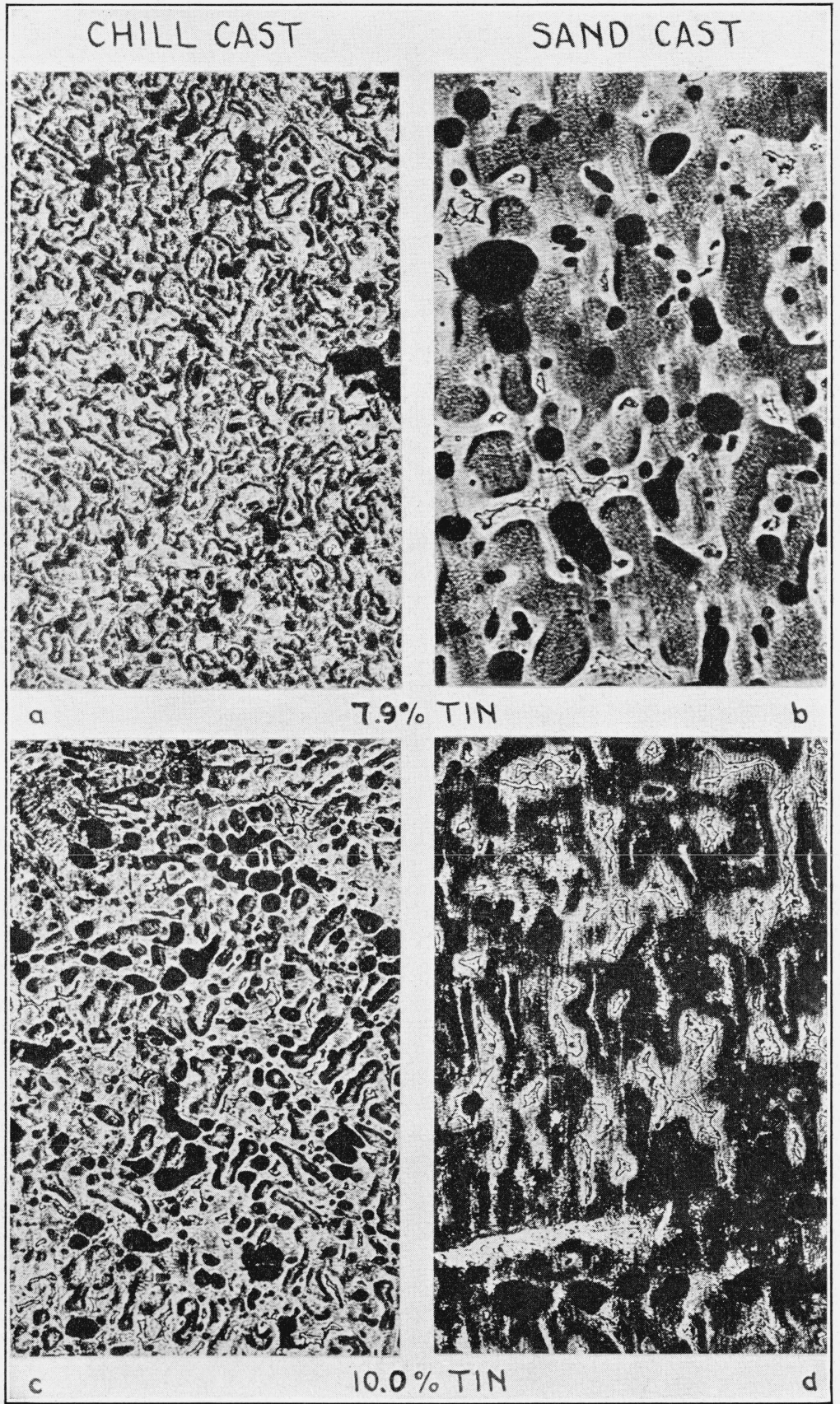

FIG. 11.-Structure of some of the bronzes varying in tin 
taining around 7.5 per cent or more of tin consisted of alpha grains, the eutectoid, and particles of lead.

The steel specimens against which the bronzes were rotated in the wear tests were taken from the center of used railroad car axles. The first axle selected, which will be designated as steel $A$, was not large enough to give the required number of specimens, and so the last few groups of wear tests were made with steel specimens taken from a second axle, designated as steel $B$. This had a chemical composition comparable to that of the axle originally used.

Details of the chemical compositions and some of the properties of the steels used in the wear tests are summarized in Table 2. Since the specimens were cut from car axles, they represent the steels with which bearings are in contact in railroad service.

TABLE 2.-Chemical composition and other details of the steels used in contact with the bronzes in the wear tests

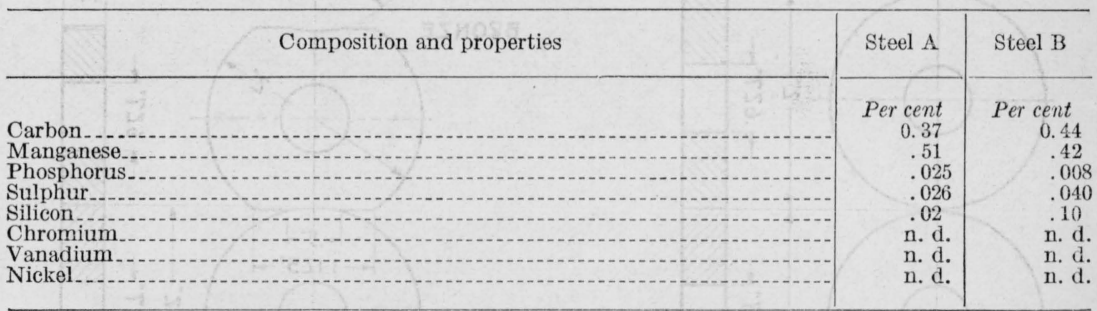

n. d. = not detected in chemical analysis.

Source: Steels A and B taken from used railroad car axles.

Microstructure: Steel A, moderately large grains of pearlite in ferrite matrix; steel B, same as A, but larger grain size.

Brinell hardness number: Steel A, 153; steel B, 129

\section{EQUIPMENT AND TEST METHODS EMPLOYED}

\section{THE AMSLER WEAR TESTING MACHINE}

The machine selected for the study of the wear of railroad bearing bronzes in this investigation is the one manufactured by Alfred $J$. Amsler, Schaffhouse, Switzerland, and is shown in Figure 12. Heretofore, it has been used largely in studying the wear of ferrous metals, but Pecoraro ${ }^{20}$ has reported its application to babbitts.

The essential features of the Amsler wear testing machine are (1) a gear train so constructed as to give either sliding or rolling friction, (2) a calibrated spring $P$ (fig. 12) for adjusting the contact pressures between the test specimens, (3) a cam device $C$ (fig. 12) which may be used to give a lateral sliding motion between the test specimens during test, and (4) a friction dynamometer and torque indicator $T$ (fig. 12) for determining the work done upon the test specimens and the torque developed during the test.

${ }^{20}$ Pecoraro, N., “Experimental tests of white metals for engines," Intl. Assoc. Test. Matls., 6th Congress, $\mathrm{II}_{10} ; 1912$. 
The motor driving the gear train may be operated at two speeds, depending upon whether it is connected to 110 or 220 volt lines. Only the low speed was used in the tests to be described in this report.

For the wear tests made under combined rolling and sliding friction the specimens used were in the form of disks initially 2 inches in diameter and 0.4 inch thick. These were mounted, respectively, one above the other on the two spindles $S_{1}$ and $S_{2}$ shown in Figure 12 and revolved in opposite directions (clockwise and counterclockwise), so that at the line of contact the surfaces of the two disks were moving in the same direction but at different speeds. There was, therefore, a positive slip between the disks. Under the conditions of operation the lower specimen $S_{2}$ had an angular velocity of approximately 240 r. p. m. and the speed of the upper specimen $S_{1}$ was equal


\section{ROLLING FRICTION \\ SPECIMENS USED FOR}

Fig. 13.-Form and dimensions of the wear-test specimens used

to 0.905 times the speed of the lower one. Thus, the surface speed of the lower specimen was approximately 126 feet per minute and the slip between the two specimens 12 feet per minute. In all tests the lateral oscillating motion produced by the cam was used. The amplitude of oscillation of the upper specimen $S_{1}$ was about $0.3 \mathrm{inch}$, and there were about four oscillations for each three revolutions of the upper test specimen.

For the wear tests made under sliding friction the gear actuating the upper shaft was disengaged, and the shaft was locked in place. The upper specimen used for such tests had a concave contact surface machined to conform to the surface of the lower specimen. The form and dimensions of the test specimens for these tests are shown in Figure 13. 
B. S. Journal of Research, RP13



FIG. 12.-The Amsler wear testing machine used in the experiments

$S_{1}$ and $S_{2}$, Test specimens

$P$, Calibrated spring for controlling contact pressures

$C$, Cam for producing lateral oscillation of test specimen $S_{1}$

$R$, Torque indicator

$O$, Oil supply reservoir for tests under lubrication 


\section{B. S. Journal of Research. RP13}

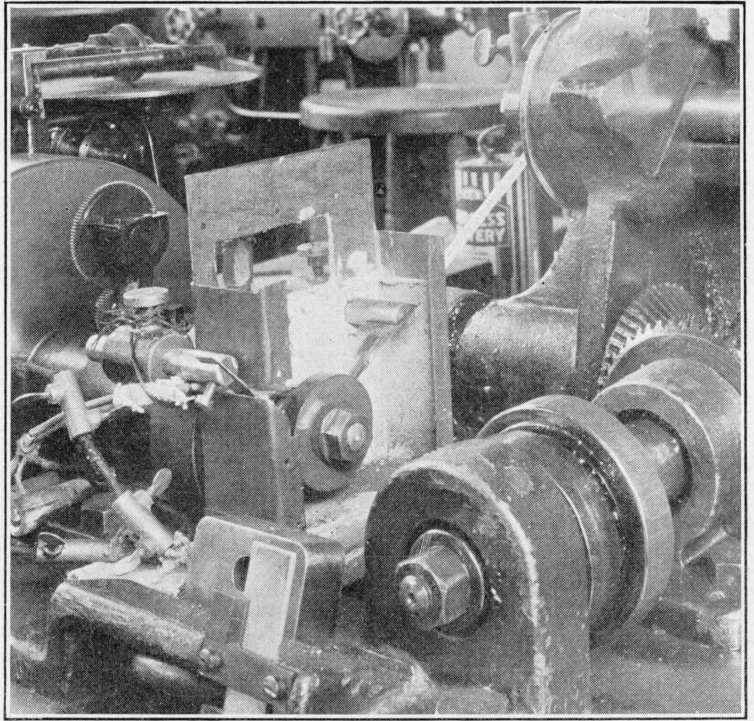

FIG. 14.-Furnace used in making wear tests at elevated temperatures

This furnace is constructed in two sections. The upper half slides on the lower half which is shown in the illustration. Note the provision made for using the copper scrapers 
The bronze specimen shown in Figure 13 for use under sliding friction is only satisfactory in cases where the total wear is low, as in the wear tests with lubrication which were made in this investigation. When appreciable wear takes place, the contact area becomes larger and progressively changes the contact pressures. These difficulties can be avoided by using specimens with straight sides, so that the contact area will remain the same whether large or small weight losses are encountered.

The range of contact pressures which could be exerted between the specimens was from 16.7 to $300 \mathrm{~kg}$ ( 37.5 to 660 pounds). The lowest pressure was obtained from the weight of the head carrying the upper spindle of the testing machine, while higher pressures could be obtained by means of the calibrated spring $P$. (Fig. 12.) All tests reported were made under contact pressures produced by the weight of the head carrying the upper spindle, namely, $16.7 \mathrm{~kg}(37.5$ pounds) total load.

The Amsler wear testing machine is also provided with an auxiliary cam which when engaged periodically releases the load by raising the head carrying the upper spindle and then lets it drop. This produces a repeated pounding of the test specimens. However, wear tests were not made under this pounding action in this investigation. The resistance of the different metals to deformation was studied in mechanical tests.

By changing weights on the pendulum dynamometer, three ranges of sensitivity can be secured, namely 50,100 , and $150 \mathrm{~kg}-\mathrm{cm}(43.4$, 86.7 , and $130 \mathrm{lb}$.-in.). An in tegrating counter turns on a disk directly connected to the gear train of the testing machine. This counter is connected to an arm attached to the pendulum, and its position on the disk is dependent upon the position of the pendulum which indicates the frictional forces between the specimens. Thus, the reading of the integrating counter is a measure of the work done upon the specimens.

A continuous torque record is obtained on a revolving drum by means of a pencil connected to the pendulum.

For tests with lubricants a chain is provided which can be suspended from one of the spindles in a pan of the lubricant. Friction between the spindle and the chain puts the latter in motion, and the chain then carries the lubricant from the reservoir to the spindle and the specimen. However, this equipment was replaced in all of the wear tests made in the presence of lubricants in this investigation. Oil was supplied drop by drop to the upper specimen through a small tube connected to an oil supply reservoir O. (Fig. 12.) The rate of flow was kept at about 60 drops per minute by means of a suitable valve. In this manner, a continuous supply of fresh oil was fed to the specimens, and the used oil frequently containing abraded metal $109673^{\circ}-28-2$ 
particles was collected in a pan at the base of the machine and not used again.

In tests at $175^{\circ}$ and $350^{\circ} \mathrm{F}$. $\left(80^{\circ}\right.$ and $175^{\circ}$ C.) the specimens were subjected to combined rolling and sliding friction within a small electric resistance furnace. A photograph of this furnace is reproduced in Figure 14. The resistances were placed at both the top and bottom of the heating chamber, and a Pyrex glass window was provided through which the specimens might be observed during the progress of the tests. Openings in the side walls permitted the use of the copper scrapers as in the tests at atmospheric temperatures. A thermometer and likewise a thermocouple and potentiometer were used in determining temperatures.

The spindle carrying the upper specimen in the testing machine was raised slightly, so that while being heated to the desired temperatures the test specimens could be rotated out of contact. This minimized temperature changes encountered in first starting rotation of the disks when the furnace had been brought to the desired temperature with the specimens at rest. After about 40 minutes at temperature the support was removed from the upper spindle and the rotation of the bronze and steel in contact was begun. From this point the procedure was similar to that used in the wear tests at atmospheric temperatures.

There is not much clearance between the spindle bearings of the Amsler wear testing machine for the installation of a heating unit, and difficulties were encountered in the first high temperature wear tests. The furnace illustrated in Figure 14 was mounted directly on the faceplate of the housing of the lower spindle bearing. Conduction of heat increased the temperature of the bearing and brought oil vapor from the bearing into the heating chamber of the furnace. This oil was deposited on the test specimens and through its lubricating action materially affected the rates of wear.

These difficulties were minimized by modifications in some of the details of construction of the bearing, namely, (1) a felt washer which quickly became soaked with oil was replaced by an aluminum washer having a very small clearance with the shaft, (2) the aluminum faceplate having a relatively high thermal conductivity was replaced by one made of bakelite, (3) a hole was drilled in the new faceplate from the bottom to the spindle and connected to a suction line through which oil drops or oil vapors were removed before they could enter the heating chamber and lubricate the specimens.

It was impracticable to prove that all oil was kept away from the test specimens, but the described changes resulted in increased wear of the bronzes, no oil was detected on the specimens, and it was possible to reproduce results. The major difficulties were, therefore, considered to have been removed. 
(a) Calculation of Unit Contact Pressures.-The chief difficulty in calculating the unit contact pressures for the two cylindrical specimens used in the wear tests under combined rolling and sliding friction is in the determination of the contact areas. The thickness of the specimens definitely determines the length of the contact area, but the width of contact is a function of the radii of the test specimens, the physical properties of the metals under test, and the total pressure between the specimens.

The equations of H. Hertz ${ }^{21}$ for the determination of the width of contact and of the unit stress existing between two curved surfaces under load were used to calculate the unit contact pressures. These equations are as follows:

$$
b=4 \sqrt{\frac{P}{\pi l} \times \frac{\frac{1}{E_{1}}\left(1-m_{1}^{2}\right)+\frac{1}{E_{2}}\left(1-m_{2}^{2}\right)}{\frac{1}{R_{1}}+\frac{1}{R_{2}}}}
$$

and

$$
S=\frac{4 P}{\pi b l}
$$

where $E_{1}$ and $E_{2}$ are the moduli of elasticity of the metals from which the specimens are made, $m_{1}$ and $m_{2}$ represent Poisson's ratios for these metals. $R_{1}$ and $R_{2}$ are the radii of the two specimens, $l$ is the length of the area of contact between the two specimens, $b$ is the width of the area of contact between the two specimens, $P$ is the total pressure between the two specimens, and $S$ is the unit stress existing between the specimens.

These equations are based on a number of assumptions, the most important of which are: (1) The contact area is small compared with the dimensions of the cylinders. (2) There are no shearing stresses at the contact surfaces; that is, only stresses normal to the contact surfaces are considered. (3) The stresses are within the limit of elasticity of the metals.

By substituting in equation (2) the value of $b$ determined in equation (1), equation (3) is obtained:

$$
S=\frac{P}{\pi l} \times \frac{1}{\sqrt{\frac{P\left[\frac{1}{E_{1}}\left(1-m_{1}{ }^{2}\right)+\frac{1}{E_{2}}\left(1-m_{2}{ }^{2}\right)\right]}{\frac{1}{R_{1}}+\frac{1}{R_{2}}}}}
$$

${ }^{21}$ H. Hertz, Misc. Papers. MacMillan \& Co. (Ltd.), p. 163; 1896. A more convenient reference is F. H. Buhlman, "Factors governing the design of roller bearings for roll necks," Iron and Steel Engr., p. 3045 ; June 1927. 
For specimens of given dimensions and materials, equation (3) may be reduced to

$$
S=C \sqrt{P}
$$

in which $C$ is a constant which may be calculated from

$$
C=\sqrt{\frac{\frac{1}{R_{1}}+\frac{1}{R_{2}}}{\pi l\left[\frac{1}{E_{1}}\left(1-m_{1}^{2}\right)+\frac{1}{E_{2}}\left(1-m_{2}^{2}\right)\right]}}
$$

The unit stresses existing between the bronze and steel specimens tested were determined by the above equations, using the following values for the constants:

$$
\begin{aligned}
& E_{1}=29,500,000 \text { lbs. } / \text { in. }^{2} \text { (steel). } \\
& E_{2}=12,500,000 \text { lbs. } \text { in. }^{2} \text { (bronzes). } \\
& m_{1}=0.3 \text { (steel). } \\
& m_{2}=0.33 \text { (bronze). } \\
& R_{1}=R_{2}=1 \text { inch. }
\end{aligned}
$$

$l=0.4$ inch (maximum length of contact area).

$l=0.25$ inch (minimum length of contact area when using the lateral oscillating motion previously referred to).

The total pressure between the specimens during the tests was about 37.5 pounds. The minimum unit contact pressure between the specimens, when $l$ was $0.4 \mathrm{inch}$, was $24,200 \mathrm{lbs} . / \mathrm{in} .{ }^{2}$, and the maximum unit contact pressure, during the lateral oscillation, when $l$ was 0.25 inch, was $30,600 \mathrm{lbs} . / \mathrm{in}^{2}$

It should be noted that these stresses are only an approximate determination of the true stresses due to the fact that various assumptions have been made, as previously outlined, and that the physical constants of the metals are not accurately known. It should also be pointed out that the proportional limits of the bronzes tested were less than the computed stresses. Therefore, plastic deformation will take place, and the actual unit contact pressures should be less than the computed values. However, the calculations made give a useful, though qualitative, characterization of some of the conditions of test.

\section{SAND ABRASION TESTS}

When placed in railroad service, bearing bronzes are frequently subjected to the abrasive action of nonmetallic particles-as, for example, road dust. It was therefore considered advisable to determine whether some of the major differences observed in the lubricated and unlubricated wear tests on the Amsler machine would be maintained when wear was produced by a nonmetallic abrasive. A sand blast, designed for sand abrasion tests, was used for these 
determinations. Abrasion is produced in this test by the blasting of sand upon the specimen instead of rubbing the nonmetallic particles upon the lubricated bronze, as actually occurs in service, but it was thought that some useful information could be obtained.

In this test a special nozzle, five-sixteenths inch diameter, lined with rubber to minimize abrasion of the nozzle, was placed in the top of a wooden box, the interior of which was also lined with rubber. The nozzle was connected to the bottom of a $Y$ pipe fitting. Sand and air were introduced through the two upper branches of the $Y$, the air passing through an inner tube in the $Y$. The lower end of this tube, which carried the air blast into the nozzle, was below the point at which the sand was introduced so as to avoid "backing up" of the sand. The introduction of the sand was controlled by a slide valve.

The Amsler wear test specimens shown at the left side of Figure 13 were used for these tests, but the holes were plugged with rubber. During the tests the specimens were mounted in the box shown in Figure 15. The flat faces were placed at an angle of $45^{\circ}$ to the axis of the nozzle, the center of the specimens being located about $2 \frac{1}{2}$ inches from the nozzle tip. An opening in the bottom of the box provided an outlet for the sand and air.

One kilogram (2.2 pounds) of standard Ottawa silica sand, 20 to 30 mesh, was blasted on the specimens with an air pressure of 60 lbs./in. ${ }^{2}$, and the loss in weight of the specimens was taken as a measure of the wear. Only new sand was used for each test so as to insure a uniform abrading material. The test procedure was to place the weighed amount of sand in a hopper, adjust the air pressure to $60 \mathrm{lbs}$./in., ${ }^{2}$ and then open the slide valve which gave an immediate and full flow until all the sand had passed through the nozzle. This required about one minute. Several consecutive tests were made on each specimen until a definite rate of wear was observed.

\section{SINGLE-BLOW IMPACT TESTS}

The impact tests were made with an Izod impact testing machine on specimens of the form and dimensions shown in Figure 16. In general, six specimens were tested for each condition of each alloy at each temperature. Suitable furnace equipment was provided for the tests at elevated temperatures. This equipment consisted of a preheating furnace, an equalizing furnace ( $A$, fig. 17$)$, and a special vise $B$, within which resistance wires were embedded. These wires (shown at $C$ in fig. 17) permitted independent control of the temperature of the vise, which could be brought to the same temperature as the test specimen. This tended to reduce the surface chilling encountered in placing heated metal specimens in the jaws of a vise at atmospheric temperatures. 
A group of specimens were heated to the desired temperature in the preheating furnace. One specimen was then removed and placed in the heated vise of the impact testing machine. The equalizing furnace ( $A$, fig. 17 ), previously heated to the same temperature, was placed over the specimen and left in this position for about 10 minutes,



FIG. 15.-Sand-blast abrasion apparatus

during which time the surface of the specimen previously cooled by momentary contact with the air was again brought to the desired temperature. The tup $D$ was then placed in position for the blow, the equalizing furnace $A$ removed, and the tup immediately released. In this way the heated specimen was exposed to the air before test for a period of less than one second. At the same time other specimens 
B. S. Journal of Research, RP13

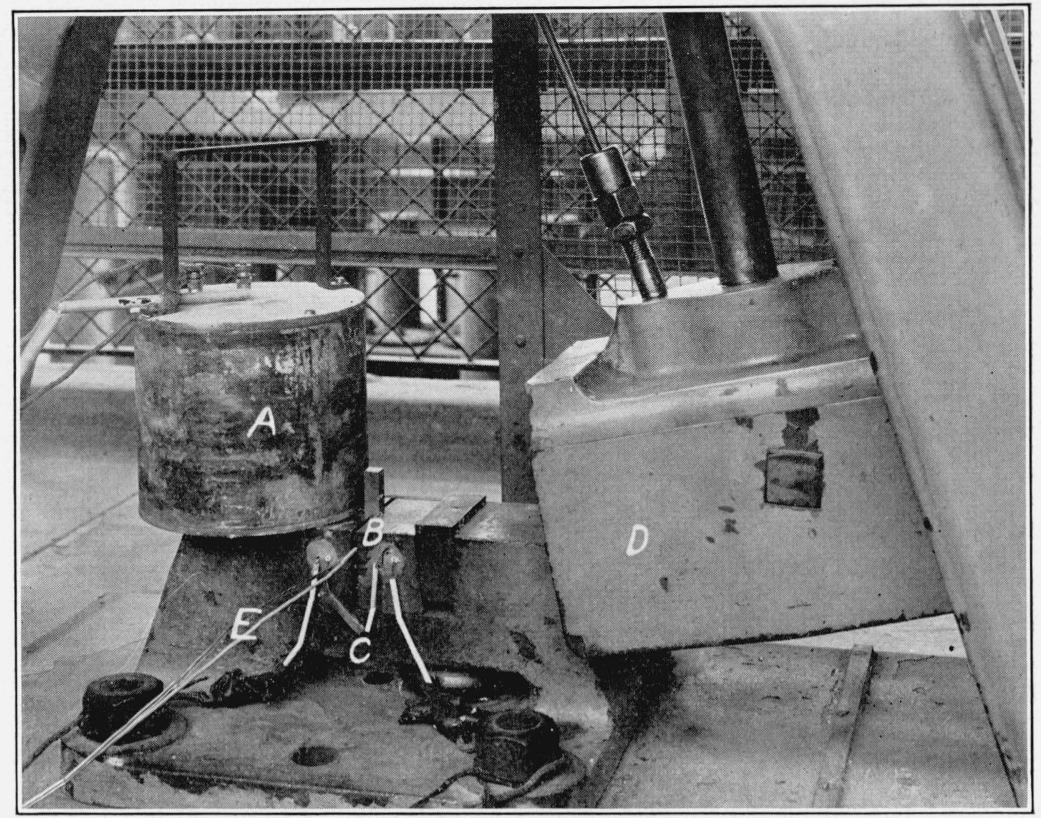

FIG. 17.-Part of equipment used in the notched-bar impact tests

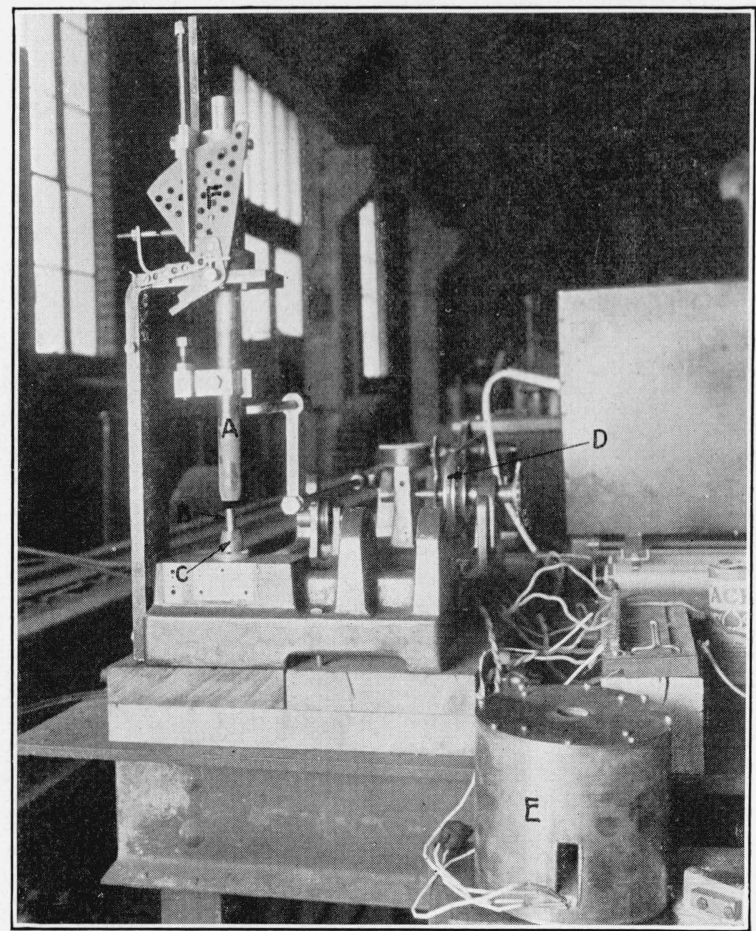

FIG. 18.-Equipment used in the pounding tests 
B. S. Journal of Research, RP13

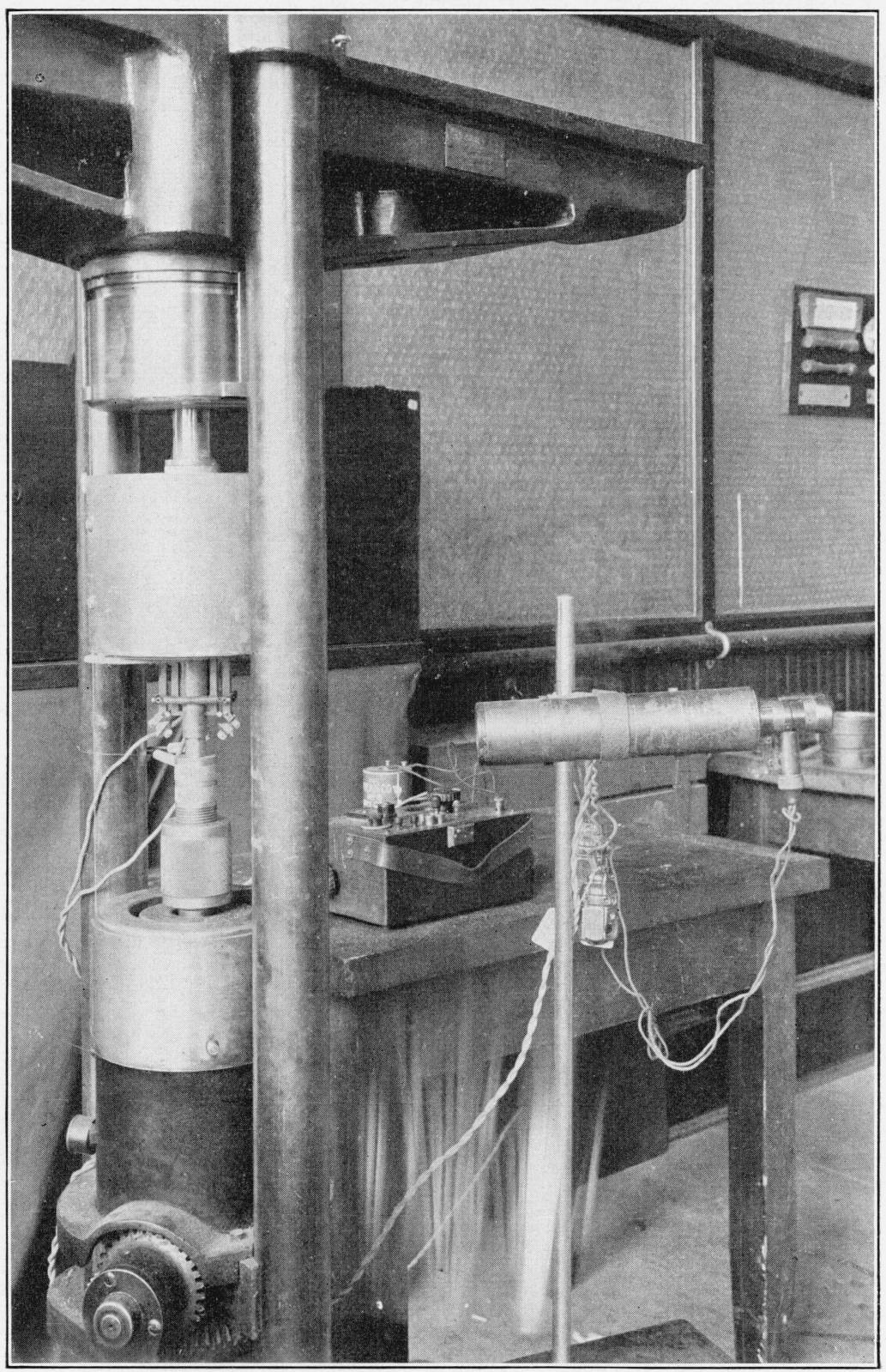

Fig. 19.-Equipment used in the tension tests 
in the preheating furnace were ready for the short heating for temperature equalization. One of the advantages of this procedure was the large saving in time effected when testing a large number of specimens.

Test temperatures were measured by a potentiometer and thermocouple ( $E$, fig. 17$)$ placed in a small hole in the test specimen.

\section{TENSION TESTS}

The tension tests were made with a hydraulic testing machine and a modified Martens extensometer on specimens of the form and dimensions shown in Figure 16. The equipment, which is illustrated in Figure 19, and the procedure employed in tests at different temperatures have already been described..$^{22}$

\section{REPEATED-BLOW POUNDING TESTS}

Pounding tests in which small cylindrical specimens were subjected to repeated blows in compression were carried out with the equipment shown in Figure 18. This consisted of a Stanton repeated impact testing machine modified to give repeated blows in compression to a specimen mounted on the anvil. In Figure 18,

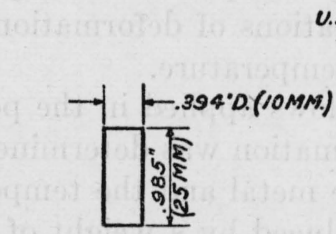

U.S. STO. THREAD OPER INCH

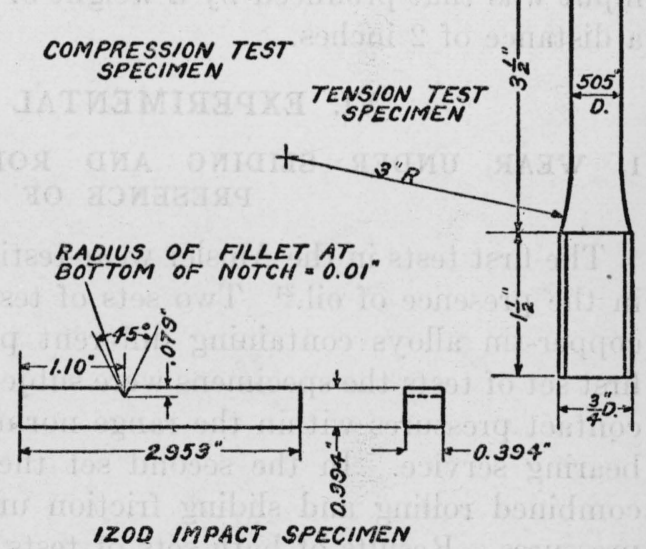

$A$ is the falling weight, $B$ is the specimen, $C$ is the anvil, $D$ the operating mechanism of the Stanton repeated impact testing machine, and $E$ the furnace within which the specimens were tested at different temperatures. The mechanism at $F$ is to insure individual blows free from the auxiliary blows associated with the rebound of the falling weight. This was not taken care of in the Stanton machine and formed an important part of the modified equipment ${ }^{23}$ shown in Figure 18.

In making tests at elevated temperatures a preheating furnace and an equalizing furnace ( $E$, fig. 18) were used to expedite the work, as in the case of the notched-bar impact tests. Specimens were kept

${ }^{22}$ French, H. J., " Methods of test in relation to flow in steels at various temperatures,” Proc. Am. Soc. Test. Matls, 26, pt. 2. p. 7; 1926. Also see Bureau of Standards Letter Circular 238; Nov. 11, 1927.

${ }_{23}$ The authors are indebted to E. M. Staples, research associate for the Bunting Brass \& Bronze Co., Toledo, Ohio, for the design and construction of this pounding machine. 
at the test temperature in the preheating furnace, removed as required, and placed in the equalizing furnace in which they remained, in this case, throughout the test.

The deformation of the specimen under the selected number of blows was measured with an ordinary micrometer in tests at atmospheric temperatures and by an optical micrometer, by sighting through a window in the heating furnace, in tests at elevated temperatures. Temperatures were measured with a potentiometer and 22gauge chromel-alumel thermocouples and were controlled from a thermocouple mounted in the anvil after this had been calibrated in terms of the average temperature along the central axis of the test specimen. Computations of deformation were based on the original length at the test temperature.

The number of blows applied in the pounding tests and the intervals at which deformation was determined varied in individual tests, depending upon the metal and the temperature of test. The energy input was that produced by a weight of 7.15 pounds falling through a distance of 2 inches.

\section{EXPERIMENTAL RESULTS}

\section{WEAR UNDER SLIDING AND ROLLING FRICTION IN THE PRESENCE OF OIL}

The first tests in the Amsler wear-testing machine were carried out in the presence of oil. ${ }^{24}$ Two sets of tests were made on a group of copper-tin alloys containing different proportions of lead. In the first set of tests the specimens were subjected to sliding friction under contact pressures within the range normally encountered in railroad bearing service. In the second set the bronzes were subjected to combined rolling and sliding friction under relatively high contact pressures. Results of both sets of tests are summarized graphically in Figures 20, 21, and 22.

A steel disk was rotated against the bronze specimen for a selected number of revolutions and the wear determined by loss of weight. Repeated and consecutive determinations were made with the same pair of specimens (bronze and steel) until a uniform wear rate was attained.

As shown in Figures 20,21, and 22, the amount and rate of initial wear varied widely for the different bronzes, but after an initial period the wear-revolution and wear-work curves turned toward the horizontal axis. After a preliminary "wearing-in" period, the wear rate dropped to very low values in the presence of a lubricant, and it appeared impracticable to develop with any degree of certainty

${ }_{24}$ The oil used (Mobiloil A) had the following properties: Viscosity at $210^{\circ} \mathrm{F} .=58$; viscosity at $100^{\circ}$ $\mathrm{F}$. $=577$; flash point $=375^{\circ} \mathrm{F}$; union color number $=8$; pour point below 20 ; neutralization number $=0.44$; carbon residue $=0.26$ per cent. These properties were determined by H. T. Kennedy, associate scientist. 
differences between the different alloys. Therefore, it seemed necessary to make wear tests without lubrication to throw additional light upon the wearing properties of these bronzes.

The described results appear to be consistent with the view that after an initial period in which the contact surfaces "wear-in"

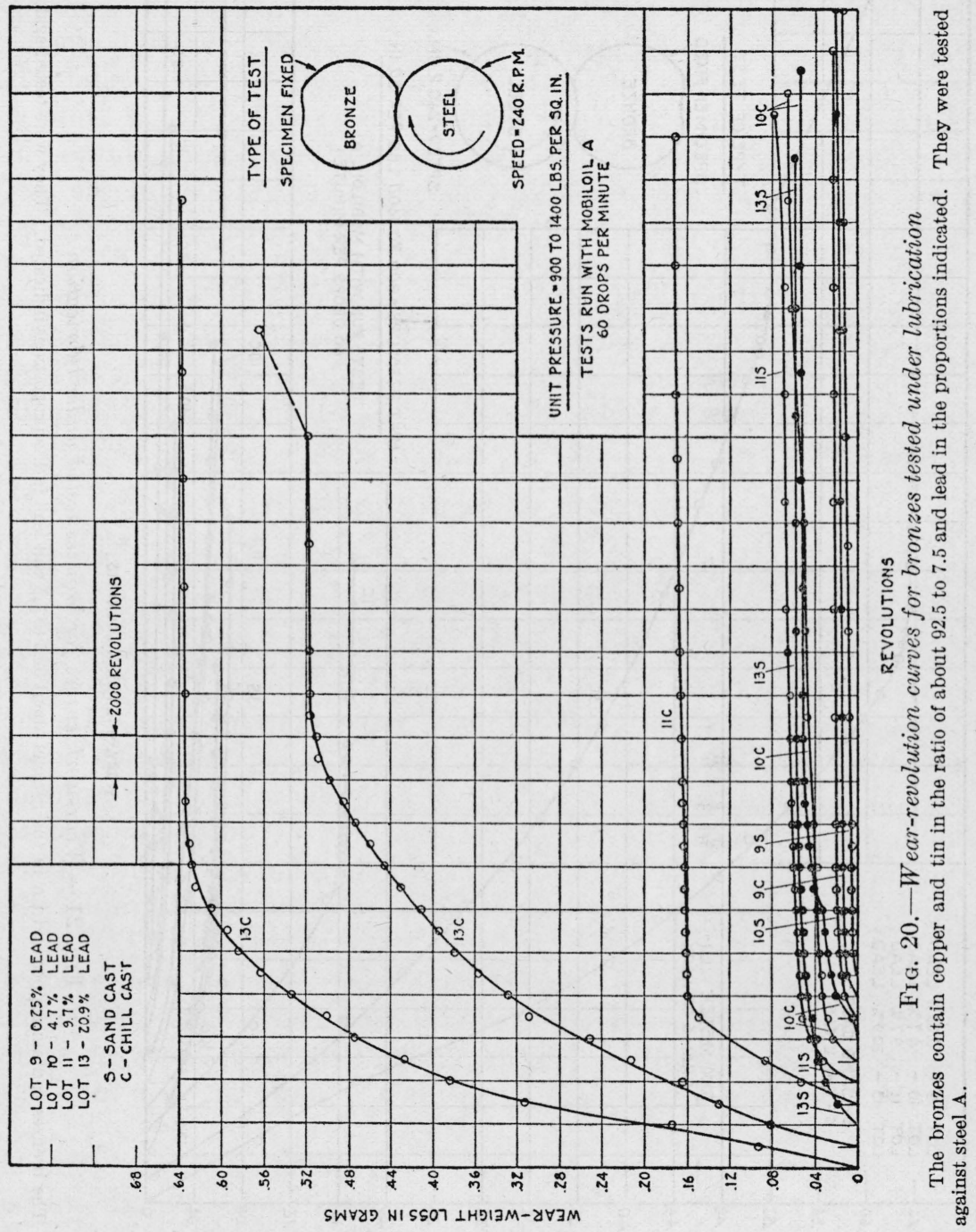

bearings will undergo little or no further wear so long as complete lubrication is maintained. Therefore, considerable attention was given to the behavior of the different metals in wear tests without lubrication.

However, some useful information concerning the different alloys was secured from the tests made in the presence of oil. Examination 
of Figures 20, 21, and 22 shows that increase in lead in the coppertin-lead alloys was accompanied by a general increase in the amount of wear and of work in the initial or "wearing-in" period and likewise by an increase in the slip (or revolutions) comprising this period.

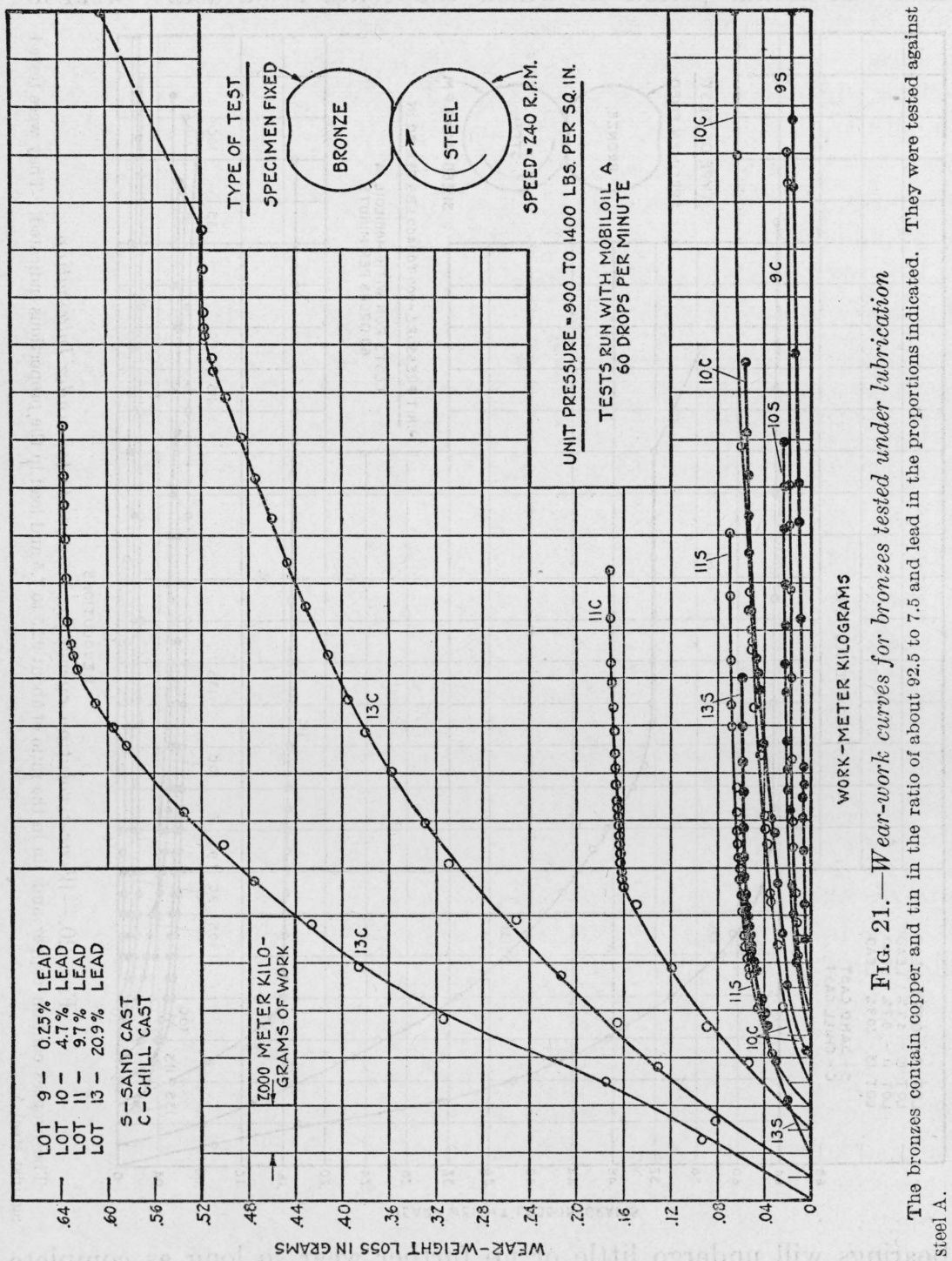

These effects are summarized graphically in Figure 23, but the curves should not be interpreted too rigorously due to the marked influence upon the total wear and the wear rate in the early stages of operation of the initial condition of the surfaces of the specimens. These were finish ground by ordinary shop methods and there were 
quite probably variations in the roughness of the test surfaces at the start of the tests.

It should be recognized that the magnitude and duration of the "wearing-in" period will also be dependent upon the lubricant and the relation of this lubricant to the initial condition of the surface of the bearing metal. They will likewise be dependent on the accuracy of the alignment of the test specimens in the Amsler wear testing machine. Under such conditions it is conceivable that the differences in duration and weight losses of the initial period may be reduced or obliterated if sufficiently smooth contact surfaces are provided and a sufficiently close alignment of the test specimens is obtained.

However, the data summarized in Figure 23 show that the "wearing-in" period was much more marked and longer in the high-lead

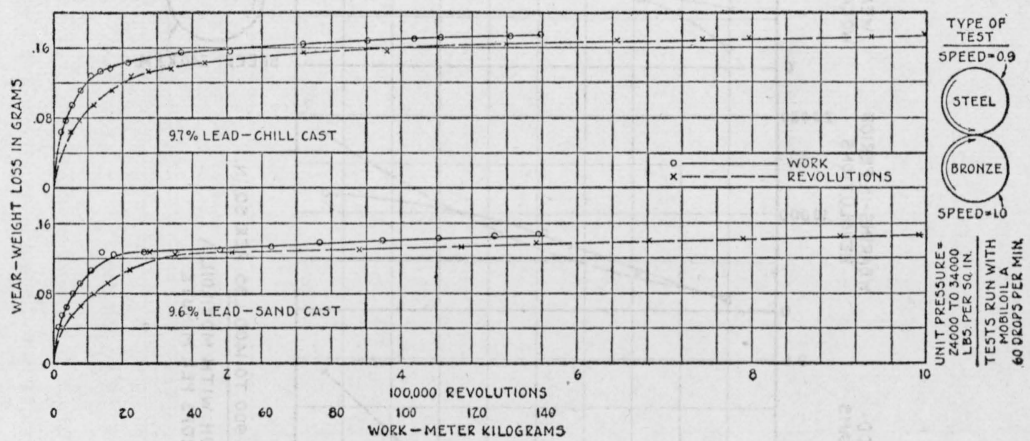

Fra. 22.-Wear-revolution and wear-work curves for bronzes tested under lubrication and high-contact pressure

The bronzes contain copper and tin in the ratio of about 92.5 to 7.5. They were tested against steel A.

bronzes than in the bronzes containing 0.25 per cent lead. It was likewise more marked in alloys cast in metal molds than in the same alloys cast in sand molds.

The torque records from these wear tests summarized in Figure 24 show that after an initial interval the torque dropped and "settled down" to relatively low values in practically all of the copper-tinlead alloys with the exception of those containing 0.25 per cent lead. These latter continued to show widely varying frictional properties throughout the duration of the wear tests. Thus, the copper-tin alloys with 0.25 per cent lead may be considered somewhat inferior to the high-lead bronzes from the standpoint of frictional properties but, as already indicated, have an advantage over the latter in having a shorter "wearing-in" period with less loss in weight.

In Figure 25 is shown a summary of the wear per unit of work in relation to the total slip. Since there are no standard methods of 
interpreting the results of wear tests, Figure 25 is included to show that an added method of examining the experimental data confirms some of the important features emphasized in the discussion of the preceding charts.

The weight changes in the steel specimens for the tests under sliding friction in the presence of oil are shown in Figure 26. In no case did the bronzes cause appreciable wear on the soft steel specimens.

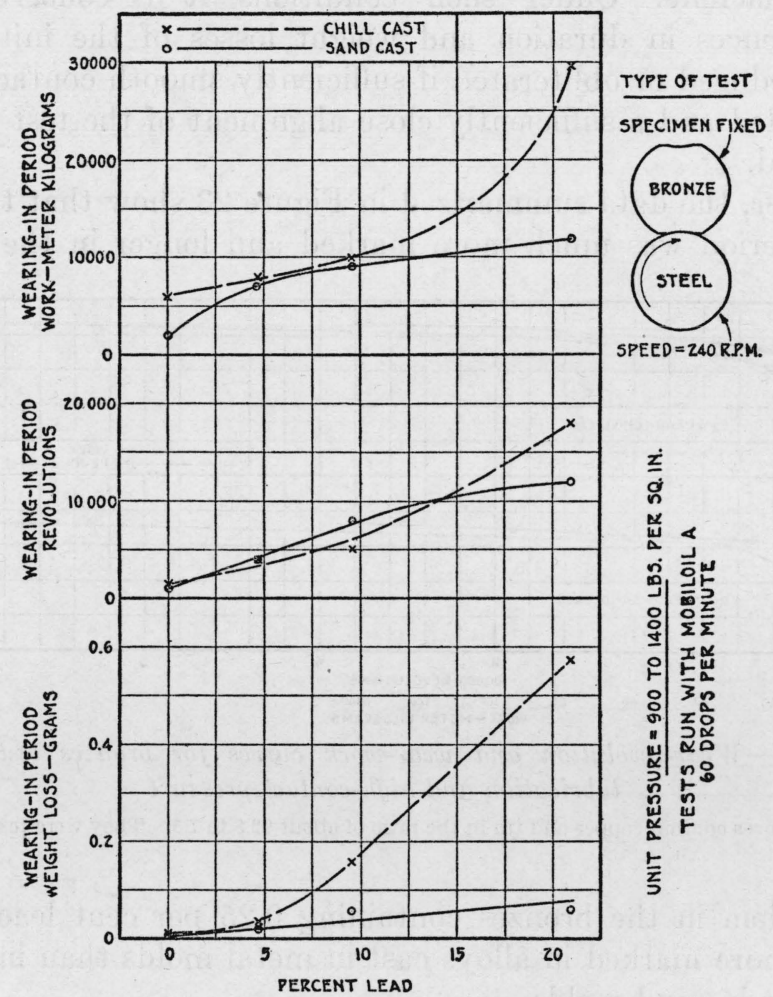

FIG. 23.-Effect of lead on the "wearing-in" period of bronzes tested under lubrication in the Amsler wear-testing machine

The bronzes contain copper and tin in the ratio of about 92.5 to 7.5. They were tested against steel A.

Some of the bronze test specimens were examined under the microscope subsequent to the wear tests to determine the degree of deformation of the metal at the contact surfaces. In no case was evidence of work hardening found in the specimens subjected to rolling and sliding friction in the presence of oil. Two of the specimens which were subjected to sliding friction in the presence of oil showed strain lines as illustrated in Figure 27, $b$. Surface flow was observed in a high-lead bronze (fig. 27,a) but not in any of the low-lead bronze specimens examined. 


\section{WEAR TESTS AT ORDINARY TEMPERATURES IN THE ABSENCE OF OIL}

Wear tests under sliding friction without oil were attended by difficulties even at fairly low contact pressures. The temperature of the bronze specimens was quickly raised and resulted in a marked flow of the surface metal. Under such conditions there was difficulty in determining just what constituted wear and how much wear took place, and there was likewise a question regarding the exact conditions

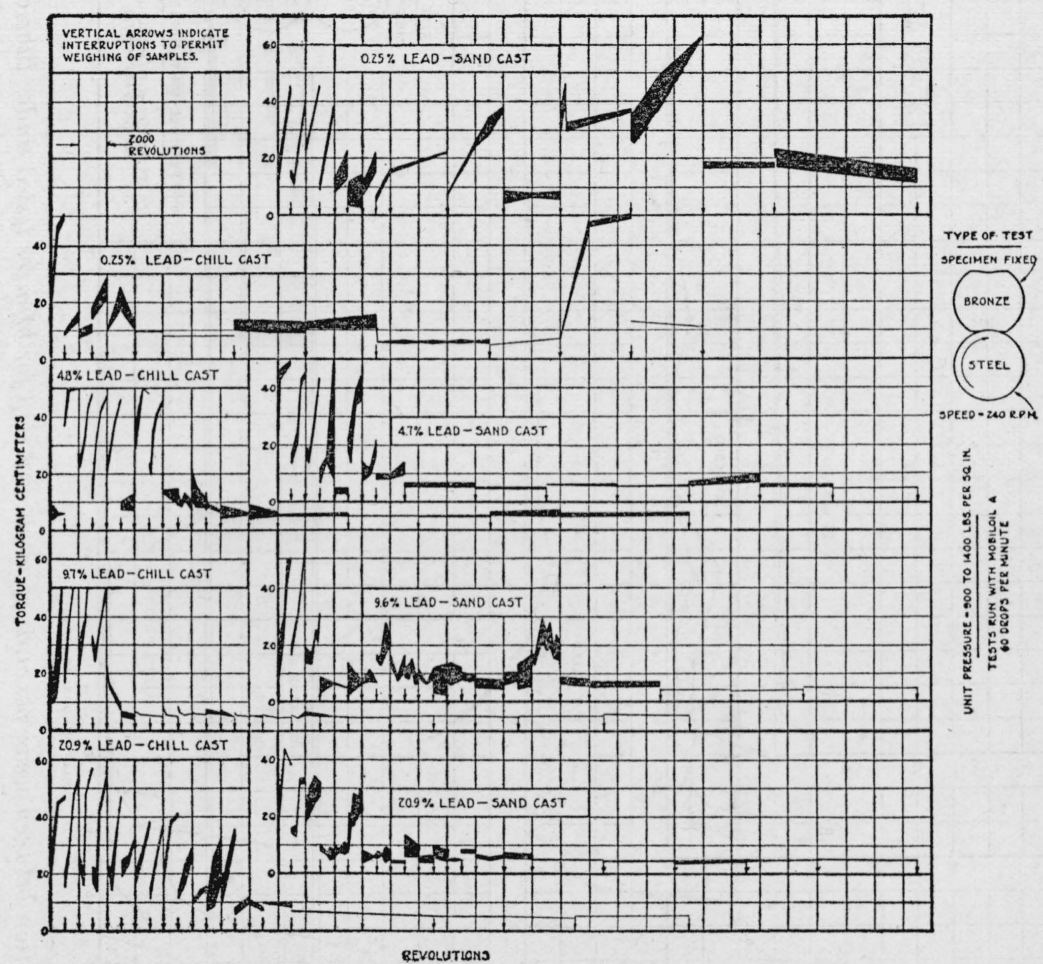

FIG. 24.-Torque in testing different bronzes against axle steel $A$ in the presence of oil in the Amsler wear-testing machine

The bronzes contain copper and tin in the ratio of about 92.5 to 7.5 and lead in the proportions indicated. The width of the black lines represents torque fluctuations.

under which the tests were made. Variations in the frictional and thermal properties of the different metals probably produced variations in the temperatures reached and direct comparisons of the experiments did not seem justified.

Such difficulties were minimized with the lower rate of slip and the small area of contact between the two disks in tests under combined rolling and sliding friction. There was less heat developed in a given time, despite the relatively high unit contact pressures, and there was probably also a better opportunity for dissipation of the heat resulting 
from the frictional forces. Therefore, all wear tests without lubricants which are described in this report were made under combined rolling and sliding friction.

(a) Film Formation.-The first tests were characterized by erratic weight losses; that is, individual specimens did not show con-

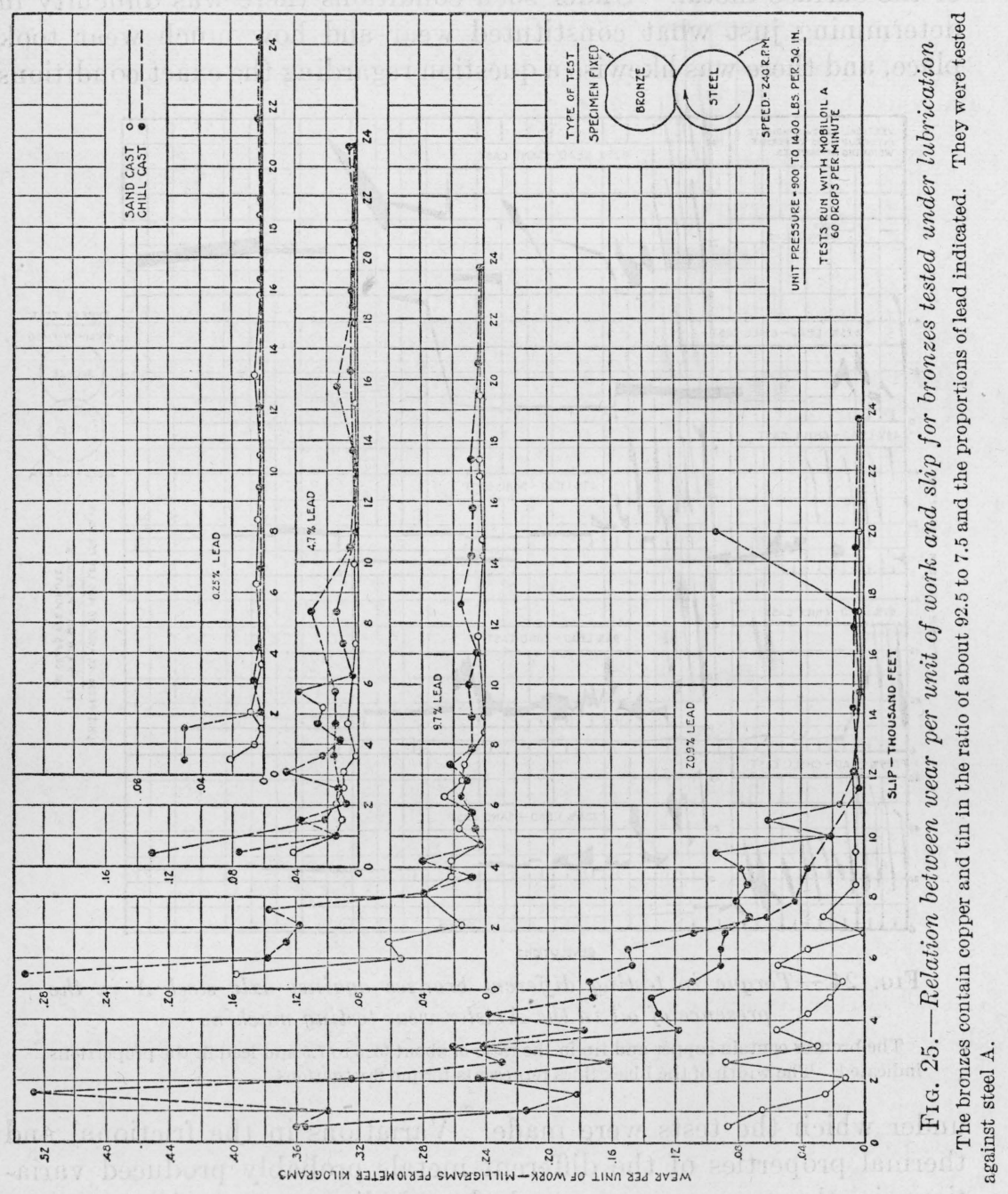

sistent rates of wear in consecutive tests, even after a preliminary period. In addition to a change in the roughness of the contact surfaces from the original ground finish, a change in color and what appeared to be a coating or film was frequently observed. Typical films are illustrated in Figures 28, $i, 30, c$, and $30, d$.

The formation of such coatings which were not present at the start of the tests appeared to be related to changes in the wearing and 
frictional properties of the metals. The compositions of the films produced are not now known with certainty, but they were apparently of two types. The first, comprising films which looked like copper oxide, was observed in the copper-tin alloys which were low in lead. These same films also occurred in the high-lead bronzes, but they were not so easy to detect in the latter alloys, due to the more frequent formation of a second type of coating, a black film which was either lead or a lead compound. Tests so far made, including X-ray analysis, have failed to reveal its exact nature.



Fig. 26.-Wear of axle steel $A$ in contact with different bronzes in the wear tests made in the presence of oil

The bronzes contain copper and tin in the ratio of about $\$ 2.5$ to 7.5 and the proportions of lead indicated. Points below 0 represent "loading" of the steel.

Diffraction patterns obtained ${ }^{25}$ in the examination of a bronze specimen containing about 15 per cent of lead are reproduced in Figure 31. Pattern $b$ is for a specimen with the black coating, while pattern $a$ is for a similar specimen without film. One of the significant differences between the two is that the lines from the specimen with the film have only about one-fifth the intensity of those from the specimen without the film. This difference is probably due to the partial absorption of the $\mathrm{X}$ rays by the black coating which reduced the energy available for diffraction by the base metal copper-tin solution. A similar result was obtained with change in casette position and location. The fact that the surface film itself yielded no

${ }^{25}$ By F. Sillers, jr., junior metallurgist. 
pattern may be due to the high degree of fragmentation, distortion, and preferred orientation to which the small quantity of material constituting the film was subjected during the wear test

Chemical analysis of a small particle taken from the surface of a black-coated specimen gave a positive test for lead, but it was not certain that the surface layer alone was being tested. When heated in the oxidizing portion of a Bunsen flame, a bronze specimen "sweated" black globules which looked like lead and which gave a lead diffraction pattern under X-ray examination. When a coated specimen was rubbed lightly with 00 French emery paper and viewed under the binocular microscope in comparison with a specimen electroplated with a thin layer of lead and similarly touched with emery paper, the appearance of the two surfaces was similar.

These features, selected from a variety of tests, do not prove, but strongly indicate, that the black coatings obtained in the wear tests contained lead.

The formation of coatings in wear tests is not restricted to the particular conditions under discussion. Coatings have been encountered in the study of the wear of gauge steels. ${ }^{26}$ Attempts were first made to carry out "dry" tests, but a coating which looked like iron oxide was soon formed on the contact surfaces of most of the hardened steels tested and tended to reduce the wear, produced erratic results, and caused the gauge and the ring within which it moved to "seize."

Few references seem to be available in technical literature which deal with such films, and aside from their nature there is little known concerning the exact conditions of formation and possible methods of control.

A recent report by G. A. Thomlinson ${ }^{27}$ is one of the few publications relating to this subject. In this report the author discusses the conditions of formation of iron oxide when a steel ball is moved in contact with other metallic surfaces.

Aside from the exact nature of such films and the conditions of formation, it appeared certain from the preliminary unlubricated wear tests of bronzes that film formation played a part in the erratic results of the wear tests, and that some method of elimination or control of films should be provided if consistently uniform results were to be obtained.

Wear is ordinarily considered to take place through the displacement and detachment of small particles from the contact surfaces. The energy accompanying the tearing off of such particles can be conceived to appreciably raise the temperature of small masses to

\footnotetext{
${ }^{26}$ French, H. J., Herschman, H. K., Wear of steels with particular reference to plug gauges, Tr. Am. Soc. Steel Treat., 10, No. 5, p. 683; November, 1926.

${ }_{27}$ Thomlinson, G. A., "The rusting of steel surfaces in contact." Proc. Roy. Soc., Series A, 115, No. A771, p. 472; July 1, 1927.
} 




FIG. 27.-Micrographs of the structure adjacent to the wearing surfaces of four bronzes containing copper and tin in the ratio of about 92.5 to 7.5 . The top layers in each picture are copper or copper and nickel plate. $\quad \times 250$

Etched with solution of $\mathrm{FeCl}_{3}$ plus $\mathrm{HCl}$ : $a$, Bronze containing 20.9 per cent lead showing surface flow under lubricated sliding friction; $b$, Bronze containing 0.25 per cent lead showing strain lines at wearing surface. Lubricated sliding friction; $c$, Bronze containing 4.7 per cent lead showing no sign of surface workhardening. Lubricated sliding friction; $d$, Same bronze as $a$, but tested under combined rolling and sliding friction 
B. S. Journal of Research, RP13



FIG. 28.- Some of the wear test specimens before and after test (approximately full size)

$a$, "Flat-wheel" condition in one of the bronze specimens

$b$, Another view of specimen $a$

$c$, Steel specimen before test (machined surface)

d, A bronze specimen before test (machined surface)

$e$, Bronze specimen showing rough type of wear

$f$, Bronze specimen showing the "flat-wheel" condition

$g$, A bronze specimen before test (machined surface)

$h$, Bronze specimen showing smooth type of wear

$i$, Bronze specimen showing film

], Bronze specimen showing ridges

$k$, Steel specimen showing ridges 
B. S. Journal of Research, RP13



FIG. 29.-Surfaces of some of the bronze specimens before and after wear tests. $\times 10$
a, Original machine-finished surface
$b$, Very rough with ridges
$d$, Smooth type of wear
$c$, Rough type of wear
$e$, "Flat-wheel" condition 
B. S. Journal of Research, RP13

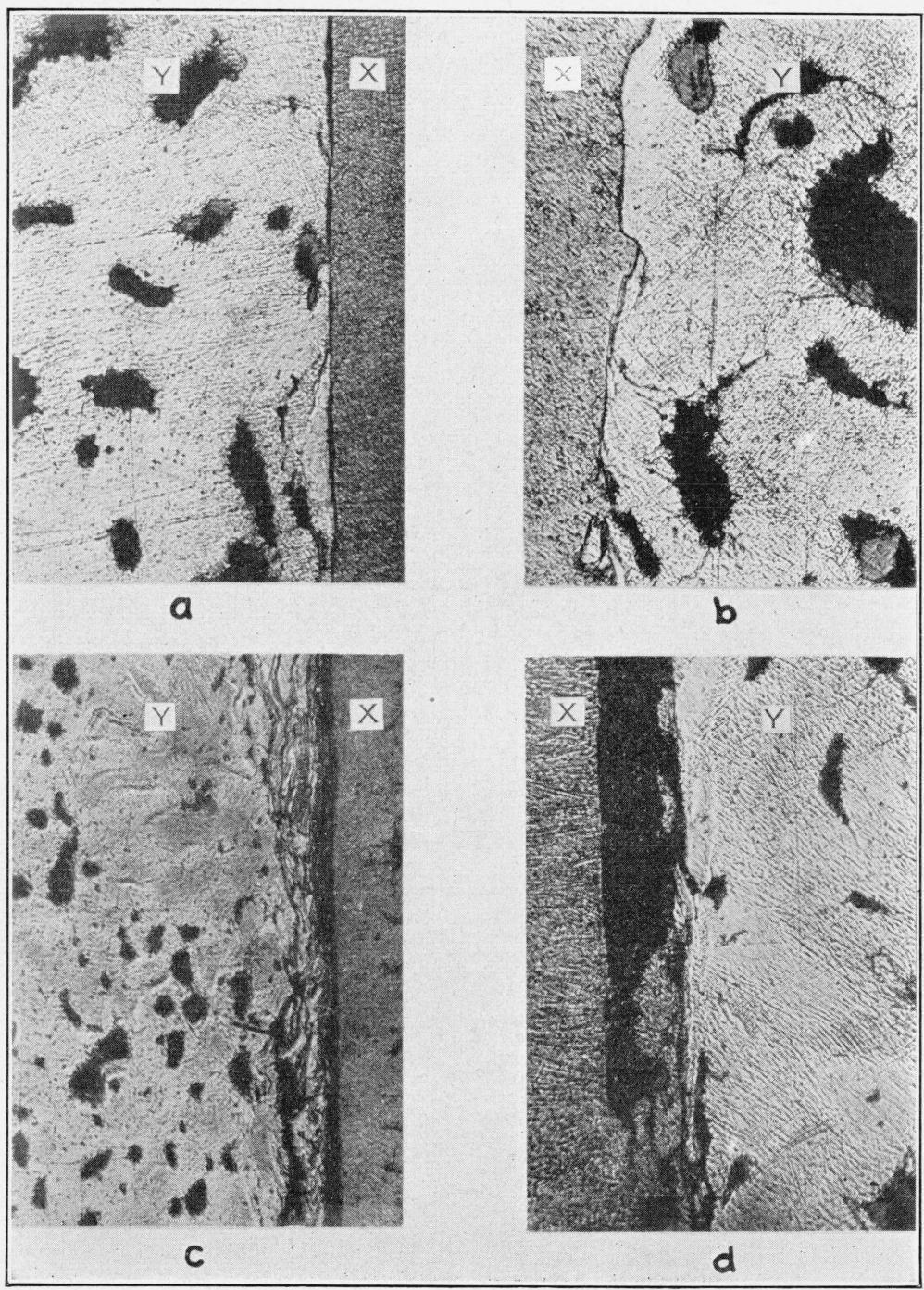

Fig. 30.-Micrographs showing the metal adjacent to worn surfaces of some of the bronze wear test specimens. $\quad \times 250$

Etched with solution of 3 parts $\mathrm{NH}_{4} \mathrm{OH}$ plus 1 part $\mathrm{H}_{2} \mathrm{O}_{2}$

$x$, Represents copper plate used to preserve the contour of the bronze surface

$y$, Represents the bronze specimen

$a$, Shows smooth type of wear

$b$, Shows rough type of wear

$c$, Shows film on surface with underlying fragmented bronze

$d$, Shows heavy film combined with rough type of wear 
B. S. Journal of Research, RP13



FIG. 31.-X-ray diffraction patterns of bronze specimens with and without black film

$a$, Without film $\quad b$, With film 
the point of rapid oxidation. In at least some cases the films formed appeared to consist of embedded oxidized particles. This was most noticeable in the tests of gauge steels previously mentioned, but





was sometimes clearly shown on bronze specimens having films which looked like copper oxide. Removal of abraded particles as soon as these became detached might reasonably be expected to result in a smaller tendency toward film formation. . 
Based on this line of reasoning, scrapers were installed on the Amsler wear testing machine. These consisted of half-hard copper strips which continually rubbed against each of the rotating disks. The scrapers caused no measurable wear of the bronzes or steels and reduced the tendency toward film formation. However, since originally used, it has been found that the scrapers were not always effective in preventing the formation of films, but they probably assist in this direction, and were used in all of the wear tests made without lubricants.

It is probable that with lubrication torn-off metal particles would not so readily become embedded in the specimens, since the oil would tend to carry away these particles. Hence, in this one respect the scrapers may be considered to make the wear tests without lubricants more nearly comparable with the metal-to-metal wear under starting conditions of a lubricated bearing.

It might be of interest to mention at this point that surface discolorations were also observed in the tests made in the presence of oil.

(b) Bronzes Varying in Lead and in Tin.-Wear-revolution and wear-work curves for tests of two series of bronzes varying, respectively, in lead and tin are shown in Figures 32 and 33. Most of these curves show a "wearing-in" period, but this is not so marked as in tests made with lubrication. Instead of approaching the horizontal axis after a preliminary period, as in the wear tests in the presence of oil, they assume a well-defined slope representing a relatively high rate of wear. So long as no unusual circumstances arise to modify the conditions of test, the slope of the wear-work or wearrevolution curves may be assumed to represent a more or less definite state of equilibrium and may be used for comparison of the different metals when subjected to unlubricated friction. Such comparisons are made in Figures 34 and 35 between chill-cast and sand-cast bronzes varying in the proportions of lead and tin.

In the alloys which contain copper and tin in the ratio of about 92.5 to 7.5 , increase in lead from 0.25 to about 5 per cent resulted in an increase in the wear per unit of work. With futher increase in lead-from about 5 to 15 per cent-the wear per unit of work decreased. In bronzes containing between about 15 and 25 per cent lead the wear rates remained practically constant.

In alloys containing copper and lead in the ratio of about 84 to 16 , increase in tin from 0.7 to around 10 per cent resulted in a general decrease in the wear per unit of work. This decrease was very rapid between 0.7 and about 3 per cent tin and became less rapid as the proportion of tin was further raised to 10 per cent.

Similar changes were observed when considering the wear per unit of slip (or wear per 10,000 revolutions) and, therefore, no separate summaries of these data have been included in this report. 
In general, alloys cast in metal molds wore much more rapidly than corresponding alloys cast in sand molds. Two exceptions were found in which the wear per unit of work was about the same for the chill-cast and sand-cast conditions. These were the copperlead mixture (with 0.7 per cent tin) and the copper-tin alloy (with 0.25 per cent lead).

SAND CAST

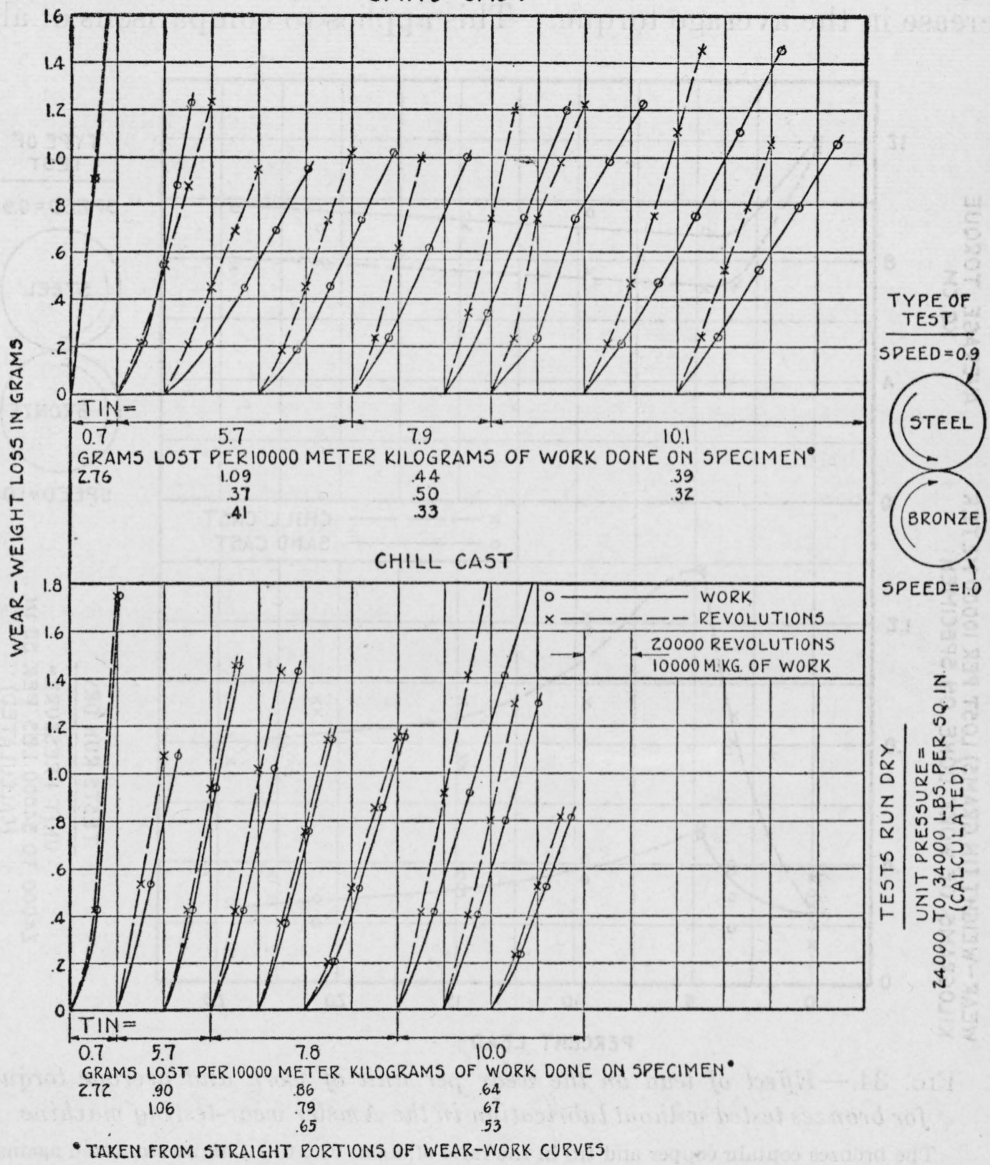

FIG. 33.-Wear-revolution and wear-work curves for bronzes tested without lubrication in the Amsler wear-testing machine

The bronzes contain copper and lead in the ratio of about 84 to 16 and tin in the proportions indicated. They were tested against steel A.

Additional information is given by the torque records taken during the wear tests. Typical torque-revolution curves for a set of bronzes varying in tin are shown in Figure 36 . Low torque values were obtained at the start in the majority of the wear tests, but as the bronze and steel specimens continued to rotate in contact the torque increased. In many cases it approached a more or less definite and 
high value, while in others it quickly reached a maximum and then gradually decreased throughout the wear-test interval. In general, however, the torque records from consecutive wear tests of any bronze specimen were quite similar and permit comparisons of average values for each set of consecutive wear tests. Such comparisons are included in Figures 34 and 35 and show that, as a general rule, decrease in the wear per unit of work is concomitant with an increase in the average torque. This applies to comparisons of alloys

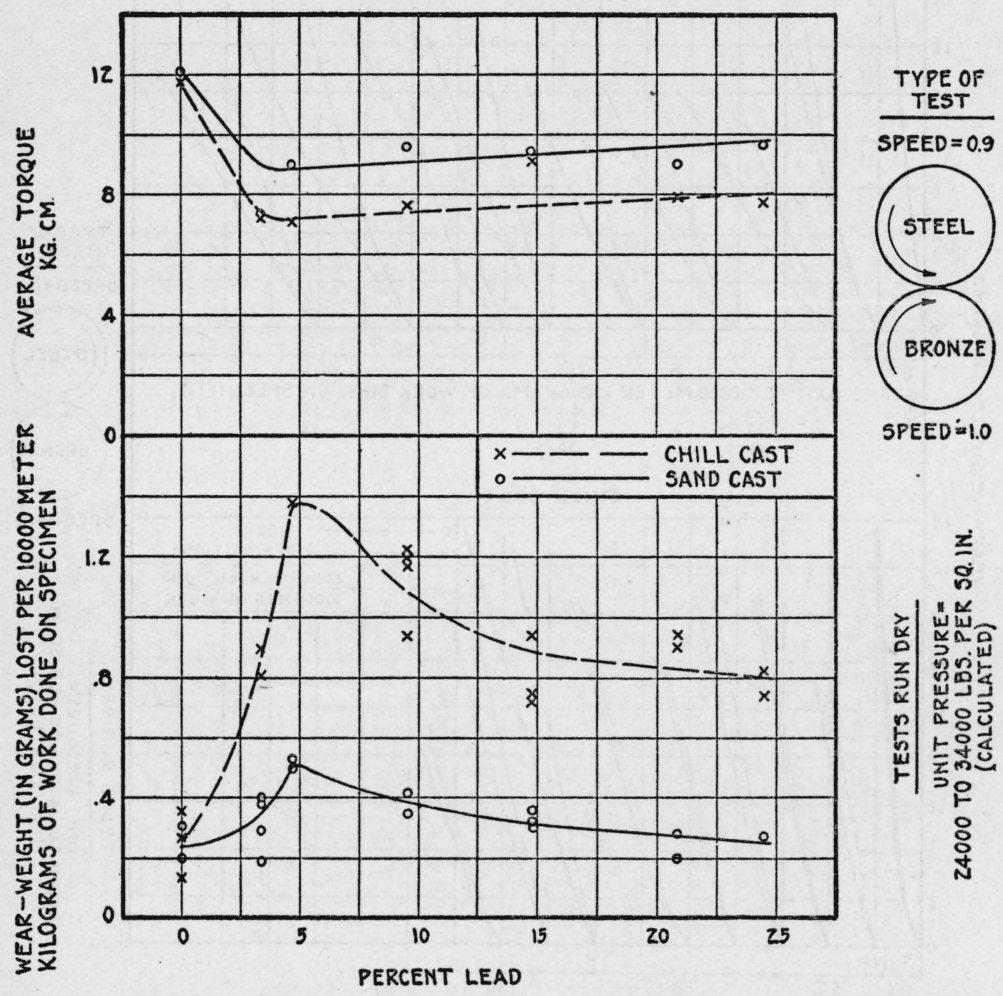

FIG. 34.-Effect of lead on the wear per unit of work and average torque for bronzes tested without lubrication in the Amsler wear-testing machine

The bronzes contain copper and tin in the ratio of about 92.5 to 7.5 and were tested against steel A.

varying in tin or lead and likewise to comparisons between the chillcast and sand-cast conditions of a given composition. Exceptions are the low-tin alloys which assumed a very rough surface condition in the wear tests and showed erratic torque values in duplicate specimens.

Since the "wearing-in" period in these wear tests without oil was relatively small and the initial rise in torque was restricted to a small portion of the test interval, the foregoing comparisons develop the interesting feature that where the average torque is high the wear 
per unit of work (also wear per revolution), subsequent to the "wearing-in" period, is frequently low. There is no obvious explanation for these effects which will, however, be given further consideration in a subsequent section of this report.

Examination of the surfaces of the test specimens throughout the progress of the tests likewise revealed differences between the dif-

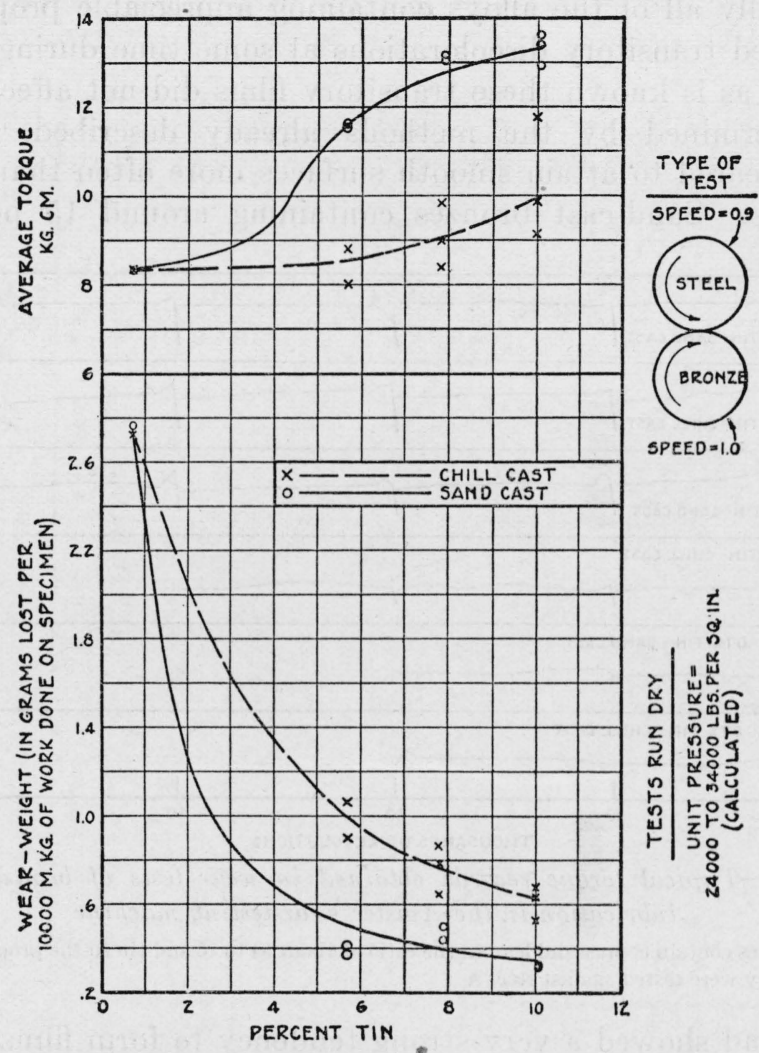

Fig. 35.-Effect of tin on the wear per unit of work and average torque for bronzes tested without lubrication in the Amsler wear-testing machine

The bronzes contain copper and lead in the ratio of about 84 to 16 and were tested against steel $\mathrm{A}$. The inflection around 2.5 per cent tin in the torque curve for sand-cast bronzes is based on additional data included in Figure 45. The form of the wear curves below 5.5 per cent tin is approximate for reasons given in Section VI, $2(c)$, of this report.

ferent alloys. Some of the surfaces became exceedingly rough and showed the ridges illustrated in Figures $28, j$, and 29, $b$. Others became moderately rough, as shown in Figures $28, h, 29, c$, and $30, b$, while in some cases films were formed as illustrated in Figures 28, $30, c$, and $30, d$. A "flat-wheel" effect was also observed and is illustrated in Figures 28, $a, 28, b, 28, f$, and 29, $e$. 
Surface roughening accompanied by ridges was quite largely restricted to the copper-lead mixture low in tin and the copper-tin alloys low in lead. These also more quickly reached the "flat-wheel" condition than the remaining alloys in the groups tested. When the "flat-wheel" condition became marked, heavy pounding resulted in the wear tests.

Practically all of the alloys containing appreciable proportions of lead showed transitory discolorations at some time during the tests, but as far as is known these transitory films did not affect the wear rates determined by the methods already described. Sand-cast alloys appeared to attain smooth surfaces more often than the chillcast alloys. Sand-cast bronzes containing around 15 per cent or

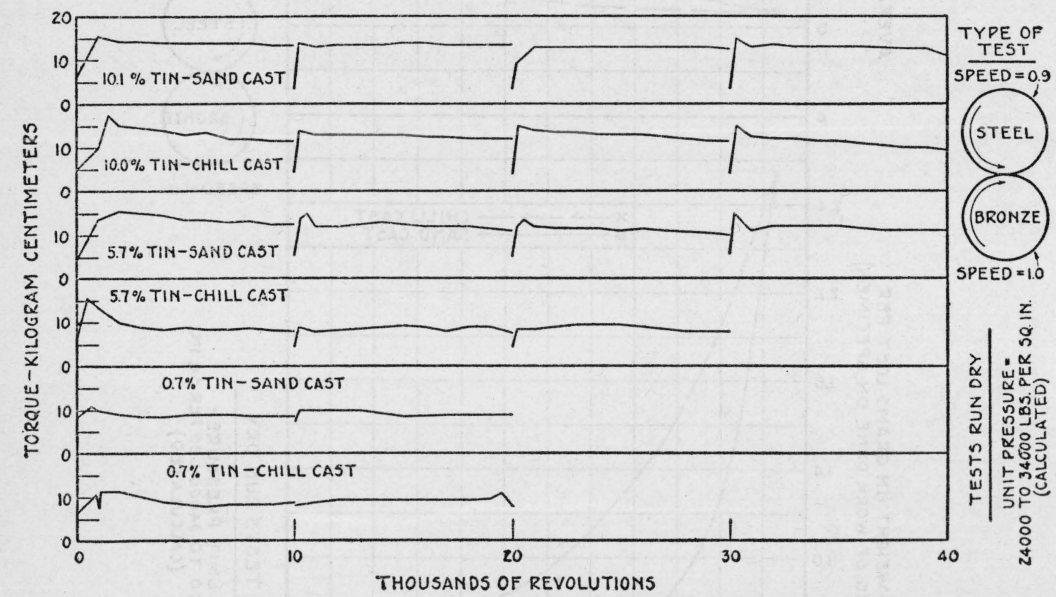

FIG. 36.-Typical torque records obtained in wear tests of bronzes without lubrication in the Amsler wear-testing machine

The bronzes contain copper and lead in the ratio of about 84 to 16 and tin in the proportions indicated. They were tested against steel $\mathrm{A}$.

more of lead showed a very strong tendency to form films which did not break down in prolonged tests. These changes in surface condition can readily be seen by comparing the different photographs with the original machine-finished surface illustrated in Figure 29, $a$.

In one or two cases fragmentation of the metal was observed immediately below the surface of the worn test specimen. An interesting example of this is shown in Figure 30, c, where the fragmented bronze is just below a dark surface film. This film is thin in comparison with that shown over the roughened surface illustrated in Figure 30, $d$.

Where surface films were produced, the wear rate usually decreased materially, and there was generally a marked decrease in the average torque. The reduction in wear rate accompanying film formation is illustrated in Figure 32, while the decreased torque accompanying both transitory films and films maintained for appreciable intervals is 
illustrated in Figure 37. Could the described films be produced when desired and also maintained, they might be of decided advantage in practical service because they would reduce the wear of the bearings and also decrease the frictional power losses when lubrication failed.

The copper-tin alloys containing 0.25 per cent lead showed the lowest wear rates, but they quickly assumed a rough surface condition (illustrated in fig. 29, $b$ ) when subjected to friction in the absence of oil. This would probably be disadvantageous from the standpoint of practical service. Short interruptions in lubrication which permitted direct metallic contact between the bearing and shaft might be expected to roughen the surface of the bearing. The recesses in the roughened surface might retain the lubricant, and so tend to maintain lubrication. On the other hand, the irregularities of the

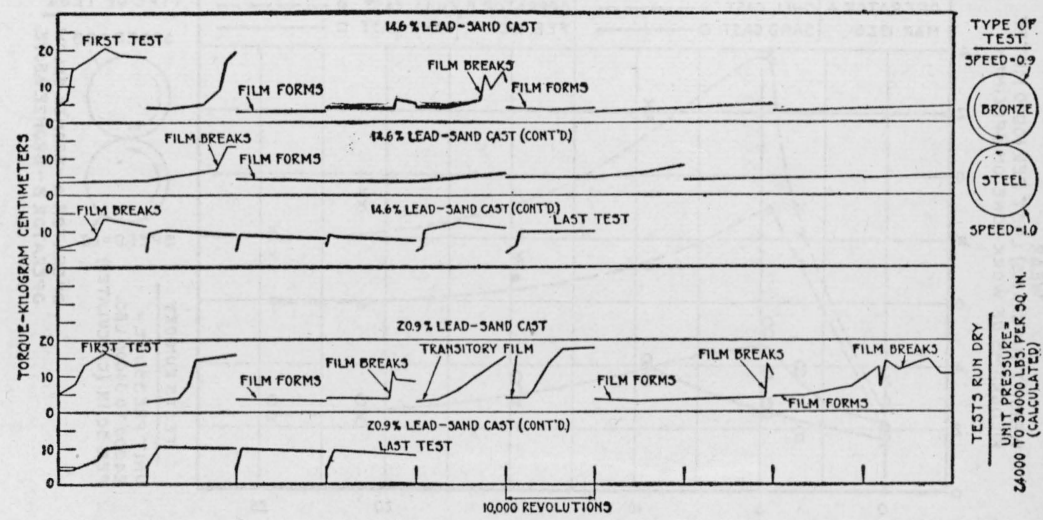

Fig. 37.-Effect of film on the torque observed in wear tests of bronzes without lubrication in the Amsler wear testing machine

The two bronzes contained copper and tin in the ratio of about 92.5 to 7.5 and lead in the proportions indicated. They were tested against steel $\mathbf{A}$.

roughened surface would probably also trap detached metallic particles and any nonmetallic abrasives which might be present and so foster the scoring of the shaft. Thus, the entrapped lubricant would be mixed with abrasive particles, and so might promote wear of both the bearing and shaft.

Another important characteristic of the bronzes low in lead is that they showed much higher torque than the bronzes containing from 10 to 25 per cent of lead. During interruptions in lubrication increased torque accompanying the roughening of the surface of the bearing would tend to raise the frictional temperatures. Maintenance of metallic contact for any appreciable time might, therefore, result in a marked increase in operating temperature which, in turn, would alter the properties of the bronze and might readily be conceived to promote, if not cause, seizure. High torque, likewise, means high power consumption in the bearings, which is also disadvantageous. 
(c) Data Showing That the Wear Test Results Can be Duplicated.-In view of the emphasis already placed upon the complexity of the problem of wear testing, the question arises whether the described differences in the wearing properties of the different bronzes would be duplicated if the original experiments were repeated. The original wear tests on the group of bronzes containing different proportions of lead, which are summarized in Figure 34, were made during March and neighboring months in the year 1926 by an operator who will be designated as A. About a year later, during February, 1927, specimens from the same castings (not necessarily the same disks) were turned down to somewhat smaller diameters, and a new operator, designated as B, was assigned the work of making a com-



FIG. 38.-Comparison of two independent sets of wear tests without lubrication made about a year apart by two different operators on bronzes varying in lead

See text for detailed discussion. The bronzes contain copper and tin in the ratio of about $\mathbf{9 2 . 5}$ to 7.5 .

plete set of tests comparable to the original. Operator B had had a limited experience with the Amsler wear-testing machine but had taken no part in the first set of experiments. He was instructed to interchange the positions of the bronze and steel specimens so that instead of having the bronzes on the lower spindle of the testing machine, as in the first set of tests, they would be mounted on the upper spindle.

The results obtained are included in Figure 38 with those obtained in the first set of tests made about a year earlier. Despite the change in position of the specimens, the use of different disks from various castings, and a change in the operator, close checks were obtained. The lower wear per unit of work in the chill-cast bronzes in the second set of tests is due to the fact that smaller disks were used. The wearing surfaces of the disks were, therefore, further from the metal which had been chilled to the greatest degree, and hence wore less rapidly. 
The differences in the wear rates in the first and second sets of tests for the sand-cast alloys containing about 2.5 to 10 per cent of lead is likewise due to a variation in the degree of chill of the metal. In one case a sand-cast specimen, which gave a relatively high rate of wear under conditions comparable to those of the first set of tests, was turned down and then gave a lower wear rate which checked the value obtained on the smaller disks used in the second set of wear tests.

Additional evidence is given in Figure 39 that the results obtained in the unlubricated wear tests can be reproduced. Two sets of experiments were made on bronzes varying in tin, but in this case the work was done by one operator. The original tests were repeated after a period of about six months, and, as shown in Figure 39, the

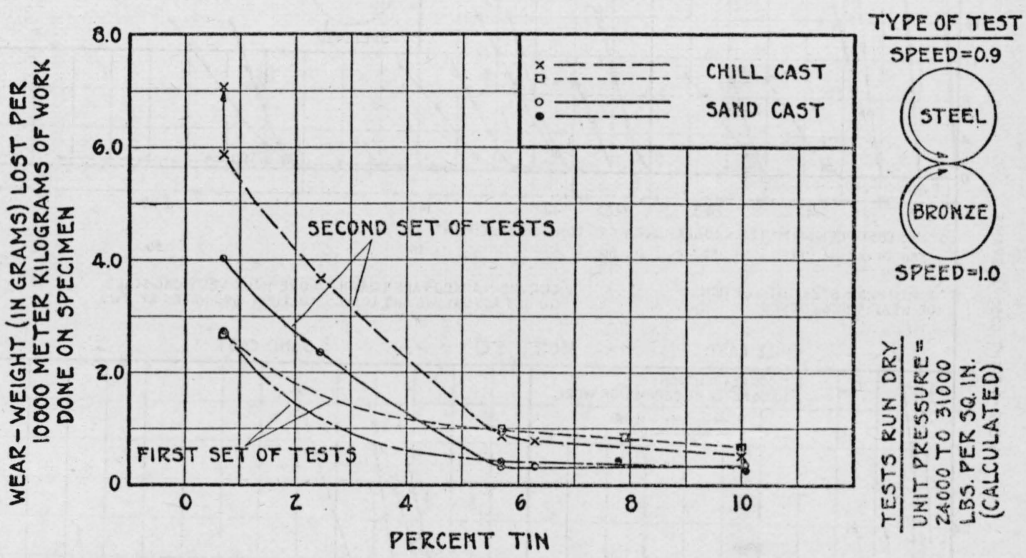

FIG. 39.-Comparison of two independent sets of wear tests without lubrication made ai an interval of six months on bronzes varying in tin

See text for detailed discussion. The bronzes contain copper and lead in the ratio of about 84 to 16 .

numerical values of the wear per unit of work are in fairly close agreement, except for the alloys containing around 2.5 per cent or less of tin. However, the general form of the curves shown in Figure 39 is the same in both sets of experiments.

The observed differences in the wear of the low-tin bronzes in the two sets of experiments may be explained by the fact that these alloys showed very high wear and quickly attained the "flat wheel" condition previously described. Only a few consecutive tests could be made before appreciable pounding was obtained in the Amsler wear-testing machine. It was, therefore, impracticable to make a sufficient number of consecutive tests for the wear-work curves to assume definite slopes. In other words, the preliminary period was not passed within the limits of the experiments, and the wear per unit of work calculated from the results of the last test interval was greater than the average 
wear rate for the last few tests. Under such conditions relatively large differences may be expected in duplicate tests. Duplicate samples do not, ordinarily, "wear-in" at exactly the same rates and at the end of a fixed number of revolutions will be at different stages of the "wearing-in" or preliminary period.

The wear rate in the last test interval for the low-tin alloy (chillcast) is indicated by the arrow in Figure 39 to permit comparison

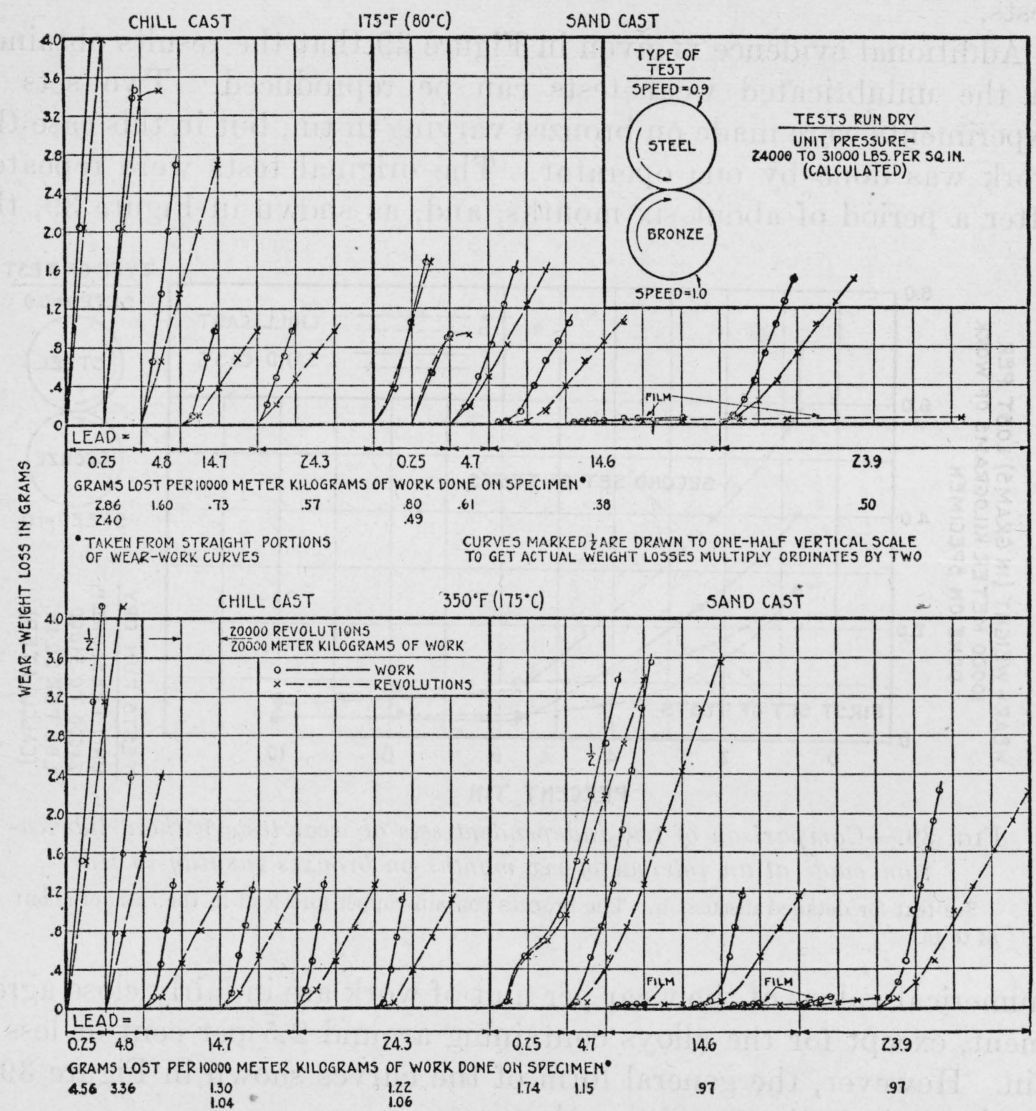

Fig. 40.-Wear-revolution and wear-work curves for bronzes tested at different temperatures without lubrication

The bronzes contain copper and tin in the ratio of about 92.5 to 7.5 and lead in the proportions indicated. They were tested against steel A.

with the average wear rates for the last few tests which are represented by the curves. The higher wear rate in the last interval does not, however, change the general form of the curves in Figure 39.

\section{WEAR TESTS AT ELEVATED TEMPERATURES IN THE ABSENCE OF OIL}

(a) Bronzes Varying in Lead.-Typical wear-revolution and wear-work curves from tests at elevated temperatures are shown in 
Figure 40, and resemble those obtained from tests at atmospheric temperatures. Sand-cast bronzes containing about 15 to 25 per cent of lead again showed a strong tendency toward film formation which was, perhaps, more marked than at atmospheric temperatures. In several cases represented in Figure 40 these films did not break down under prolonged test, and after a short initial period the specimens showed practically no wear. Therefore, duplicate samples

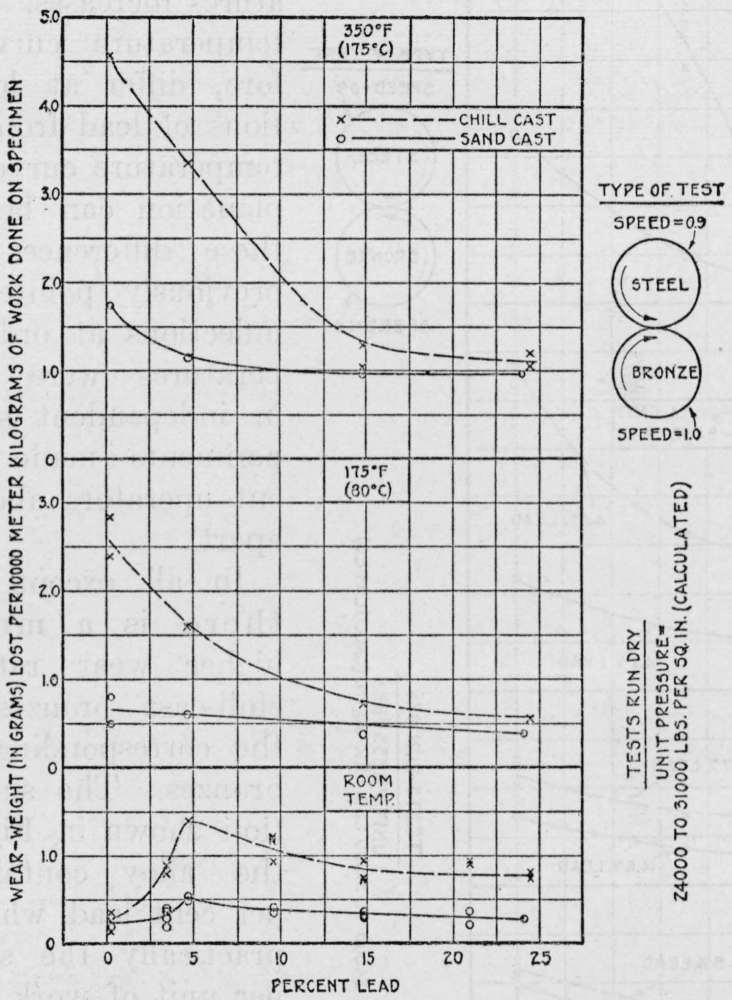

FIG. 41.-Effect of lead on the wear per unit of work for bronzes subjected to friction without lubrication at different temperatures

The bronzes contain copper and tin in the ratio of about 92.5 to 7.5. They were tested against steel A.

were tested and, as a general rule, no such permanent films were encountered. In addition to low-wear rates accompanying film formation, there was generally a decrease in the average torque.

The effects of variations in lead on the wearing properties of both chill-cast and sand-cast bronzes at different temperatures are shown in Figure 41. At 350 and $175^{\circ} \mathrm{F}$. $\left(175\right.$ and $80^{\circ} \mathrm{C}$.) the wear per unit of work decreases rapidly from 0.25 to about 12 or 15 per cent lead but shows only minor changes with further increase to 25 per cent lead, 
Above about 5 per cent lead the room temperature curves have the same general form as those for tests at elevated temperatures;

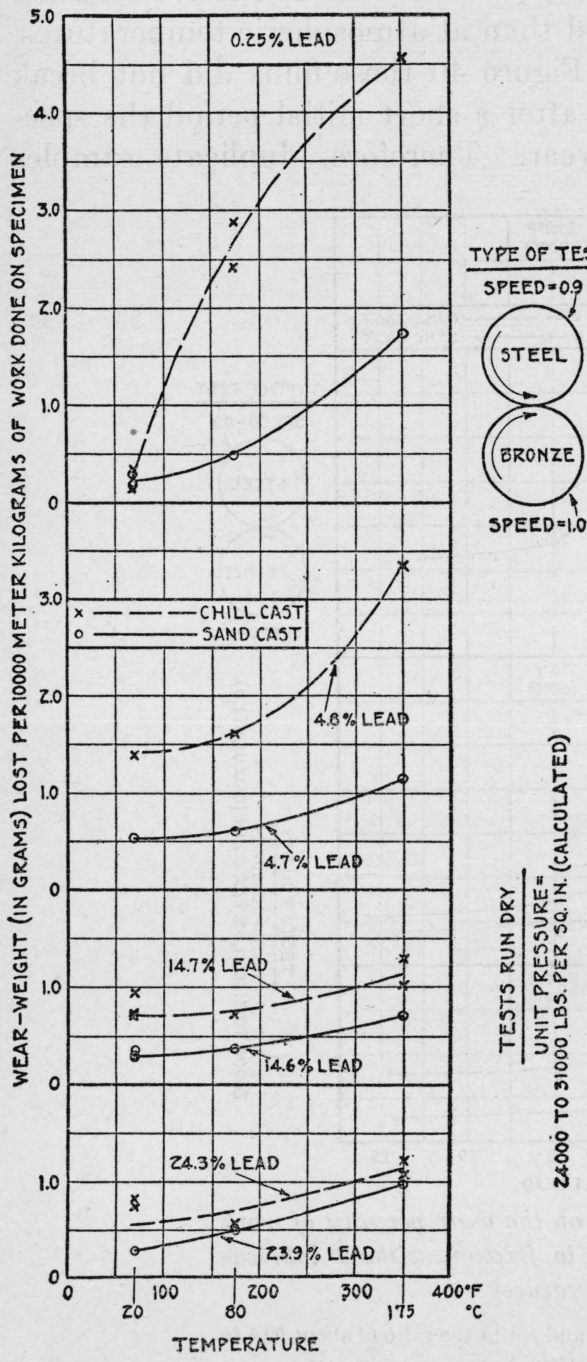

FIG. 42.-Effect of temperature on the wear per unit of work of bronzes varying in lead when subjected to friction without lubrication in the Amsler wear testing machine

These are the same tests referred to in Figure 41. with decrease in lead below about 5 per cent the wear rate at atmospheric temperatures decreases, while that at the elevated temperatures increases. The room temperature curves, therefore, differ at low proportions of lead from the high temperature curves. No explanation can be given for these differences, but, as previously pointed out, the inflections at ordinary temperatures were duplicated in independent sets of experiments made by different operators about a year apart.

In all except one case there is a measurably higher wear rate in the chill-cast bronzes than in the corresponding sand-cast bronzes. The single excepI ion shown in Figure 41 is the alloy containing 0.25 per cent lead, which showed practically the same wear per unit of work at atmospheric temperatures in the chill-cast and the sand-cast conditions. The chill-cast bronzes also appear to "wear in" more rapidly than the corresponding sand-cast bronzes.

Figure 41 shows that the large differences in wearing properties of the bronzes are between the low-lead and the highlead alloys, and that variations in lead between about 15 and 25 per cent do not materially affect the wear rates. 
Figure 42 shows that rise in temperature increases the wear rate, but that this increase is greater in bronzes containing about 5 per cent or less of lead than in those with 15 to 25 per cent of lead.



Fig. 43.-Effect of tin on the wear per unit of work for bronzes subjected to friction without lubrication at different temperatures

The bronzes contain copper and lead in the ratio of about 84 to 16 . They were tested against steel $\mathrm{A}$ at atmospheric temperatures and against steel $\mathrm{B}$ at other temperatures.

(b) Bronzes Varying in Tin.-The effects of tin on the wearing properties of copper-tin-lead alloys at different temperatures are summarized in Figure 43. The wear per unit of work decreases appreciably with increase from 0.7 to about 5 per cent tin in both the chill-cast and sand-cast specimens; further increase from about 5 to 10 per cent tin does not appreciably affect the wear rates at any 
of the test temperatures. However, as shown in Figure 44, increase in the wear rate produced by increase in temperature above atmospheric is less in the bronze containing 10 per cent tin than in bronzes containing 2.5 per cent or less of tin. In all cases alloys cast in metal molds wore faster than corresponding alloys cast in sand molds.



FIg. 44.-Effect of temperature on the wear per unit of work of bronzes varying in tin when subjected to friction without lubrication in the Amsler wear testing machine

These are the same tests referred to in Figure 43.

With increase in the test temperatures the copperlead mixture and the bronze containing 2.5 per cent tin showed increasing tendencies to assume the "flatwheel" condition previously described. The wear also became so high that only a few consecutive tests could be made before appreciable pounding was observed. It was therefore impracticable to make a sufficient number of consecutive tests for the wear-work curves to assume definite slopes. For these reasons the wear per unit of work calculated from the results of the last test interval was greater than the average wear rate for the last few tests. The wear rates in the last test for each of the alloys mentioned above are indicated by arrows in Figures 43 and 44 . It may be seen that the differences between the average wear rates, represented by the curves, and the wear rate in the final test, represented by the arrows, become greater as the test temperature is increased and as the tin content of the bronzes is decreased. However, in no case does the somewhat higher wear rate in the last test change the conclusions which were drawn from the average rates of wear represented by the curves in Figures 43 and 44 .

The foregoing comparisons, which are based on the wear per unit of work, are confirmed by comparisons based on the wear per unit of 
slip. Therefore, separate summaries of the wear per unit of slip are not included in this report.

(c) Frictional Properties $v$. Wear.-Comparisons of the average torque and wear in the high temperature wear tests developed effects similar to those observed in tests at atmospheric temperatures previously described. This may be seen from comparison of Figure 45 with Figures 41 and 43 . In general, the wear per unit of work was high when the average torque was low, and, conversely, the wear was low when the average torque was high. This was not always true, but was found quite generally in the comparison of the chill-cast and sand-cast alloys of any selected composition and likewise in comparison of the bronzes containing appreciably different proportions

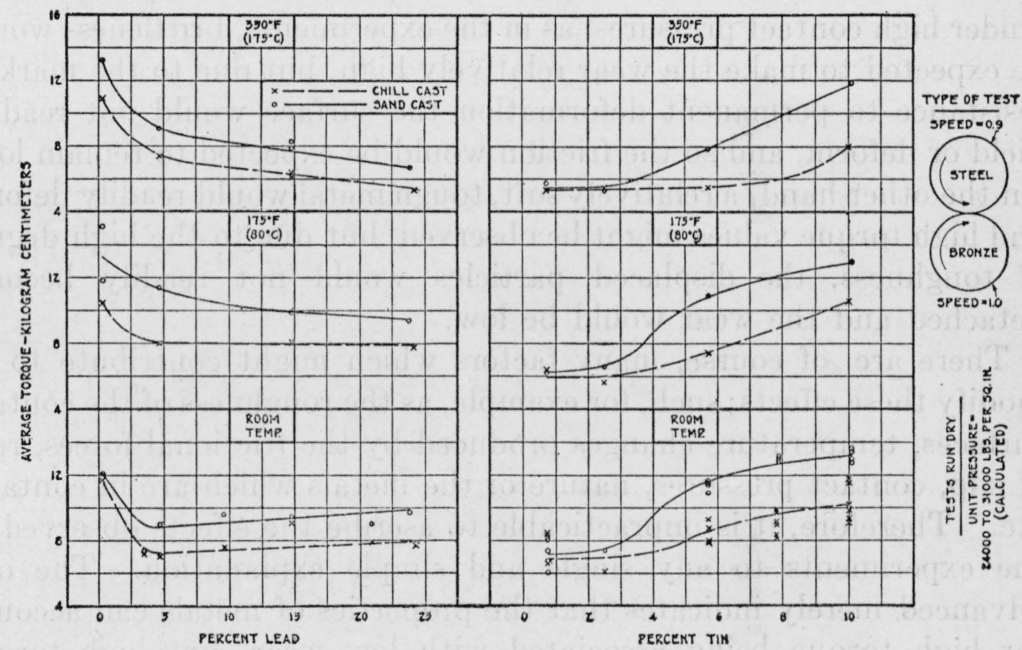

Fig. 45.-Effect of lead and of tin on the frictional properties of bronzes subjected to friction without lubrication at different temperatures

These data were obtained in the tests referred to in Figures 41 to 44 , inclusive.

of lead or of tin. The alloys containing around 2.5 per cent or less of tin are exceptions. These developed exceedingly rough surfaces in the wear tests and showed erratic torque values in duplicate specimens, so that the curves are only indicative of the general trends at the low tin side of the diagrams.

As indicated in a previous section of this report, there is no obvious explanation for such effects which might, at first glance, be considered unusual. However, the cases where high wear is concomitant with relatively low average torque are so numerous in the described experiments that it seems important to consider possible reasons for such behavior.

The torque records obtained from the pendulum dynamometer on the Amsler wear testing machine represent the total resistance to 
slip; that is, the total of the frictional forces at the contact surfaces of the two metals. Wear is conceived to take place by the displacement and detachment of small particles from the contact surfaces, and, as has already been pointed out, the resistance to displacement and detachment depends not only on the resistance of the metals to permanent deformation (hardness) but also on toughness.

If two alloys are considered which differ in toughness and in their resistance to permanent deformation (hardness) so that the one may be characterized as hard and brittle while the other is relatively soft and tough, differences in the wearing and frictional properties may be expected. The alloy which is hard and brittle would be expected to offer high resistance to permanent deformation, but when particles at the surface were once displaced, they might readily break off. Under high contact pressures, as in the experiments, brittleness would be expected to make the wear relatively high, but due to the marked resistance to permanent deformation the surface would not readily yield or deform, and so the friction would be expected to remain low. On the other hand, a relatively soft, tough metal would readily deform and high torque values might be observed, but due to the high degree of toughness, the displaced particles would not readily become detached and the wear would be low.

There are, of course, many factors which might contribute to or modify these effects; such, for example, as the roughness of the contact surfaces, temperature changes produced by the frictional forces, rate of slip, contact pressures, nature of the metals which are in contact, etc. Therefore, it is impracticable to ascribe the effects observed in the experiments to any single and simple explanation. The one advanced merely indicates that the properties of metals can account for high torque being associated with low wear, but high torque combined with high wear might be observed with changes in one or more of the conditions of test. Furthermore, the assumed differences in hardness and toughness upon which the foregoing explanation is based were certainly much greater than those existing in the alloys tested.

The question of how best to express the wear rate was given considerable thought. Generally, other investigators have reported wear in terms of distance traveled. This does not give a complete picture. Several factors which are known to have a very marked effect upon the wear are entirely independent of the distance traveled by a weartest specimen. Such variables as the condition of the test surfaces, the presence or absence of film, the normal pressure, all of which are known to influence the wear, are entirely independent of revolutions of the test roller. True, in evaluating wear tests upon the basis of revolutions some of these factors can be fixed and so noted, but others, such as the condition of the contact surfaces, quite frequently change 
continuously throughout a test. This change is reflected in the amount of wear and friction but not in the distance traveled by the test specimen.

In evaluating wear as a function of work, an effort is made to correlate the wear with a physical expression which not only reflects the physical conditions of test but which is also a measure of the actual energy required to produce a certain amount of wear under certain conditions. Such factors as pressure, condition of the test surfaces, etc., are reflected in the frictional force existing between the test surfaces, and changes in these factors produce corresponding changes in the friction. To calculate the energy consumed in friction during a test, the distance traveled by the test specimen must also be used, since work is force (the friction existing between the specimens) times the distance traveled. Thus, in evaluating wear as a unit of work a more complete picture is obtained of the wearing properties of the metals than is given by the wear per unit of slip.

In other words, wear per unit of work gives an indication of the resistance of the metal to wear when subjected to definite frictional forces. While influenced by the conditions of operation, it does not express results directly in terms of speed, pressure, etc. Wear per unit of slip gives an indication of the wear to be expected under certain operating conditions; that is, certain pressures, speeds, etc., and does not bring into view the frictional forces encountered.

It should be recognized that conditions may be encountered where comparisons based solely on wear per unit of work may be misleading or difficult to translate into terms of practical service. For example, low values of wear per unit of work may result from moderate wear per revolution and moderately high frictional properties (torque in the wear tests) or from somewhat lower wear per revolution and relatively low torque. Metals which showed only moderately low values of wear per unit of work through the latter combination of wear and frictional properties would have an advantage over metals which showed the lowest wear per unit of work produced through the former combination since low wear and low friction are both important from the standpoint of bearing service. Hence, until a more complete understanding is obtained of the relation between frictional properties and wearing properties of metals it is advisable, to consider wear, work, and distance traveled as well as other features, such as the character of the worn surfaces which have been discussed in this report.

Attention has already been called in Section VI, 2, $(b)$ to the fact that the changes in wear per unit of work produced by variations in chemical composition and methods of casting were similar to those in the wear per unit of slip (revolutions) for the groups of alloys con.. $109673^{\circ}-28-4$ 
sidered. It was therefore unnecessary to include graphical summaries both of the wear per unit of work and the wear per unit of slip.

(d) Wear of the Steels.-As a general rule, the weight losses were erratic for the steel specimens which were rotated in contact with the bronzes. Therefore, it was impracticable to make comparisons of the wear per unit of work or the wear per unit of slip. However, the different bronzes produced different effects upon the steels against which they were tested, and these effects may be illustrated in a general way by comparing the total wear of the steels in the first 40,000 revolutions of the bronze specimens. Where films were formed which temporarily reduced the wear, the values selected for comparisons represent the weight losses of the steels for the



FIG. 46.-Wear of the axle steel in contact with the different bronzes in the wear tests without lubrication

first 40,000 revolutions of the bronze subsequent to the breakdown of the film. These comparisons should not be interpreted too rigorously, because it was rarely possible to remove entirely the particles from the bronzes which were deposited on the steel specimens. The data in Figure 46 are intended only to give a general idea of differences observed in the tests.

Examination of Figure 46 shows three particularly interesting features, as follows: (1) As the lead content of the bronzes was raised the wear of the steel decreased. With the high-lead bronzes the steel specimens frequently showed no wear but, on the contrary, increased in weight. This increase was probably due to the fact that the deposit of particles from the bronze on the steel was large in compari- 
son with the wear of the steel. (2) As the tin content of the bronzes was raised, the wear of the steel specimens increased. (3) With but few exceptions the wear of the steels was greater when in contact with sand-cast bronzes than when used against the corresponding chill-cast alloys.

The bronzes which caused the highest wear of the steels would naturally be expected to score shafts in practical service much more quickly than those which had the smallest effect upon the steel specimens in the described tests. Therefore, in this respect, there is a distinct advantage to the high-lead bronzes.

\section{SAND ABRASION TESTS}

The form of the curves obtained by plotting the total weight of sand blasted upon the specimens against the total loss in weight were quite similar to the wear-work curves obtained under unlubricated friction in the Amsler machine; that is, after a short initial period, the weight loss was directly proportional to the amount of sand used. The results of the sand-blast tests are summarized in Figure 47.

In all cases but one the sand-cast alloys were more resistant to the sand abrasion than the corresponding chill-cast alloys. "The one exception was the bronze containing 0.25 per cent lead which showed practically the same wear in the chill-cast and sand-cast conditions. This is similar to the effect observed in the Amsler unlubricated wear tests on the same alloys.

As shown in Figure 47, increase in lead increased the rate of wear in the bronzes containing an approximately constant ratio of copper to tin. Furthermore, the numerical values of the wear of the highlead bronzes are exceedingly high in comparison with the wear of the bronze containing 0.25 per cent lead. The lead content is therefore an important factor in the resistance of these alloys to sand abrasion. The lead particles which are mechanically held in the matrix are probably torn out, and because of the high specific gravity of lead the weight losses are large.

Figure 47 also shows that increase in tin from 0.7 to 10 per cent decreases the wear in the alloys containing an approximately constant ratio of copper to lead. In these alloys the proportion of lead decreased as the proportion of tin increased. As already indicated, decrease in lead resulted in a greatly improved resistance to the sand abrasion; therefore, the decrease in wear with increase in tin which is shown by the curves in the upper part of Figure 47 is due to the benefits of lowered lead as well as to the beneficial effects of increased tin.

With one major exception the sand-blast abrasion tests placed the alloys in the same general order as that given by the Amsler 
wear tests without oil. In both types of test alloys cast in metal molds wore more rapidly than the corresponding alloys cast in sand molds. Likewise, wear resistance was improved by increase in tin from 0.7 to about 5 per cent; between 5 and 10 per cent tin the changes in wearing properties were small.

Variations in lead produced opposite effects in the Amsler wear tests and the sand-abrasion tests. In the former increase in lead

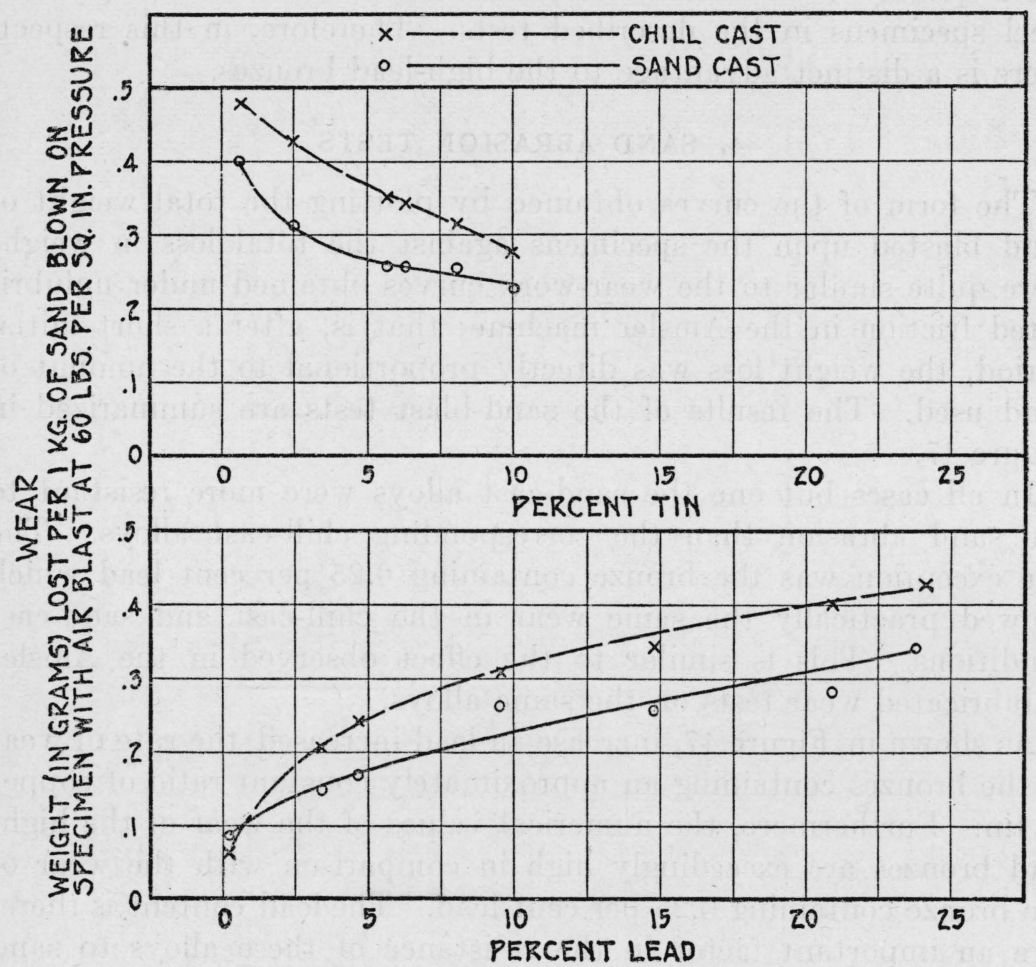

Fig. 47.-Effect of lead and of tin on the wear of bronzes subjected to sand abrasion

The alloys varying in lead contained copper and tin in the ratio of about 92.5 to 7.5 ; those varying in tin contained copper and lead in the ratio of about 84 to 16.

improved resistance to wear while in the latter it decreased wear resistance.

\section{SINGLE-BLOW IMPACT TESTS}

The results of the impact tests are summarized graphically in Figures 48 to 51 , inclusive. With the exception of the alloys low in lead, the resistance to impact in the Izod test was very low. As shown in Figure 48 , increase in lead from 0.25 to 25 per cent produced a progressive decrease in impact resistance at all temperatures between atmospheric and $600^{\circ} \mathrm{F}$. $\left(315^{\circ} \mathrm{C}\right.$. $)$. The magnitude of this decrease was generally greater with lead increase from 0.25 to about 10 per 
cent than from 10 to 25 per cent; it was likewise greater at $350^{\circ} \mathrm{F}$. $\left(175^{\circ} \mathrm{C}\right.$.) and lower temperatures than at $600^{\circ} \mathrm{F}$. $\left(315^{\circ} \mathrm{C}\right.$.).

Figure 49 shows that the impact resistance increased with increase in tin from a trace to about 5 per cent and then decreased with increase from around 5 to 10 per cent tin. These changes were of somewhat greater magnitude in the sand-cast bronzes than in the

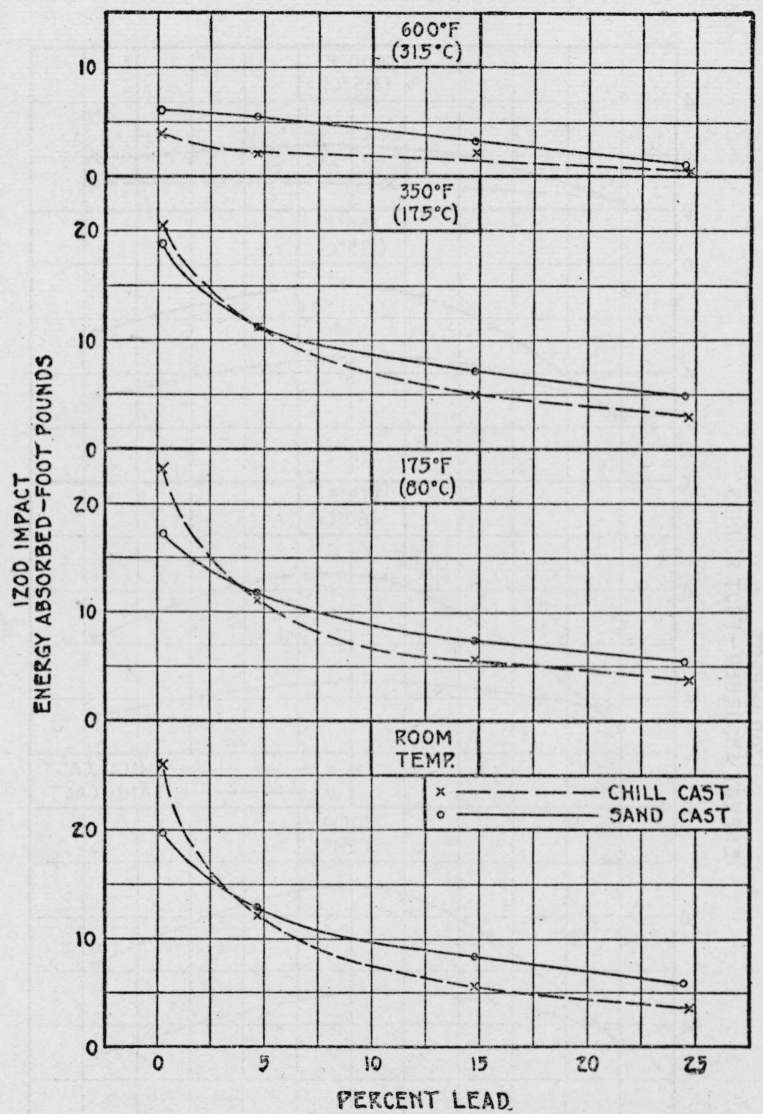

FIG. 48.-Effect of lead on the notched-bar impact resistance of bronzes at different temperatures

The bronzes contain copper and tin in the ratio of about 92.5 to 7.5.

chill-cast bronzes; they were likewise more marked at $350^{\circ} \mathrm{F} .\left(175^{\circ} \mathrm{C}\right.$.) and lower temperatures than at $600^{\circ} \mathrm{F}$. ( $315^{\circ} \mathrm{C}$.).

Figures 10 and 11 show that the eutectoid first appeared in the castings with around 7.5 per cent tin. So long as the limit of solid solution of tin in copper is not exceeded, an increase in the tin content improves the impact resistance of the bronzes (fig. 49), but additions producing appreciable amounts of the eutectoid appear to lower the impact values. 
With one exception, the sand-cast bronzes showed about equal or greater resistance to impact than the corresponding chill-cast bronzes. This was the bronze with 0.25 per cent lead in which the chill castings showed a better impact resistance than the sand castings at all temperatures except $600^{\circ} \mathrm{F}$. $\left(315^{\circ} \mathrm{C}\right.$.).

Chill-cast bronzes have a finer grain size, smaller lead particles, and, when sufficiently high in tin, more of the eutectoid than corre-



FIG. 49.-Effect of tin on the notched-bar impact resistance of bronzes at different temperatures

The bronzes contain copper and lead in the ratio of about 84 to 16 .

sponding sand-cast bronzes. Provided no appreciable proportions of the brittle eutectoid are present, chill-cast bronzes with their fine grain size would be expected to show a better impact resistance than corresponding sand-cast bronzes with their coarse structure. This is actually the case in the bronzes with 0.25 per cent lead which are considered in Figure 48. 
With the addition of appreciable proportions of lead, another factor comes into play. Despite the beneficial effects of small grain size in chill-cast metal, the sand-cast bronzes high in lead showed a higher notch toughness than the chill-cast bronzes of like chemical composition. Lead itself tends to reduce impact resistance, as is shown in Figure 48. The small and finely distributed particles of lead in the chill-cast bronzes (figs. 6 and 7 ) probably are more effective in reducing impact resistance than the fewer large particles in the corresponding sand-cast bronzes, since small particles more effectively break up the continuity of structure than the same weight of material distributed in large particles.

These features which are associated with grain size are not only a function of rates of cooling but also of pouring temperatures. While the latter variable was under control, detailed records of pouring temperatures were not furnished by the manufacturer. It is therefore possible that differences in pouring temperature were superimposed upon differences in the rates of cooling to give the effects described.

Thus, five important features are shown by the impact tests: (1) Bronzes with small amounts of lead show better resistance to notched-bar impact than the high-lead bronzes. Hence, lead may be said to exert a deleterious effect on the notch toughness of bronzes. (2) Increase of tin in copper within the alpha solid solution range tends to increase impact resistance of bronzes; much more than this amount of tin (which results in the formation of appreciable amounts of the alpha-delta eutectoid) tends to reduce the notch toughness. (3) In the high-lead bronzes containing from about 10 to 25 per cent lead and from 2 to 10 per cent tin the sand-cast metal has a generally better notch toughness than corresponding chill-cast metal. This is probably due to the form and distribution of the lead particles which more than counteract the beneficial effects of the fine-grained matrix in the chill castings. (4) In bronzes with small amounts of lead this order of superiority may be reversed. In such alloys the full benefits are derived from the fine-grained structure, and the chill-cast bronzes may show higher notch toughness than the corresponding sand-cast bronzes with a coarse-grained structure. With intermediate proportions of lead, around 5 per cent, the impact resistance is about the same for the sand-cast and chill-cast metals. Here the benefits of fine grain in the chill castings seem to be balanced by the deleterious effects of the finely disseminated lead. (5) Increase in temperature to $600^{\circ} \mathrm{F}$. $\left(315^{\circ} \mathrm{C}\right.$.) tends to reduce the differences in impact resistance referred to in items (1) to (4), inclusive, and tends to lower the notch toughness. However, the decrease in impact resistance of the bronzes is more marked between $350^{\circ}$ and $600^{\circ} \mathrm{F}$. $\left(175^{\circ}\right.$ and $315^{\circ} \mathrm{C}$.) than between atmospheric temperatures and $350^{\circ}$ F. $\left(175^{\circ}\right.$ C.), as is shown in Figures 50 and 51. 


\section{TENSILE TESTS}

The results of the tensile tests are summarized in Figures 52 to 58 , inclusive. With the exception of the tests at $350^{\circ} \mathrm{F}$. $\left(175^{\circ} \mathrm{C}\right.$.) made on individual specimens of alloys with different proportions of tin, the charts are based on the averages of the results of two or more tests on each metal in each condition at each temperature.

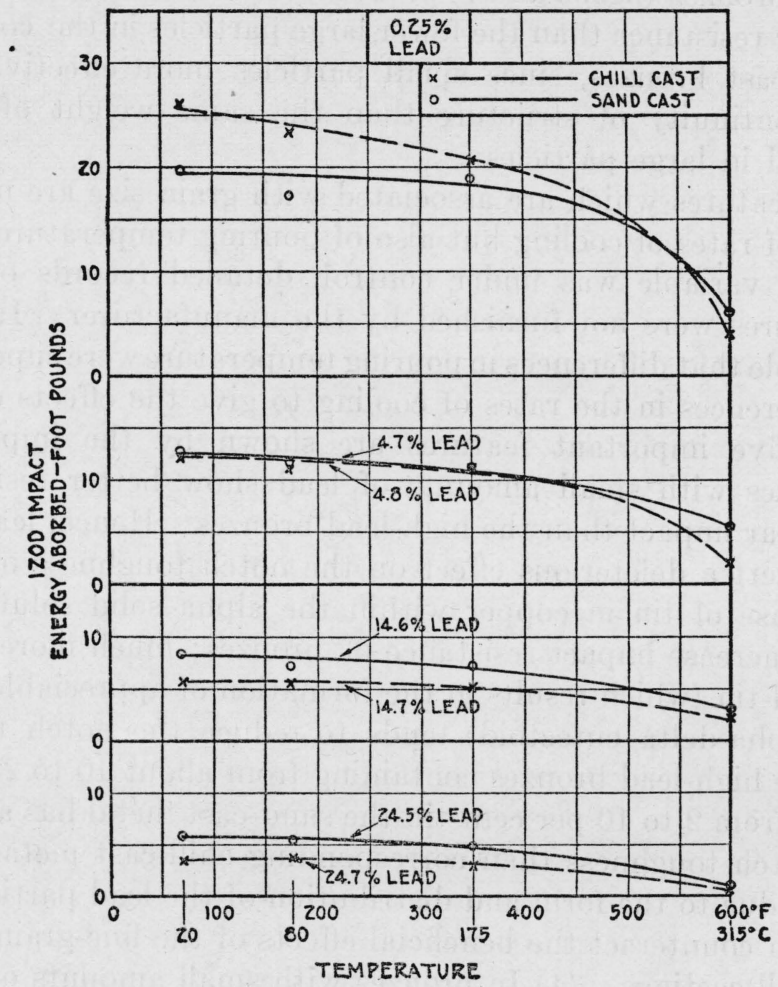

Fig. 50.-Effect of temperature upon the notched-bar impact resistance of bronzes containing different proportions of lead

The bronzes contain copper and tin in the ratio of about 92.5 to 7.5. These are the same tests referred to in Figure 48.

Increase in lead from 0.25 to around 25 per cent produced a general decrease both in the strength factors and ductility at atmospheric temperatures. On the other hand, increase in tin from a trace to about 10 per cent resulted in a general increase both in the strength factors and ductility. However, as shown in Figure 53, this improvement in tensile properties was much larger for the increase between a trace and 2.5 per cent than between 2.5 and 10 per cent.

In the alloys with different proportions of lead (fig. 52) and likewise those with different proportions of tin (fig. 53) the chill castings 
quite generally showed a higher tensile strength than the corresponding sand castings, and this was frequently, but not always, accompanied by decreased ductility.

The values of elongation and reduction of area showed a somewhat wider scatter from smooth curves than the values of tensile strength, due quite largely to the uneven elongation and contraction



Fig. 51.-Effect of temperature upon the notched-bar impact resistance of bronzes containing different proportions of tin

The bronzes contain copper and lead in the ratio of about 84 to 16 . These are the same tests referred to in Figure 49.

of these metals in tension tests. This makes it difficult to secure values which adequately represent ductility for general comparisons. However, the tensile tests show that high resistance to static stress is improved in copper-tin-lead alloys by (1) low lead, (2) high tin (up to about 10 per cent), and (3) chill casting. The improvement secured by controlling the first two of these three variables is accompanied by improved ductility; that secured from control of casting conditions may be accompanied either by increased or decreased 




FIG. 52.-Effect of lead on the tensile properties of bronzes at different temperatures

The bronzes contain copper and tin in the ratio of about 92.5 to 7.5 . 


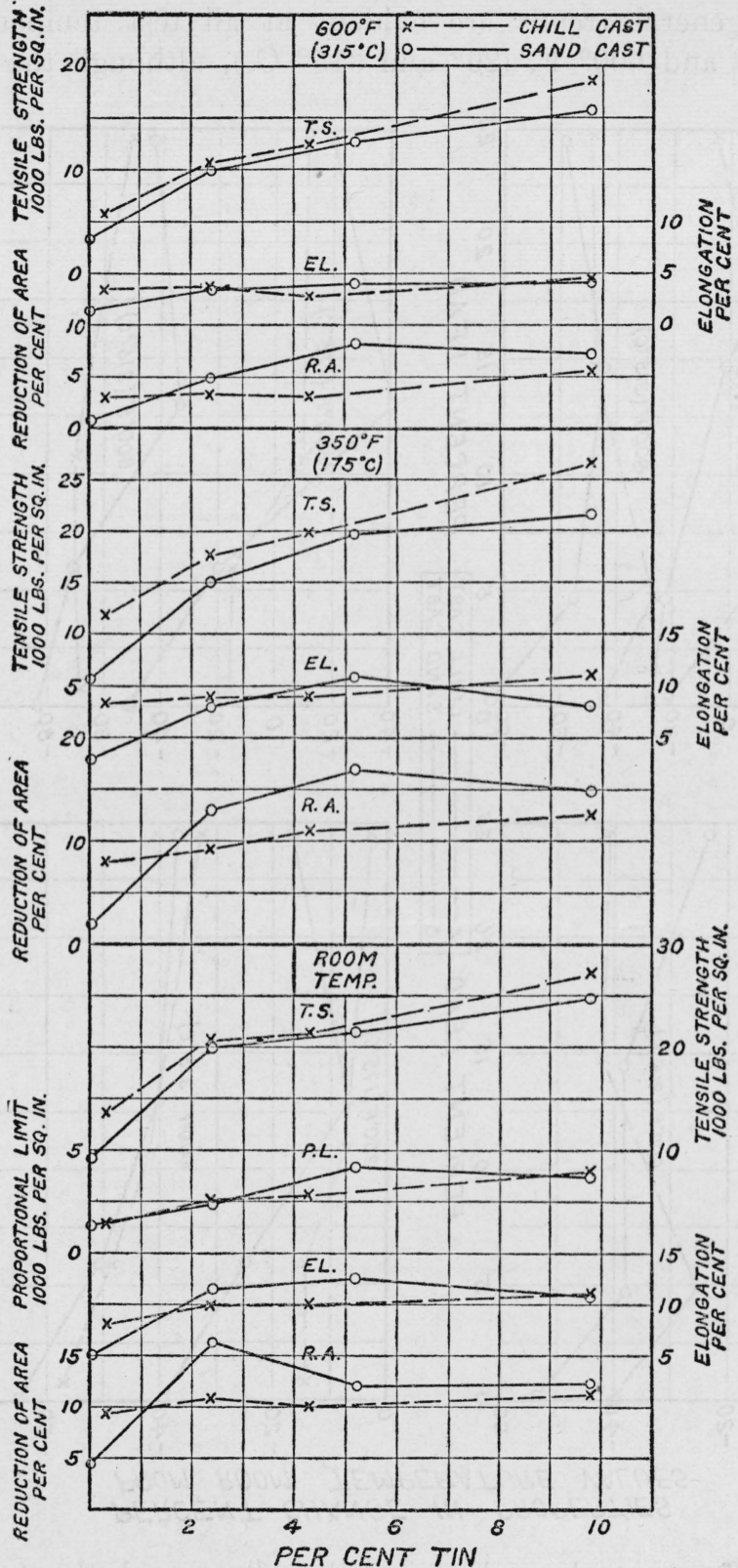

FIG. 53.-Effect of tin on the tensile properties of bronzes at different temperatures

The bronzes contain copper and lead in the ratio of about 84 to 16 . 
elongation and reduction of area in tensile tests at atmospheric temperatures or by no appreciable changes in the ductility.

These general trends are evident at all test temperatures between $70^{\circ}$ and $600^{\circ} \mathrm{F}$. $\left(20^{\circ}\right.$ and $315^{\circ} \mathrm{C}$.), although the magnitude


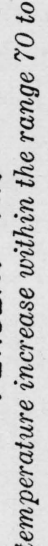

క్ำ

N.


은

है

\& 8

Е

5ㅇำ

$\infty \quad \frac{0}{8}$

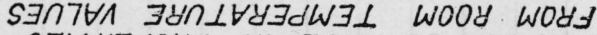





of the differences depends upon the alloys and the temperatures considered.

Increase of temperature above atmospheric produced a decrease in the tensile strength of the bronzes (fig. 54), but these changes 
became smaller as the tin content of the bronzes increased. They were likewise less in a majority of the chill-cast bronzes than in the corresponding sand-cast bronzes, but did not seem to be affected in any regular manner by variations in the proportions of lead. (Fig. 54.)

Decreased strength resulting from increased temperature was accompanied by decreased reduction of area except in the bronzes with 5 to 10 per cent tin which showed somewhat higher ductility at $350^{\circ} \mathrm{F} .\left(175^{\circ} \mathrm{C}\right.$.) than at atmospheric temperatures or $600^{\circ} \mathrm{F}$. $\left(315^{\circ} \mathrm{C}.\right)$.

Thus, the high-tin bronzes (maximum 10 per cent tin) not only have higher resistance to static stress at atmospheric temperatures

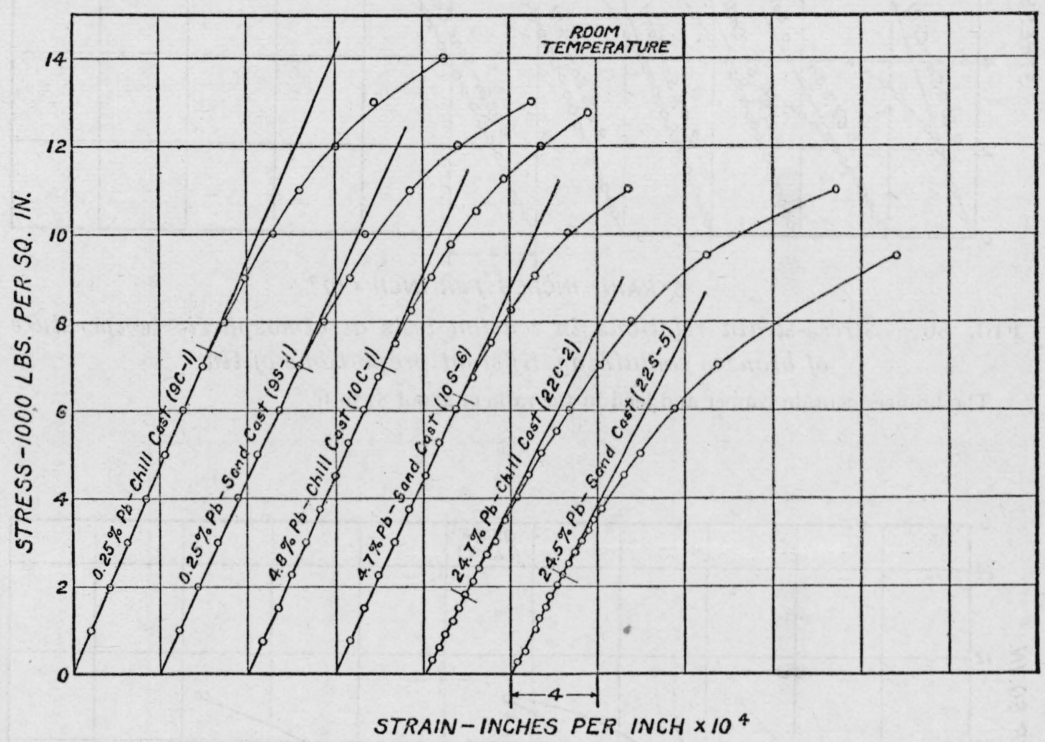

FIG. 55.-Stress-strain relations in tension tests at atmospheric temperature of bronzes containing different proportions of lead

The bronzes contain copper and tin in the ratio of about 92.5 to 7.5

than low-tin bronzes (less than about 5 per cent tin), but also retain a greater proportion of their strength at elevated temperatures up to $600^{\circ} \mathrm{F}$. $\left(315^{\circ} \mathrm{C}\right.$.). The same applies to the higher tensile strength of the chill-cast bronzes when compared to sand castings of similar chemical composition.

Typical stress-strain curves secured from the tension tests at atmospheric temperatures and $350^{\circ} \mathrm{F} .\left(175^{\circ} \mathrm{C}\right.$.) are given in Figures 55 to 58 , inclusive.

In a number of cases the strain, subsequent to the first applications of stress, decreased with equal increases in the load. This change was sometimes followed by a range in which the stress and strain appeared to be proportional and sometimes by further "steps" in 


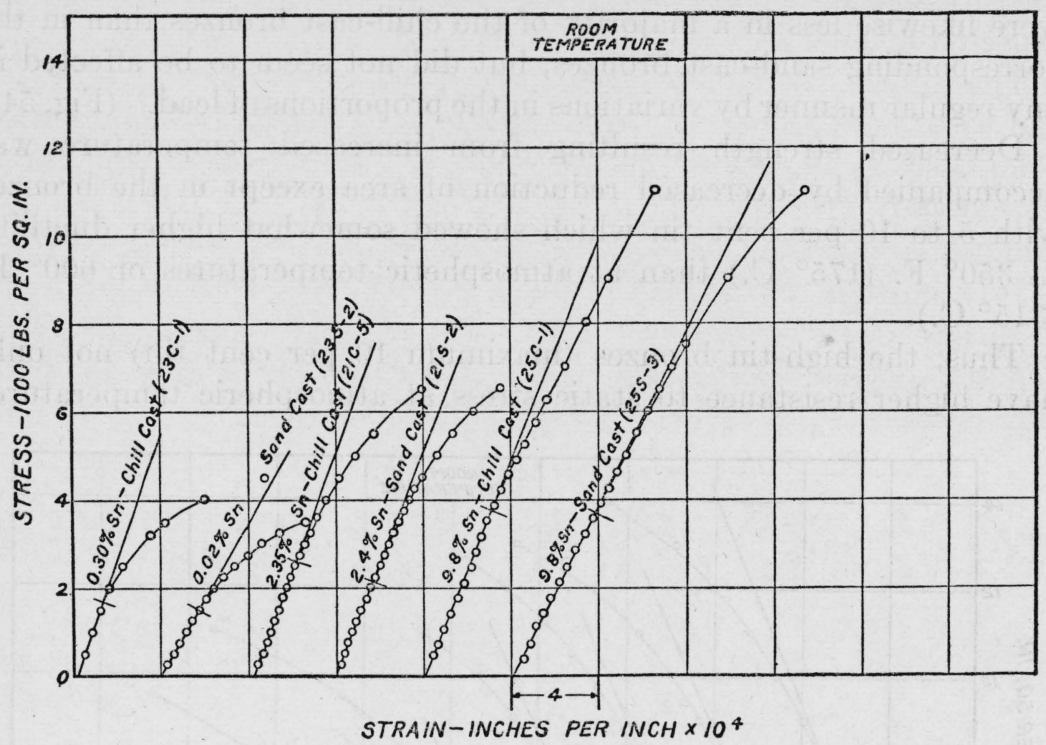

FIG. 56.- Stress-strain relations in tension tests at atmospheric temperature of bronzes containing different proportions of tin

The bronzes contain copper and lead in the ratio of about 84 to 16 .

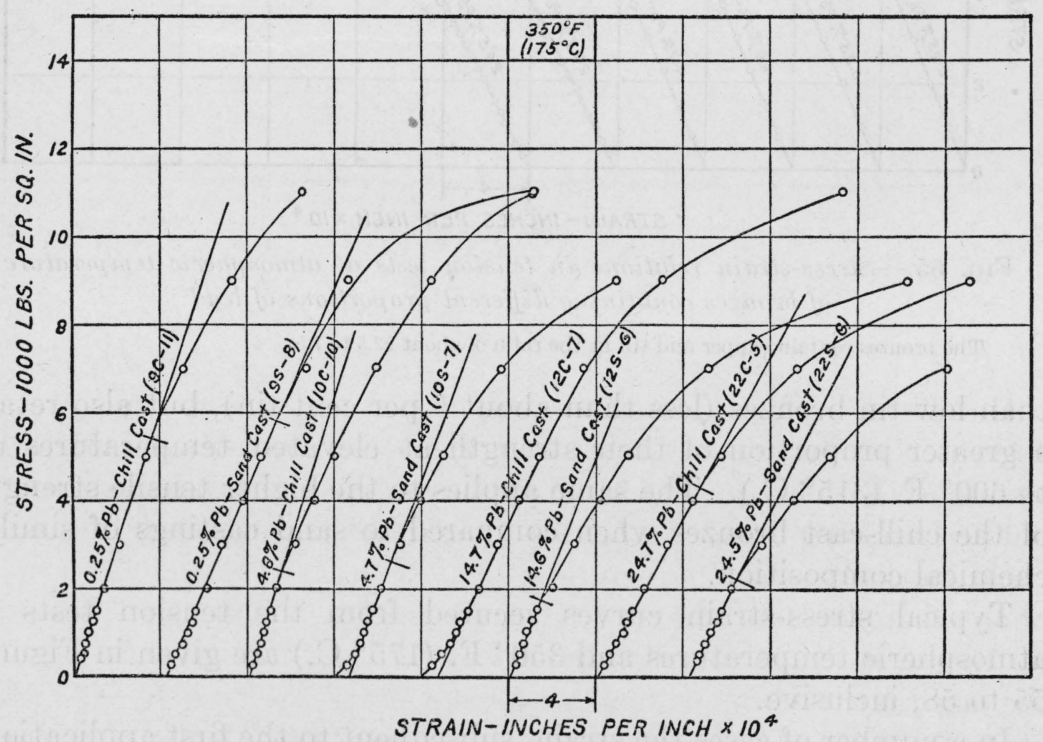

FIG. 57. - Stress-strain relations in tension tesis at $350^{\circ} \mathrm{F}$. $\left(175^{\circ} \mathrm{C}\right.$.) of bronzes containing different proportions of lead

The bronzes contain copper and tin in the ratio of about 92.5 to 7.5. 
the stress-strain curves before the strain increased definitely in the expected manner.

These effects were more often observed in tests at $350^{\circ} \mathrm{F}$. $\left(175^{\circ} \mathrm{C}\right.$.) and were more prominent than in tests at atmospheric temperatures. They also became more marked when the strain was not measured immediately after an increase in the stress but was measured two minutes later.

It is possible that these effects are associated with localized slip at stresses well below the customarily reported proportional limits and the increased importance of the time factor when the temperature is raised from atmospheric to $350^{\circ} \mathrm{F}$. $\left(175^{\circ} \mathrm{C}\right.$.).

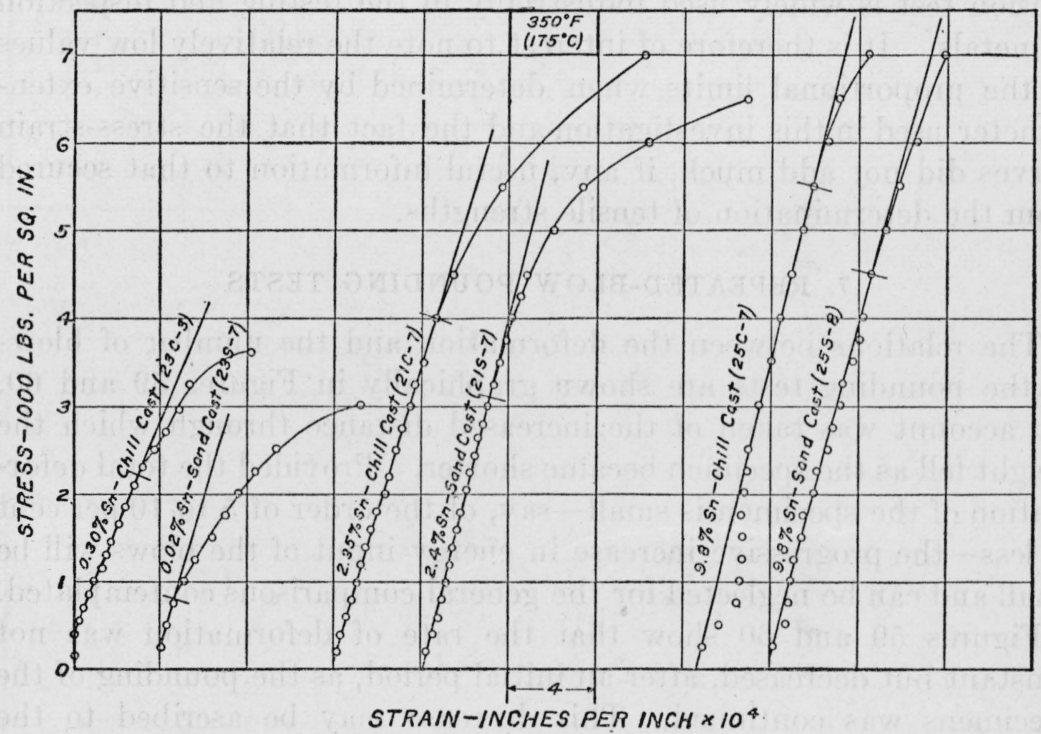

Fig. 58. - Stress-strain relations in tension tests at $350^{\circ} \mathrm{F}$. $\left(175^{\circ} \mathrm{C}\right.$.) of bronzes containing different proportions of tin

The bronzes contain copper and lead in the ratio of about 84 to 16 .

Handford, ${ }^{28}$ with special test equipment, has observed slip at stresses well below the customarily reported proportional limits in open-hearth steel, nickel, cupro-nickel, brass, and copper at atmospheric temperatures. Such slip may be accompanied by more rapid localized strain hardening at $350^{\circ} \mathrm{F}$. $\left(175^{\circ} \mathrm{C}\right.$.) than at atmospheric temperatures and result in more readily visible discontinuities in the stress-strain curves. In support of this, attention is called to the fact that the proportional limits of some of the bronzes are higher at $350^{\circ} \mathrm{F}$. $\left(175^{\circ} \mathrm{C}\right.$.) than at atmospheric temperatures.

${ }^{28}$ Handford, C., " $\Lambda$ valve method of detecting minute slipping in metals," Phil. Mag., 6th series, $4 \%$, p. $896 ; 1924$, 
These differences were small, numerically, and it is recognized that the values of proportional limits are not only dependent upon the sensitivity of the test equipment but also upon the methods of interpreting the data. They seem significant in this case, as a majority of the bronzes, especially those cast in chill molds, showed a higher resistance to pounding at $350^{\circ} \mathrm{F}$. $\left(175^{\circ}\right.$ C. $)$ than at atmospheric temperatures. (See fig. 61.) The pounding tests also emphasized the importance of the time factor at $350^{\circ} \mathrm{F} .\left(175^{\circ} \mathrm{C}\right.$.) in that they also showed evidence of "stepped" deformation in a few cases. (Figs. 59 and 60.)

Bearings are not ordinarily subjected to tension in service, but the tension test is widely used industrially in the testing and inspection of metals. It is therefore of interest to note the relatively low values of the proportional limits when determined by the sensitive extensometer used in this investigation and the fact that the stress-strain curves did not add much, if any, useful information to that secured from the determination of tensile strengths.

\section{REPEATED-BLOW POUNDING TESTS}

The relations between the deformation and the number of blows in the pounding tests are shown graphically in Figures 59 and 60. No account was taken of the increased distance through which the weight fell as the specimen became shorter. Provided the total deformation of the specimen is small-say, of the order of 5 to 10 per cent or less - the progressive increase in energy input of the blows will be small and can be neglected for the general comparisons contemplated.

Figures 59 and 60 show that the rate of deformation was not constant but decreased, after an initial period, as the pounding of the specimens was continued. This decrease may be ascribed to the work hardening of the metal.

The duration of the initial period of rapid deformation varied considerably with the chemical composition of the bronzes and the method of casting. Likewise, the amount of the first rapid deformation increased with the proportion of lead and decreased with increase in the proportion of tin within the limits investigated. It was also greater, in general, in sand-cast bronzes than in the corresponding chill-cast bronzes.

Similar changes are shown graphically in Figure 61, where comparisons are given of the number of blows required to produce a 5 per cent decrease in the height of the test cylinders. Here the number of blows may be taken to represent the resistance to pounding.

Increase in lead from 0.25 to around 5 per cent produced a marked decrease in the resistance to pounding; with lead increase from around 5 to 25 per cent a further but small decrease was observed. 
The resistance to pounding increased slightly with tin increase from a trace to about 5 per cent and showed a very large increase when the tin was raised from 5 to 10 per cent. In practically all cases the

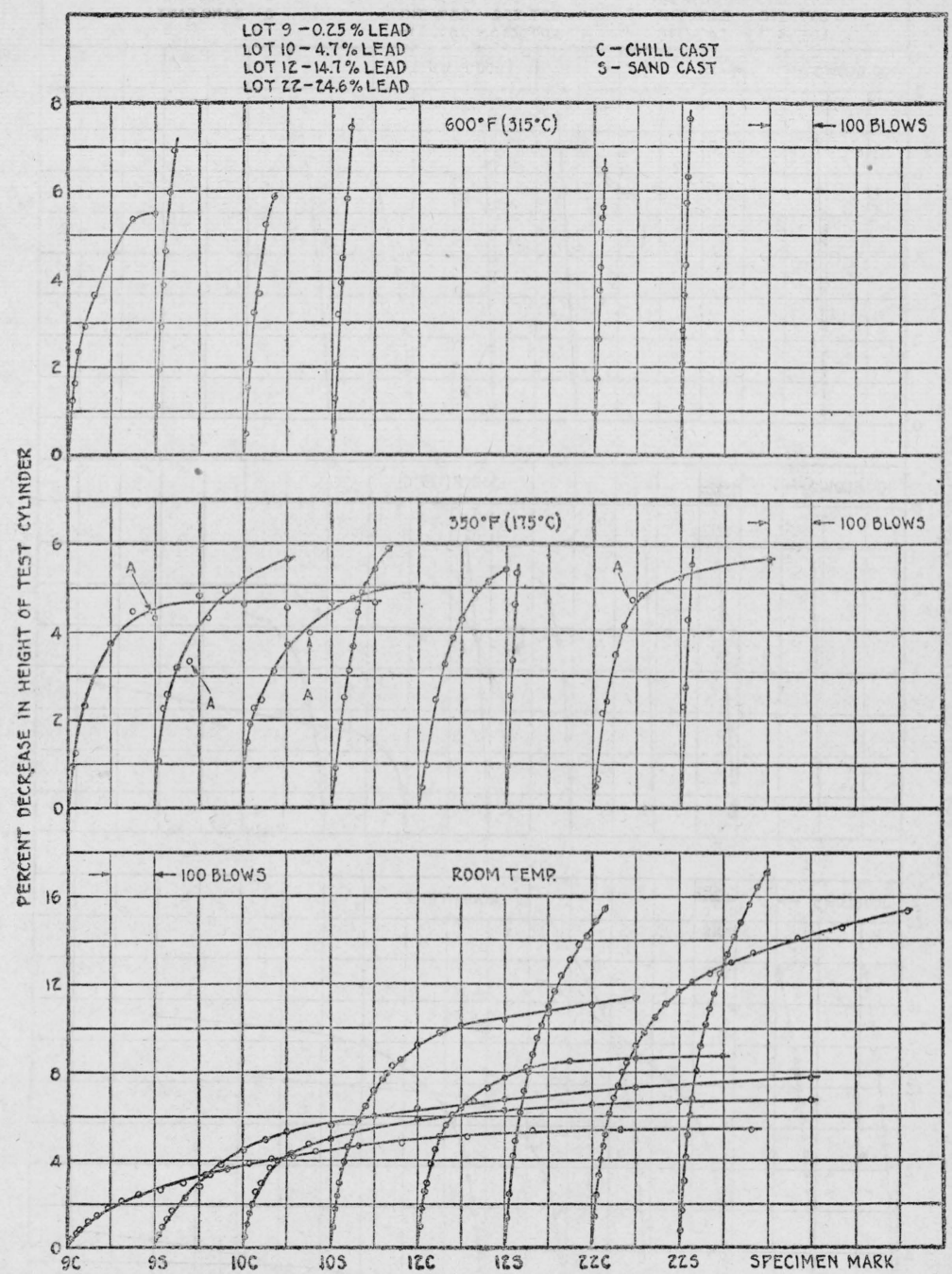

FrG. 59.-Relation between the number of blows and the deformation in the pounding tests of bronzes containing different proportions of lead

The bronzes contain copper and tin in the ratio of about 92.5 to 7.5. Letter A and arrows indicate discontinuities in deformation referred to in the text.

chill-cast bronzes showed a higher resistance to pounding than the corresponding sand-cast bronzes.

The described effects from variations in chemical composition and method of casting were similar at $350^{\circ}$ and $600^{\circ} \mathrm{F}$. $\left(175^{\circ}\right.$ and $315^{\circ} \mathrm{C}$.) to those at atmospheric temperatures, although the magnitude of 


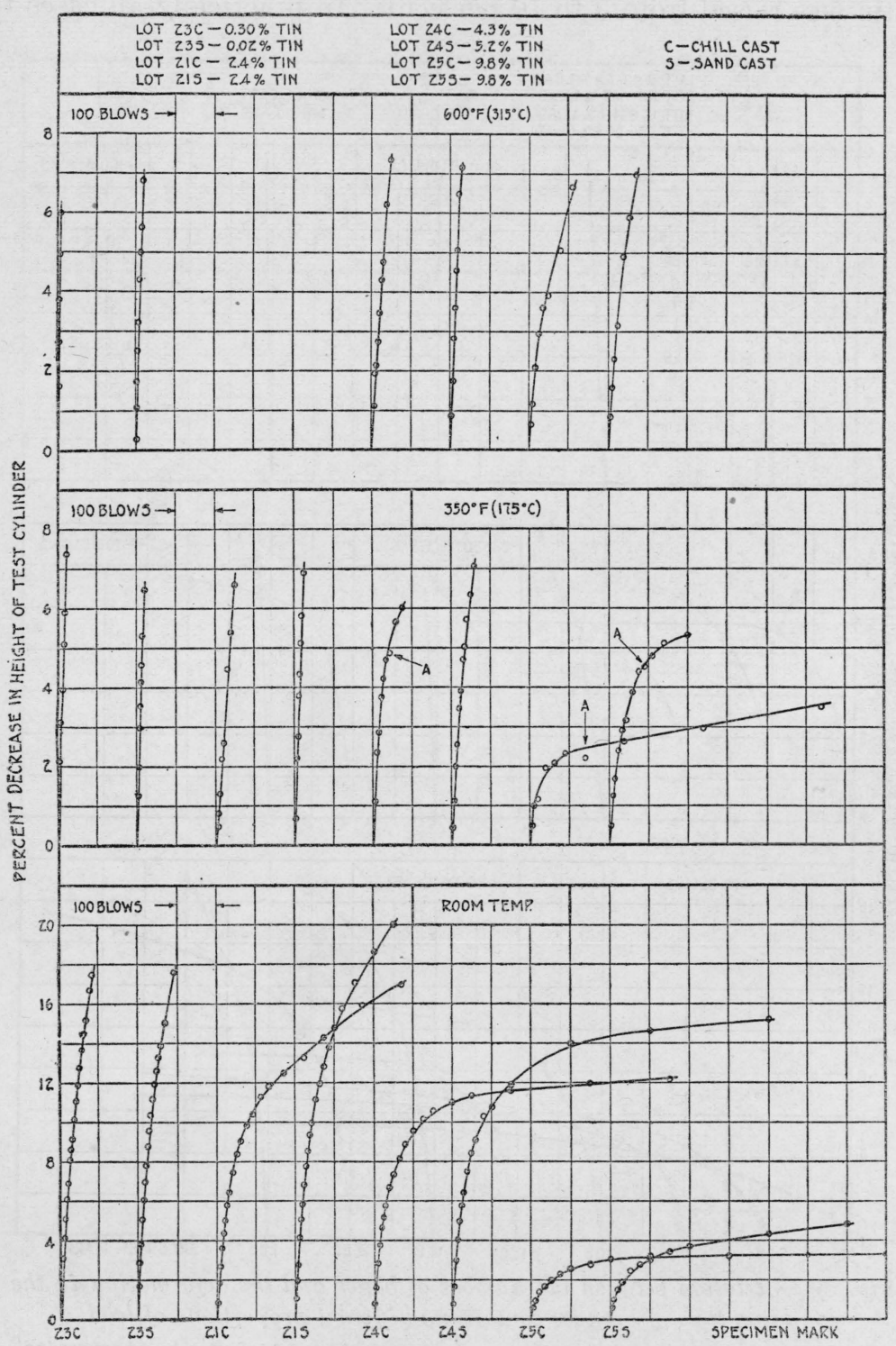

FIG. 60.-Relation between the number of blows and the deformation in the pounding tests of bronzes containing different proportions of tin

The bronzes contain copper and lead in the ratio of about 84 to 16. Letter A and arrows indicate discontinuities in deformation referred to in the text. 


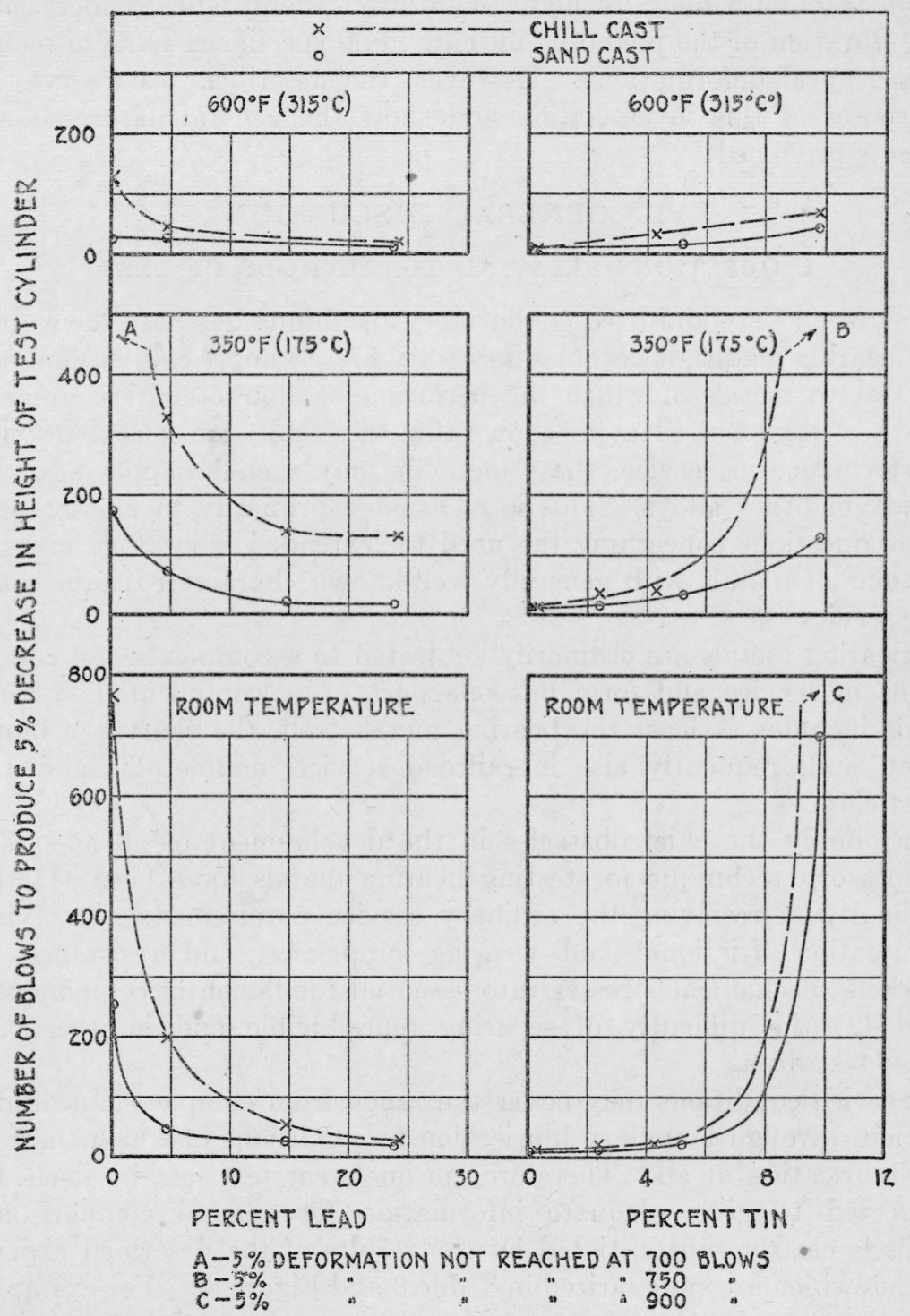

FIG. 61.-Resistance to pounding of the different bronzes at different temperatures

These are the same bronzes referred to in Figures 59 and 60. 
these effects decreased with increase in temperature, particularly between $350^{\circ}$ and $600^{\circ} \mathrm{F}$. ( $\left(175^{\circ}\right.$ and $315^{\circ} \mathrm{C}$.).

Probably further useful information could have been obtained from tests with blows of higher and lower energy and by increasing the duration of the pounding on individual specimens so as to secure larger total deformations. However, the described tests serve the purposes of this investigation and show the general nature of the effects produced.

\section{GENERAL DISCUSSION}

\section{QUESTIONS RELATING TO METHODS OF TEST}

Since no "standardized" laboratory technique has been developed for bearing metals, it becomes necessary first to apply chosen methods of test to metals of which the performance, characteristics are generally well known. Having shown that the results are consistent with performance in service, these methods may then be applied to the study of other alloys. This is mentioned primarily to answer possible questions concerning the need for extended laboratory investigations of metals with generally well-known characteristics in bearing service.

Bearing metals are ordinarily subjected to a complex set of conditions in service and form but one part of a complicated system. This includes at least the bearing metal itself, the shaft, the lubricant, and frequently also in railroad service, nonmetallic abrasive particles.

Probably the chief obstacles in the development of an adequate laboratory technique for testing bearing metals have been (1) the difficulty of resolving the ordinary service requirements, involving lubrication, frictional and wearing properties, and resistance to various mechanical stresses into essential fundamental components, and (2) the difficulty of securing reproducible and interpretable wear-test data.

Service conditions may cover the range from complete film lubrication, through boundary lubrication to conditions in which there is no lubrication at all. Therefore, no one wear test can, by itself, be expected to give adequate information for general comparisons. This is clearly substantiated by the results of the described experiments which are summarized in Table 3 and Figure 62. For example, the wear tests in the presence of oil gave comparisons of the "wearingin" periods of the bronzes while the tests without oil gave an indication of the behavior which might be expected when lubrication failed in service. Likewise, tests at atmospheric temperatures did not in all cases develop differences corresponding to those at elevated temperatures. 
TABLE 3.-General summary of the results of the wear tests

\begin{tabular}{|c|c|c|c|c|c|c|c|c|}
\hline \multirow[b]{2}{*}{ Metals containing-- } & \multirow[b]{2}{*}{$\begin{array}{l}\text { Casting } \\
\text { method }\end{array}$} & \multicolumn{2}{|c|}{ Lubricated wear tests 1} & \multicolumn{4}{|c|}{ Unlubricated wear tests 1} & \multirow[b]{2}{*}{ Remarks } \\
\hline & & $\begin{array}{l}\text { Weight loss } \\
\text { and dura- } \\
\text { tion of } \\
\text { "wearing- } \\
\text { in" period }\end{array}$ & $\begin{array}{l}\text { Torque } \\
\text { after } \\
\text { "wwearing- } \\
\text { in" period }\end{array}$ & $\begin{array}{l}\text { General wear } \\
\text { rate } 2\end{array}$ & $\begin{array}{l}\text { Average } \\
\text { torque } 2\end{array}$ & $\begin{array}{l}\text { Surfaces formed } \\
\text { under wear }\end{array}$ & $\begin{array}{l}\text { Corresponding } \\
\text { wear on the axle } \\
\text { steel }\end{array}$ & \\
\hline $\begin{array}{l}84 \mathrm{Cu}: 16 \mathrm{~Pb} ; 0.7 \text { per cent } \\
\text { tin }\end{array}$ & $\left\{\begin{array}{l}\text { Chill.... } \\
\text { Sand.... }\end{array}\right.$ & & & Very high & Low & $\begin{array}{l}\text { Rough and flat } \\
\text { wheel. }\end{array}$ & $\begin{array}{l}\text { Negligible_......... } \\
-\end{array}$ & Too soft; not a good bearing. \\
\hline $\begin{array}{l}92.5 \mathrm{Cu}: 7.5 \mathrm{Sn} ; 0.25 \text { per } \\
\text { cent } \mathrm{Pb}-\ldots\end{array}$ & $\left\{\begin{array}{l}\text { Chill_.. } \\
\text { Sand... }\end{array}\right.$ & Low & Erratic.. & $\begin{array}{l}\text { High }{ }^{3}+\ldots \ldots \\
\text { Intermediate }^{3}-\end{array}$ & High &  & Relatively high..- & $\begin{array}{l}\text { Good where good lubrication } \\
\text { and low operating tempera- } \\
\text { tures can be maintained. }\end{array}$ \\
\hline $\begin{array}{l}84 \mathrm{Cu}: 16 \mathrm{~Pb} \text { with } 5 \text { to } 10 \\
\text { per cent } \mathrm{Sn} \text {. } \\
92.5 \mathrm{Cu}: 7.5 \mathrm{Sn} \text { with } 12 \text { to } \\
25 \text { per cent } \mathrm{Pb} \text {. }\end{array}$ & Chill..... & High & Low & Low ...... & $\begin{array}{l}\text { Low to interme- } \\
\text { diate. } \\
\text { Intermediate to } \\
\text { high. }\end{array}$ & $\begin{array}{l}\text { Strong tendency } \\
\text { to film. }\end{array}$ & $\begin{array}{l}\text { Relative wear in- } \\
\text { termediate to } \\
\text { low. }\end{array}$ & $\begin{array}{l}\text { Good for starved lubrication and } \\
\text { elevated temperatures. }\end{array}$ \\
\hline
\end{tabular}

1 On the Amsler testing machine.

At any temperature between 70 and $350^{\circ} \mathrm{F}$. ( 20 and $175^{\circ} \mathrm{C}$.) selected for comparison.
Except at atmospheric temperatures where wear is low. 


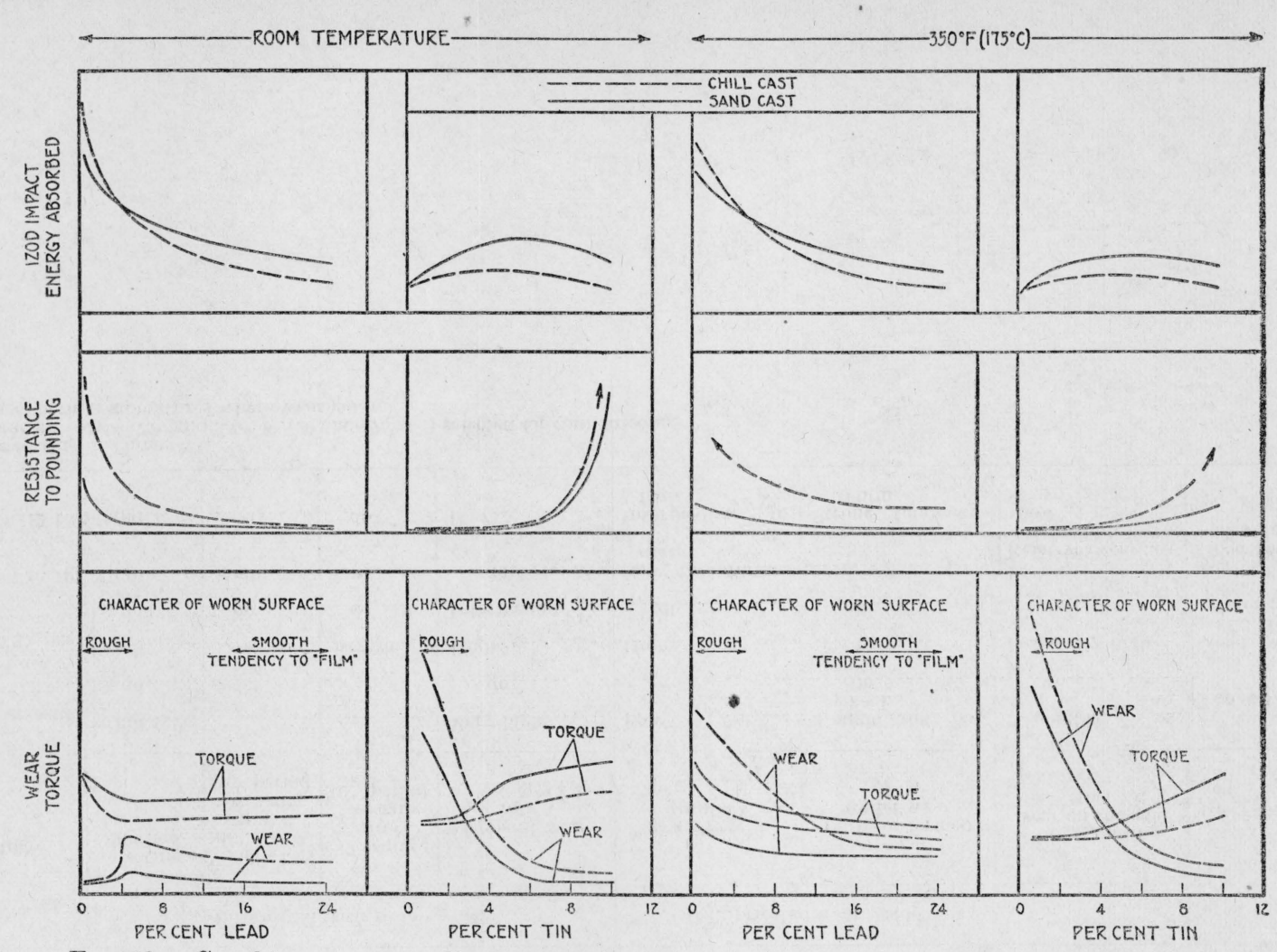


Tests of short duration, in which no account is taken of variations in the initial surface conditions of the metals or of possible film formation, are interpreted with difficulty and liable to be misleading. Until such time as definite relations can be developed between the performance in service or corresponding long-time tests and tests of short duration, it seems important to continue tests somewhat beyond the point at which a state of actual or apparent equilibrium is reached.

The wear tests which were made are near two extremes of practical service in that they approach, respectively, conditions of complete film lubrication and the absence of all lubrication. They may not indicate what is to be expected under the intermediate conditions comprising unstable boundary lubrication but gave definitely reproducible data and constitute a foundation upon which to build tests representing other conditions.

It is generally recognized that with complete film lubrication wear is unimportant. It is also probable that difficulties would be encountered in securing reproducible data on wear under conditions of boundary lubrication, so that it seemed logical to turn to unlubricated wear tests which could be carried out without the production of excessive frictional temperatures.

A similar situation is found in considering the results of the mechanical tests as is shown in Table 4 . The single-blow impact tests, repeated-blow pounding tests, and tensile tests are not interchangeable, but some seem better adapted than others to the study of bearing bronzes. 
TABLE 4.-General summary of the results of the mechanical tests

\begin{tabular}{|c|c|c|c|c|c|c|c|}
\hline \multirow{2}{*}{ Metals containing- } & \multirow{2}{*}{$\begin{array}{l}\text { Casting } \\
\text { method }\end{array}$} & \multirow{2}{*}{$\begin{array}{l}\text { Impact resistance }{ }^{1} \\
\text { (Izod) }\end{array}$} & \multicolumn{2}{|c|}{ Tensile properties ${ }^{2} 3$} & \multicolumn{3}{|c|}{ Resistance to pounding } \\
\hline & & & Tensile strength & Reduction of area & $70^{\circ}$ F. $\left(20^{\circ}\right.$ C. $)$ & $350^{\circ}$ F. $\left(175^{\circ}\right.$ C. $)$ & $600^{\circ} \mathrm{F} .\left(315^{\circ} \mathrm{C}.\right)$ \\
\hline $\begin{array}{l}84 \mathrm{Cu}: 16 \mathrm{~Pb} \text {; trace to } 0.3 \\
\text { per cent } \mathrm{Sn} \text { - } \\
\text { 84 } \mathrm{Cu}: 16 \mathrm{~Pb} \text { trace to } 5 \text { per } \\
\text { cent } \mathrm{Sn} \\
84 \mathrm{Cu}: 16 \mathrm{~Pb} ; 5 \text { to } 10 \mathrm{per} \\
\text { cent } \mathrm{Sn} \\
92.5 \mathrm{Cu}: 7.5 \mathrm{Sn} ; 0.25 \mathrm{per} \\
\text { cent } \mathrm{Pb} \text {. } \\
92.5 \mathrm{Cu}: 7.5 \mathrm{Sn} ; 0.25 \text { to } 5 \text { per } \\
\text { cent } \mathrm{Pb} \\
\text { 92.5 Cu: } 7.5 \mathrm{Sn} ; 5 \text { to } 25 \text { per } \\
\text { cent } \mathrm{Pb}\end{array}$ & 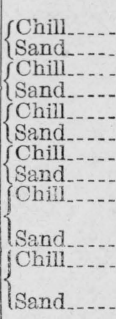 & $\begin{array}{l}\text { Low } \\
\text { Low to high } \\
\text { Low } \\
\text { High to intermediate.. } \\
\text { High_..... } \\
\text { Intermediate_... } \\
\text { High to intermediate.. } \\
\text { Intermediate to low } \\
\text { Low }{ }^{5} .\end{array}$ & $\begin{array}{l}\text { Low } \\
\text { Low to intermediate } \\
\text { Intermediate to high } \\
\text { - do do } \\
\text { High high } \\
\text { Very high to high. } \\
\text { High to intermediate. } \\
\text { Intermediate. }\end{array}$ & $\begin{array}{l}\text { Low do } \\
\text { Intermediate } \\
\text { do.4 } \\
\text { High }{ }^{4} \\
\text { do }{ }^{4} \\
\text { Intermediate }{ }^{4} \\
\text { intermediate } \\
\text { do }\end{array}$ & $\begin{array}{l}\text { Low } \\
\text { Low to high } \\
\text { High do } \\
\text { Intermediate... } \\
\text { High to intermediate. } \\
\text { Intermediate to low } \\
\text { Low }\end{array}$ & $\begin{array}{l}\text { Low } \\
\text { Low to high } \\
\text { Low to intermediate. } \\
\text { Very high } \\
\text { Intermediate } \\
\text { Very high to high in- } \\
\text { termediate. } \\
\text { Intermediate to low } \\
\text { High intermediate to } \\
\text { medium low } \\
\text { Low }\end{array}$ & $\begin{array}{l}\text { Low. } \\
\text { Do. } \\
\text { Do. } \\
\text { Do. } \\
\text { Do. } \\
\text { Do. } \\
\text { Medium-low. } \\
\text { Low. } \\
\text { Me dium-low } \\
\text { to low. } \\
\text { Low. } \\
\text { Do. } \\
\text { Do. }\end{array}$ \\
\hline
\end{tabular}

${ }^{1}$ Increase in temperature above $175^{\circ} \mathrm{F} .\left(80^{\circ} \mathrm{C}\right.$.) caused decrease in impact resistance of bronzes of similar chemical composition.

2 Increase in temperature caused decrease in tensile properties for bronzes of similar chemical composition. Increase of $\mathrm{Pb}$ from 5 to 25 per cent has comparatively little efiect on tensile strength of sand-cast bronzes at temperatures between 70 and $600^{\circ} \mathrm{F}$. (20 to $315^{\circ} \mathrm{C}$.).

Very little elongation change noted with change in chemical composition.

${ }^{4}$ Reduction of area greater at $350^{\circ} \mathrm{F}$. (175 $5^{\circ} \mathrm{C}$.) than at 70 or $600^{\circ} \mathrm{F}$. $\left(20\right.$ to $315^{\circ} \mathrm{C}$.) .
${ }^{\circ}$ Impact resistance at $350^{\circ} \mathrm{F}$. $\left(175^{\circ} \mathrm{C}\right.$.) greater than at 70 or $600^{\circ} \mathrm{F}$. $\left(20\right.$ or $\left.315^{\circ} \mathrm{C}.\right)$. 
Tension tests, with the sensitive extensometer used in this investigation, require considerable time, particularly when carried out at elevated temperatures, and are therefore expensive to make. They did not show features of importance which were not also developed by the more rapidly made pounding and notched-bar impact tests. Furthermore, the customary tension test specimen is larger than the test specimens used in the two other types of test, and there is therefore a greater tendency toward variations in structure and properties from one part to another in specimens taken from cast metals, particularly from chill castings. While these latter objections can be overcome by using smaller test specimens, the tension test does not as closely simulate important service conditions as do the pounding tests, since bearings are not ordinarily subjected to static tension stresses.

For these reasons the pounding tests and notched-bar impact tests are favored as the first basis of comparison of bearing bronzes. Tensile tests and hardness tests may be added when necessary to meet special requirements. However, there does not appear to be a sharp distinction between the several tests. A more important feature is the interpretation of results.

This is, perhaps, well illustrated by consideration of the bronzes with 5 to 10 per cent tin. Within these limits increase in the tin materially improved the resistance to pounding, but resulted. in a slight decrease in the resistence to notched-bar impact.

It will be recalled that within this range of tin content the bronzes changed from the alpha solid solution type to alloys containing the alpha solid solution plus the brittle eutectoid. The presence of this eutectoid evidently exerts a very favorable influence upon the resistance of the bronzes to deformation (pounding), but this is produced at the expense of notch toughness.

The pounding tests can not justly replace the notched-bar impact tests nor are the two to be directly compared. Ordinarily a closer similarity in results would be expected between the tensile strength and the resistance to pounding, but differences will probably also be encountered in such comparisons.

The tests described in this report do not characterize completely the properties which are of interest in the application of bronzes in bearings. For example, the wear tests made at a fixed range of pressures and one rate of slip might be supplemented to advantage by tests made under other pressures and other speeds.

Other properties than those considered are of interest in the application of metals in bearings. One which has not yet been mentioned is the ability of a bearing metal to adsorb a film of the lubricant, so that the film is not readily broken down to permit metal to touch metal (bearing to touch shaft). 
Attempts were made ${ }^{29}$ with an experimental "oiliness tester" to differentiate among some of the bearing metals, but no useful results were obtained.

\section{CHILL CASTING v. SAND CASTING}

The sand-cast bronzes quite generally showed lower wear than the corresponding chill-cast bronzes. At first glance this may seem contradictory to the recent experiences of some railroads which have found their over-all costs for locomotive side-rod bearings to be lower with chill-cast bronzes than with sand-cast bronzes. It is not known definitely whether or not these practical comparisons are based on alloys of similar chemical composition, but a sufficient number of such reports have been encountered to justify consideration of the relations between such experiences in service and the described results of laboratory tests.

Under ordinary conditions there is a difference in machining properties in favor of chill-cast metal. Easy machining should not only contribute directly to lower costs, but also indirectly through increased bearing life associated with the better fits which would be a natural consequence of good working properties.

Another matter for consideration is the character of the failure of locomotive side-rod bearings. It has been common practice to state that bearings have worn out when they are no longer serviceable, whether the unserviceability was the result of abrasion, fracture under impact at high temperatures, so-called pounding out, or other causes.

The experience of one railroad has been that "chill brass is largely removed from wear, whereas the sand-cast brass breaks up more frequently in service." 30 This is consistent with the results of the laboratory experiments which showed that the chill-cast bronzes wore more rapidly than corresponding sand-cast bronzes but raises the question of why the sand castings break up more frequently in service since they showed better notch toughness than the chill castings.

Such breakage rarely takes place under the first application of shock in service except in imperfect castings. It is the result of repeated shocks which can be expected to work harden and deform the bronze. As shown in the laboratory pounding tests (fig. 61), the chill-cast bronzes had a higher resistance to deformation than corresponding sand-cast bronzes. Since the sand castings deform more readily, there would be a greater tendency than with chill-cast metal

${ }^{29}$ With a modified Deeley machine devised by W. H. Herschel, associate physicist. The Deeley machine is described in a report of the Lubricants and Lubrication Inquiry Committee of the British Department of Scientific and Industrial Research, 1920. The modifications referred to consist principally of a motor drive and refined temperature control.

30 Private communication. 
for the bearing to "pound out" under the repeated shocks in service. This would have the effect of increasing the shock intensity and possibly account for the fact that the sand-cast bearings more often break up in service than do the chill-cast bearings.

There is, perhaps, room for considerable argument on the question of the superiority of one metal or method of casting over another in respect to the effects of pounding in service. Very few railroad castings are applied without grease grooves of some sort. Service stresses are concentrated at these grooves and result in conditions comparable to those obtaining in the impact tests, although in service the stresses are repeatedly applied as in the pounding tests. Certainly a more complete picture is obtained from the results of both the pounding tests and impact tests than is given by either test alone.

While the foregoing comparisons indicate a closer correlation between some service experiences and the pounding tests, one manufacturer of bearing metals has cited a case where a closer correlation appears to exist between practical performance and the impact tests.

His comments ${ }^{31}$ are as follows:

For example, we have the early failures of poured-on lateral plates used for facing the driving truck and trailer boxes adjacent to the hub of the wheel. These lateral plates cause so much trouble by failure from excessive wear and cracking that many of our railroad customers have been replacing the poured-on lateral plate with sand castings applied to the box by means of studs. The poured-on lateral plate is applied at the railroad shops. Molten bronze is poured on the box face after the bronze bearing has been pressed into the box. The lateral is held against the steel box face by means of dovetailing. The lateral plate is then machined and lubrication grooves cut in the brass. The poured-on lateral plate, due to its rapid cooling against the steel face of box, has a very close, fine grain and is very brittle in structure. It is a chill casting in every sense of the word.

Sand-cast lateral plates, however, do not show the failures characteristic of the poured-on lateral plates and are rapidly replacing the old-style plate.

Each application should be given special consideration and tests chosen which will most closely simulate the conditions of service. It is not only necessary to consider the service conditions, but also to consider carefully the interpretation of the results obtained from the selected types of test.

\section{EFEECTS OF LEAD AND TIN IN BEARING BRONZES}

While the bronzes studied fall within a limited range of chemical composition, there are alloys in the group which should meet a variety of service conditions. Brief consideration will be given to their fields of application as judged from the described laboratory tests, but it should not be inferred that any one alloy is the best for a given purpose, since a narrow range of alloys is considered and subsequent comments are primarily concerned with the interpretation of the laboratory test data.

${ }^{31}$ Private communication. 
Bronzes with less than about 5 per cent tin do not appear to be suited for bearing service, since their wearing properties and mechanical properties are both relatively poor. (Fig. 62.) They will, therefore, be excluded from further consideration.

There are decided advantages in the high-lead bronzes for service where lubrication can not be maintained. These bronzes containing about 12 to 25 per cent lead did not wear as rapidly as the low-lead bronzes nor assume as rough a surface under friction produced by metal to metal contact without oil. Provided wear is the chief factor to be considered and an approximately constant copper-tin ratio is maintained, variations in lead seem unimportant within the range 12 to 25 per cent. (Fig. 62.)

Where it is also important to have high resistance to pounding, high-notch toughness, and static strength at atmospheric and elevated temperatuzes, lead may advantageously be kept near the low limit of the specified range, since the strength and notch toughness decrease with increase in the lead. However, these differences are relatively small and for many purposes the bronzes containing from, say, 15 to 25 per cent lead may be considered to be interchangeable.

When the mechanical properties become of primary importance and lubrication can be maintained so that wear is of secondary interest, there are advantages in low lead and high tin. (Fig. 62.) Both favor high strength and resistance to pounding of the bronzes. Low lead and increase in tin up to the point where appreciable proportions of the eutectoid were observed likewise improved the notch toughness. Furthermore, the high-tin bronzes with appreciable proportions of lead and the low-lead bronzes with about 5 to 8 per cent tin maintained a superiority over the high-lead bronzes in their mechanical properties at elevated temperatures, although this was not of the same magnitude as at atmospheric temperatures.

\section{SPECIFICATIONS}

While variations in the proportions of lead and tin in the bronzes are important in relation to the requirements of service, the effects of some of these changes in chemical composition are much less important than variations arising from the method of casting. For example, the differences in wearing properties produced by increase in lead from 15 to 25 per cent are smaller than those resulting from a change from sand to chill molds. Other examples will be found in discussion of the results of the different tests described in previous sections of this report and in Figure 62.

On the whole, there does not seem to be any real justification for the very wide variation in the specifications of different carriers for bearings of similar design subjected to similar service as outlined in the introduction to this report. It will be seen from Figures 1 and 2 that there are not only wide differences in the type compositions 
employed for similar service but also what appear in the light of the described tests to be unnecessary restrictions in the prescribed limits of chemical composition.

The fact that car-journal bearings are replaced without serious difficulties on foreign lines with metals varying widely in chemical composition confirms the viewpoint reached from the laboratory tests that the existing specifications may to advantage be revised and brought more nearly into conformity. Some of the wide variations appear unimportant, and unnecessary restrictions are now encountered. Likewise, a generally improved performance could probably be obtained by more uniform specifications based on the selection of the type compositions best adapted to certain broad requirements.

The effects of impurities upon copper-tin-lead alloys were not considered in this report. Before complete specifications can be drawn information should be obtained on the effects produced by impurities, such as iron and antimony and the effects of elements intentionally added, such, for example, as phosphorus, zinc, nickel, etc. Information on the effect of annealing or other methods of control of the amount of "coring" of the alpha solid solution would also be pertinent.

However, it is of interest to note that the grouping of the bronzes resulting from the described laboratory tests is consistent with the limits of tin and lead in the tentative standards of the American Society for Testing Materials for journal bearings for use on locomotive tenders, passenger and freight equipment cars, specification B67-27T. In these specifications tin may vary from 5 to 7 per cent and lead from 15 to 22 per cent.

\section{SUMMARY AND CONCLUSIONS}

A study was made of the wearing and mechanical properties of two groups of copper-tin-lead alloys in both chill-cast and sand-cast conditions. The first group consisted of bronzes with a copper-tin ratio of about 92.5 to 7.5 and lead varying from 0.25 to 25 per cent; in the second group the bronzes contained a copper-lead ratio of about 84 to 16 and tin varying from a trace to 10 per cent.

The bronzes were tested under rolling and sliding friction without lubricants at atmospheric and elevated temperatures up to $350^{\circ} \mathrm{F}$. $\left(175^{\circ} \mathrm{C}\right.$.), under lubricated rolling and sliding friction in the presence of oil, and in the presence of abrasives at atmospheric temperatures, and under tension, impact, and pounding at temperatures from $70^{\circ}$ to $600^{\circ} \mathrm{F}$. $\left(20^{\circ}\right.$ to $315^{\circ} \mathrm{C}$.). The results of these tests developed the following features:

1. No one of the selected laboratory tests yielded information which was, by itself, adequate for general comparisons. Each of the wear tests and the mechanical tests contributed information of value in developing the characteristics of the different bronzes. 
2. Variations in the chemical composition of the bronzes produced major changes in properties, but within certain ranges variations in chemical composition were much less important than variations in the method of casting.

3. As a general rule, chill-cast bronzes wore faster and had lower notch toughness than corresponding sand-cast bronzes, but showed better resistance to pounding and higher tensile strength at temperatures between $70^{\circ}$ and $600^{\circ} \mathrm{F}$. ( $\left(20^{\circ}\right.$ and $315^{\circ} \mathrm{C}$.). The few exceptions to this are shown in detail in the report.

4. In alloys with a practically constant ratio of copper to tin increase in lead produced a general improvement in wearing properties, but this was more marked between 0.25 and 12 per cent than between 12 and 25 per cent lead. At the same time the resistance to pounding, notch toughness, and tensile strength decreased.

5 . In alloys with a practically constant ratio of copper to lead increase in tin from 0.7 to around 5 per cent resulted in a marked decrease in the wear produced by rolling and sliding friction without oil and a general improvement in the wearing properties. Further increase in tin from around 5 to 10 per cent did not materially modify the wearing properties but resulted in improved tensile strength and resistance to pounding. There was also an improvement in notch toughness with increase in tin to about 7 per cent, represent. ing the proportion above which appreciable amounts of the brittle alpha-delta eutectoid appeared. With higher tin a slight decrease was observed in the impact values.

6 . The bronzes with less than about 5 per cent tin did not seem to have the combination of mechanical and wearing properties necessary for good service as bearings. Where wearing properties are of primary importance the high-lead bronzes have distinct advantages over the low-lead bronzes. Likewise the bronzes with around 8 to 10 per cent tin (and 12 to 15 per cent lead) seem better adapted to service where the chief requirements are resistance to pounding and static stress than bronzes with around 4 to 6 per cent tin.

7. There is a considerable range of chemical composition within which the variations in mechanical and wearing properties are small. This includes a range from 15 to 25 per cent lead and from around 4 to 7 per cent tin. Since alloys within the entire range have given reasonably good performance in locomotive and journal bearings, there does not seem to be justification for the wide variations in specifications now used by different carriers for parts subjected to similar service. This refers not only to the type compositions but also to the limits of chemical composition for any one type.

8. It has been shown that reproducible wear tests can be obtained in the laboratory. The results, when combined with suitable mechanical tests, gave comparisons which were consistent with some experiences in practical service. 


\section{ACKNOWLEDGMENTS}

In addition to the acknowledgments recorded throughout this report, the authors are indebted to R. F. Staubley, jr., laboratory apprentice, for assistance in many of the wear tests and the mechanical tests; to H. K. Herschman, assistant metallurgist, and S. Epstein, associate metallurgist, for the metallographic work; and to many other of their associates for helpful criticisms and suggestions.

Washington, May 19, 1928. 
